\title{
Programação de múltiplos cross-docks com múltiplas docas
}

\author{
Pâmella Sátiko Miyazaki Tenório
}



Data de Depósito:

Assinatura:

\section{Pâmella Sátiko Miyazaki Tenório}

\section{Programação de múltiplos cross-docks com múltiplas docas}

Dissertação apresentada ao Instituto de Ciências Matemáticas e de Computação - ICMC-USP, como parte dos requisitos para obtenção do título de Mestra em Ciências - Ciências de Computação e Matemática Computacional. VERSÃO REVISADA

Área de Concentração: Ciências de Computação e Matemática Computacional

Orientadora: Profa. Dra. Franklina Maria Bragion de Toledo 
Ficha catalográfica elaborada pela Biblioteca Prof. Achille Bassi e Seção Técnica de Informática, ICMC/USP, com os dados fornecidos pelo(a) autor(a)

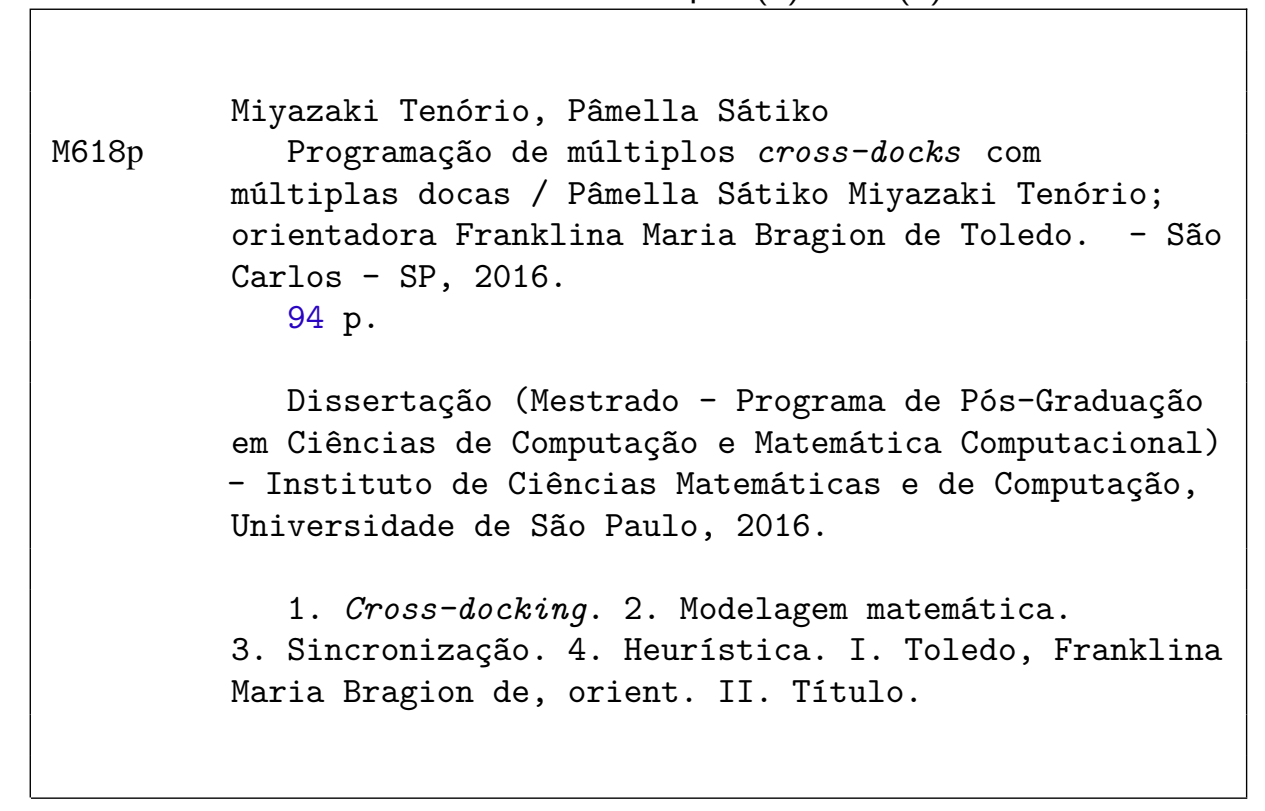




\section{Pâmella Sátiko Miyazaki Tenório}

\section{Scheduling of multiple cross-docks with multiple docks}

Master dissertation submitted to the Instituto de Ciências Matemáticas e de Computação - ICMCUSP, in partial fulfillment of the requirements for the degree of the Master Program in Computer Science and Computational Mathematics. FINAL VERSION

Concentration Area: Computer Science and Computational Mathematics

Advisor: Profa. Dra. Franklina Maria Bragion de Toledo

\section{USP - São Carlos}

August 2016 

Este trabalho é dedicado à minha família, pelo amor e apoio, e a toda comunidade científica, que sempre busca melhorar o dia-a-dia com pesquisas.

Em especial, a todos os pesquisadores do Instituto de Ciências Matemáticas,

Computação e Estatística (ICMC). 

Os agradecimentos principais são direcionados à banca, ao apoio financeiro do CNPq (132271/2014-1, 306918/2014-5), da FAPESP (2013/07375-0) e a Deus.

Agradecimentos especiais são direcionados à Professora Doutora Franklina Maria Bragion de Toledo, pelo apoio e excelente trabalho de orientação, a todos que compõem o Instituto de Ciências matemáticas, Computação e Estatística da Universidade de São Paulo (ICMC/USP) e ao Laboratório de Otimização do ICMC/USP (LOt - www.otm.icmc.usp.br). 

"Os que se encantam com a prática sem ciência são como os timoneiros que entram no navio sem timão nem bússola, nunca tendo certeza do seu destino." (Leonardo da Vinci) 



\section{RESUMO}

MIYAZAKI TENÓRIO, P. S.. Programação de múltiplos cross-docks com múltiplas docas. 2016. 94 f. Dissertação (Mestrado em Ciências - Ciências de Computação e Matemática Computacional) - Instituto de Ciências Matemáticas e de Computação (ICMC/USP), São Carlos $-\mathrm{SP}$.

Cadeias de suprimentos podem ter operações seguindo diferentes estratégias de distribuição e a utilização de cada uma dessas estratégias pode resultar em diferentes operações e custos. A estratégia de cross-docking auxilia na redução dos custos de distribuição de produtos, consolidando cargas, e a redução de tempo e custos de armazenamento, uma vez que o tempo máximo de estoque permitido pela estratégia é de cerca de 24 horas. O objetivo deste trabalho é apresentar um modelo para o problema de cross-docking, em que cargas são entregues e reorganizadas de forma a atender a outras cargas que são coletadas e garantir que as janelas de tempo para início das operações sejam atendidas. Devido à falta de instâncias para o problema disponíveis na literatura, buscou-se gerar um benchmark e disponibilizá-las à comunidade científica. Uma vez que o problema é de difícil solução exata, um método heurístico para a resolução do problema foi desenvolvido. Os resultados mostraram que o modelo proposto resulta em boas soluções quando comparado ao modelo da literatura. O estudo de calibração do software IBM CPLEX mostrou que a calibração dos parâmetros pode resultar em melhores soluções e, por fim, a matheurística se mostrou competitiva com o CPLEX, principalmente para cenários em que a proporção de entregas e coletas diverge.

Palavras-chave: Cross-docking, Modelagem matemática, Sincronização, Heurística. 



\section{ABSTRACT}

MIYAZAKI TENÓRIO, P. S.. Programação de múltiplos cross-docks com múltiplas docas. 2016. 94 f. Dissertação (Mestrado em Ciências - Ciências de Computação e Matemática Computacional) - Instituto de Ciências Matemáticas e de Computação (ICMC/USP), São Carlos $-\mathrm{SP}$.

Supply chains may have operations which follow different distribution strategies and each one of these strategies may result in different operations and costs. The Cross-docking strategy helps to reduce the products' distribution costs by consolidating loads and reducing storage costs as the maximum inventory time is approximately 24 hours. The aim of this research is to present a model for the cross-docking problem where loads are delivered and reorganized so as to cater for other loads that are collected and ensure that time windows are respected. Due to the lack of instances available in the literature, a benchmark was generated and was made available to the scientific community. As the problem is difficult to obtain the exact solution, a heuristic method was developed. The results showed that the proposed model has good solutions when compared to the literature model. A study of the IBM CPLEX software showed that tuning can result in better solutions and the matheuristcs was competitive with the software, mainly in scenarios where deliveries and pickups are very different.

Key-words: Cross-docking, Mathematical modelling, Synchronization, Heuristics. 



\section{LISTA DE ILUSTRAÇÕES}

Figura 1 - Percentual de cada operação em um armazém. . . . . . . . . . . . . 26

Figura 2 - Cross-docking com cross-dock único. . . . . . . . . . . . . . . . . . . . 29

Figura 3 - Centro de distribuição (cross-docking) com três cross-docks. . . . . . . . . 30

Figura 4 - Organização de problemas de Cross-docking. . . . . . . . . . . . . . 31

Figura 5 - Uma solução para um exemplo do problema estudado. . . . . . . . . . . 35

Figura 6 - Horizonte de planejamento do exemplo da Figura 5 . . . . . . . . . . 36

Figura 7 - Ilustração das janelas de tempo, flexível e rígida. . . . . . . . . . . . . . 43

Figura 8 - Ilustração do resultado de uma instância pequena a partir do modelo de Javanmard, Vahdani e Tavakkoli-Moghaddam (2014). . . . . . . . . . . . 54

Figura 9 - Ilustração do resultado de uma instância pequena a partir do modelo proposto MPJT. . . . . . . . . . . . . . . . . . . 54

Figura 10 - Dados do exemplo para a ordenação . . . . . . . . . . . . . . . 72

Figura 11 - Exemplo para a ordenação $O_{c r} \ldots \ldots \ldots \ldots$. . . . . . . . 72

Figura 12 - Exemplo para a ordenação $O_{f o} \ldots \ldots \ldots$. . . . . . . . . 73

Figura 13 - Gráfico solução x tempo para o kernel inicial de problemas de pequena dimensão. . . . . . . . . . . . . . . . . . . . . . 74 



\section{LISTA DE ALGORITMOS}

Algoritmo 1 - Kernel search adaptado de Angelelli, Mansini e Speranza (2010). . . . . 71 

Tabela 1 - Resumo dos artigos. . . . . . . . . . . . . . 35

Tabela 2 - Grupos de instâncias gerados e quantidade de variáveis correspondentes. . . 49

Tabela 3 - Resultados dos modelos para mesma proporção de entregas e coletas. . . . . 50

Tabela 4 - Resultados dos modelos para muitas entregas e poucas coletas. . . . . . . 51

Tabela 5 - Resultados dos modelos para poucas entregas e muitas coletas . . . . . . 52

Tabela 6 - Resultados de instâncias para calibração do CPLEX, com tempo limite de

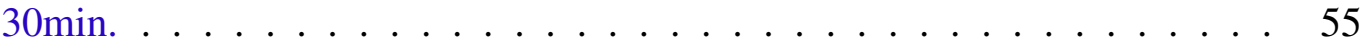

Tabela 7 - Melhores soluções encontradas para as instâncias-teste de calibração do CPLEX com 10min com os parâmetros padrão do software. . . . . . . . . . 55

Tabela 8 - Soluções encontradas para as instâncias-teste de calibração após calibração automática do CPLEX com 10min de execução. . . . . . . . . . . . . . 56

Tabela 9 - Soluções das instâncias-teste de calibração para o parâmetro de ênfase com 10 min de execução. . . . . . . . . . . . . . . . . . . 56 56

Tabela 10 - Soluções das instâncias-teste de calibração para o parâmetro LP method com $10 \min \ldots \ldots \ldots \ldots \ldots \ldots$

Tabela 11 - Soluções para as instâncias-teste de calibração para o parâmetro de seleção de variáveis com 10min de execução. . . . . . . . . . . . . . . . . . . . . 59

Tabela 12 - Soluções das instâncias-teste de calibração para a heurística LB com 10min de execução. . . . . . . . . . . . . . . . . . . . . . .

Tabela 13 - Soluções das instâncias-teste de calibração para a heurística RINS com 10min de execução. . . . . . . . . . . . . . . . . . . . . . . . . .

Tabela 14 - Soluções das instâncias-teste de calibração para a heurística FP (Feasibility Pump) com 10min de execução. . . . . . . . . . . . . . . . . .

Tabela 15 - Soluções das instâncias-teste de calibração para todos os cortes ao mesmo tempo com 10min de execução.

Tabela 16 - Resultados da calibração das instâncias-teste dos cortes por cliques com 10min de execução.

Tabela 17 - Resultados das instâncias-teste de calibração para o parâmetro de cortes covers com 10min de execução. . . . . . . . . . . . . . . . . . . . . .

Tabela 18 - Resultados das instâncias-teste de calibraccão para o parâmetro de cortes flow covers com 10min de execução. . . . . . . . . . . . . . . . . . . . .

Tabela 19 - Resultados das instâncias-teste de calibração para o parâmetro de cortes flow path com 10min de execução. . . . . . . . . . . . . . . . . . . . 63 
Tabela 20 - Comparação entre os resultados da calibração automática, das calibrações manuais e o padrão do software com 10min de execução. . . . . . . . . . .

Tabela 21 - Resultados após a calibração do modelo proposto para instâncias com mesma proporção de entregas e coletas com 10min de execução. . . . . . . . . . . .

Tabela 22 - Resultados após a calibração do modelo proposto para instâncias com muitas entregas e poucas coletas. . . . . . . . . . . . . . . .

Tabela 23 - Resultados após a calibração do modelo proposto para instâncias com poucas entregas e muitas coletas. . . . . . . . . . . . . . .

Tabela 24 - Resultados dos testes da combinação da estratégia $S_{x y}$ com as estratégias $O_{c r}$ e $O_{f o}$ para o kernel search com até 10 min de execução. . . . . . . . . . . .

Tabela 25 - Resultados dos testes da combinação da estratégia $S_{x}$ com as estratégias $O_{c r}$ e $O_{f o}$ para o kernel search com até 10 min de execução. . . . . . . . . . . .

Tabela 26 - Resultados dos testes da combinação da estratégia $S_{y}$ com as estratégias $O_{c r}$ e $O_{f o}$ para o kernel search com até 10 min de execução. . . . . . . . . . . .

Tabela 27 - Resultados obtidos pelo kernel search para a combinação das estratégias $K S_{x y, c r}$ e $K S_{x y, f o}$ à estratégia de adaptação $A_{k}$ com tempo máximo de execução do método de 10 min. . . . . . . . . . . . . . . . . . . . . .

Tabela 28 - Resultados obtidos pelo kernel search para a combinação das estratégias $K S_{x, c r}$ e $K S_{x, f o}$ à estratégia de adaptação $A_{k}$ com tempo máximo de execução do método de $10 \mathrm{~min}$.

Tabela 29 - Resultados obtidos pelo kernel search para a combinação das estratégias $K S_{y, c r}$ e $K S_{y, f o}$ à estratégia de adaptação $A_{k}$ com tempo máximo de execução do método de $10 \mathrm{~min}$.

Tabela 30 - Resultados obtidos pelo kernel search para as configurações da Fase 1 para a seleção $S_{x y}$ combinadas à estratégia de adaptação $A_{b}$. . . . . . . . . .

Tabela 31 - Resultados obtidos pelo kernel search para as configurações da Fase 1 para a seleção $S_{x}$ combinadas à estratégia de adaptação $A_{b} \ldots$. . . . . . . . . .

Tabela 32 - Resultados obtidos pelo kernel search para as configurações da Fase 1 para a seleção $S_{y}$ combinadas à estratégia de adaptação $A_{b} \ldots$. . . . . . . . . .

Tabela 33 - Resultados obtidos pela combinação $K S_{x y, c r, k}$ sem e com a calibração manual definida na Seção 4.3 . . . . . . . . . . . . . . . . . .

Tabela 34 - Resultados obtidos pela combinação $K S_{x, f o, k}$ sem e com a calibração manual definida na Seção 4.3 . . . . . . . . . . . . . . . . . . .

Tabela 35 - Resultados obtidos pela combinação $K S_{y, c r, b}$ sem e com a calibração manual definida na Seção 4.3 . . . . . . . . . . . . . . . . . . .

Tabela 36 - Resultados obtidos para 15 instâncias de calibração utilizando as 3 melhores estratégias para o kernel search com no máximo 10min de execução. . . . .

Tabela 37 - Resultados do kernel search com tempo limite de 10 min e de 30 min para o Cenário 1 (mesma proporção de entregas e coletas). . . . . . . . . . . . . . 
Tabela 38 - Resultados do kernel search com tempo limite de $10 \mathrm{~min}$ e de $30 \mathrm{~min}$ para o Cenário 2 (muitas entregas e poucas coletas). . . . . . . . . . . . . 88

Tabela 39 - Resultados do kernel search com tempo limite de $10 \mathrm{~min}$ e de $30 \mathrm{~min}$ para o Cenário 3 (poucas entregas e muitas coletas). . . . . . . . . . . . . . 89 



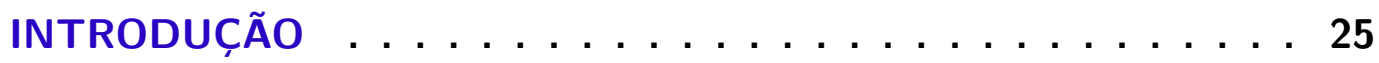

2 DEFINIÇÃO DO PROBLEMA E REVISÃO BIBLIOGRÁFICA . . . 29

2.1 Problema de integração do planejamento e da programação de uma rede de distribuição . . . . . . . . . . . . . . . . . . . 32

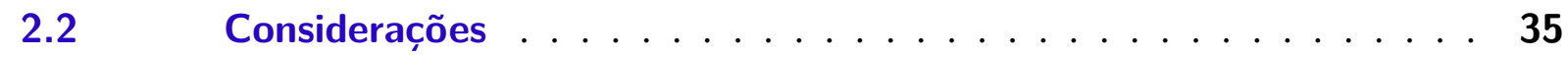

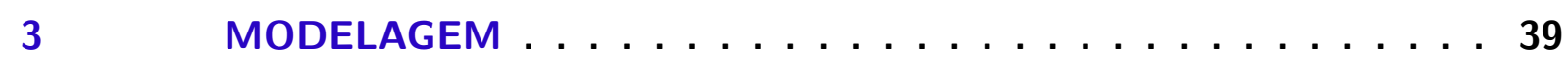

3.1 Modelo da literatura .................. 40

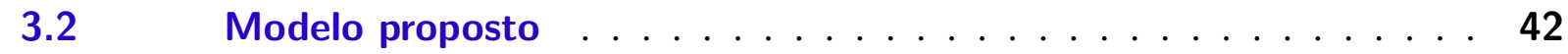

4 ANÁLISE DOS MODELOS . . . . . . . . . . . . . . . 47

4.1 Geração de instâncias . . . . . . . . . . . . . . 47

4.2 Comparação entre os modelos . . . . . . . . . . . . . 48

$4.3 \quad$ Calibração do CPLEX para o MPJT . . . . . . . . . . . . . 53

$4.4 \quad$ Conclusões da calibração . . . . . . . . . . . . . . . 64

5 HEURÍSTICA PROPOSTA . . . . . . . . . . . . . . 69

$5.1 \quad K e r n e l$ search . . . . . . . . . . . . . . . . 69

$5.2 \quad K e r n e l$ search para o problema estudado . . . . . . . . . . 70

5.2.1 Critério de ordenação das variáveis . . . . . . . . . . . . . . 71

5.2.2 Seleção de variáveis para a construção do kernel inicial e dos buckets 73

5.2.3 Melhorias propostas . . . . . . . . . . . . . 76

6 ANÁLISE dA HEURÍSTICA . . . . . . . . . . . . 77

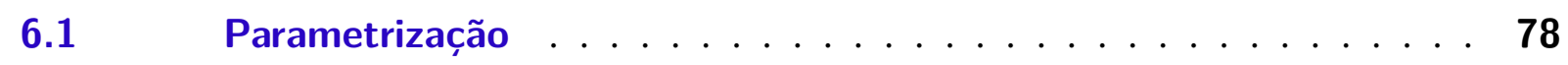

$6.2 \quad$ Análise dos cenários . . . . . . . . . . . 85

7 CONCLUSÕES E PESQUISAS FUTURAS . . . . . . . . . . 91

REFERÊNCIAS . . . . . . . . . . . . . . . . . . 93 



\section{INTRODUÇÃO}

A estratégia de distribuição de produtos é uma importante atividade para o gerenciamento eficiente de uma cadeia de suprimentos. Sua utilização contribui para a redução de custos operacionais e busca garantir que as operações internas da rede de distribuição sejam realizadas da forma mais eficiente, como exemplo garantir que mercadorias sejam entregues nos prazos estabelecidos.

As estratégias mais comuns para atividades de distribuição de produtos, segundo Buijs, Vis e Carlo (2014), são: entrega direta ou por rotas de entrega, entrega utilizando-se armazéns (warehousing), e entrega utilizando-se docas cruzadas (cross-docking). A escolha adequada da estratégia a utilizar garante redução dos custos e o melhor gerenciamento da rede.

As estratégias de entrega direta, em que produtos são enviados diretamente da origem ao destino, e de rotas de entrega, em que existem grupos de rotas conectando origens e destinos, possuem o benefício de ter custos fixos baixos, uma vez que não dependem de instalações logísticas intermediárias. Porém, se as cargas forem pequenas e/ou os destinos de entrega (coleta) estiverem geograficamente dispersos, tais tipos de entrega (coleta) podem se tornar dispendiosos, uma vez que os veículos tendem a operar parcialmente vazios. Para tentar reduzir os custos intermediários nestas situações, as empresas podem utilizar armazéns (warehousing) ou docas de distribuição (cross-docks).

A utilização de armazéns permite a consolidação de cargas de veículos, ou seja, as cargas são recebidas e estocadas num armazém (ou centro de distribuição) em que os produtos são desembarcados e armazenados para que posteriormente sejam enviados a seus destinos. Desta forma, tanto as cargas de entrega quanto de envio podem ser organizadas para obter um melhor aproveitamento dos meios de transporte. Buijs, Vis e Carlo (2014) destacam que as principais operações em um armazém são: o descarregamento das cargas, o armazenamento dos produtos, a localização dos produtos armazenados, e a elaboração das cargas de entrega (carregamento). Por um lado, estas operações permitem organizar as cargas em busca da redução de custos de 
transporte, por outro, resultam em custos adicionais de estoque e de manipulação de mercadorias. Segundo Ghiani, Laporte e Musmanno (2004), a manipulação de mercadorias representa a maior porcentagem dos custos em um armazém, cerca de 50\%, enquanto o descarregamento (recebimento) representa $17 \%$, o armazenamento $15 \%$ e o carregamento $18 \%$, como ilustra a Figura 1.

Figura 1 - Percentual de cada operação em um armazém.

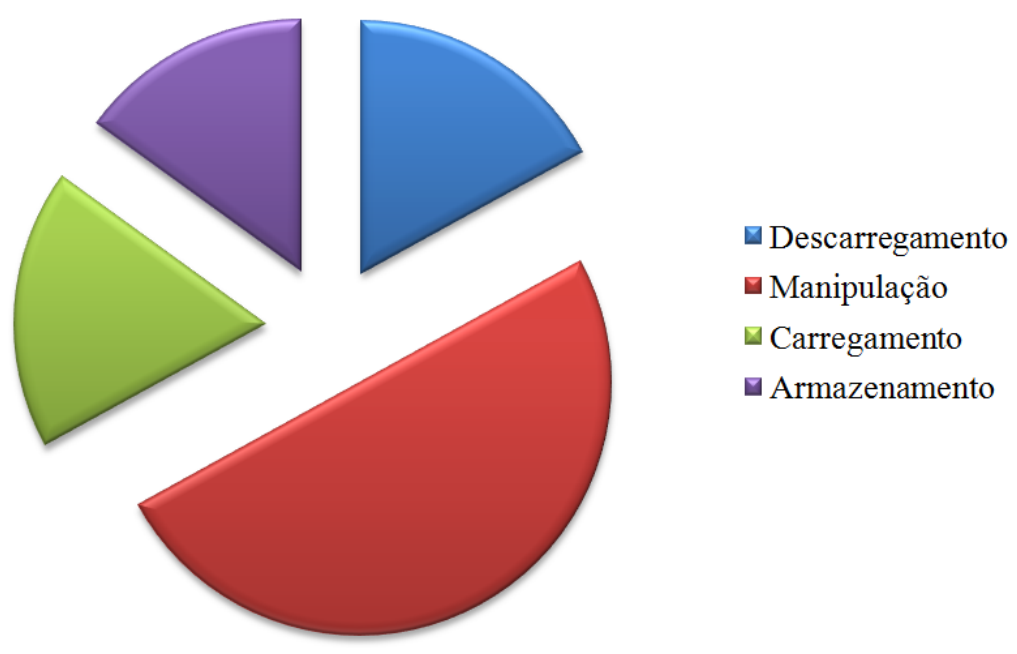

Fonte: adaptado de Ghiani, Laporte e Musmanno (2004).

Cross-docking é uma estratégia de distribuição em que os produtos recebidos não permanecem em estoque nas estações de distribuição por longos períodos de tempo, o que tipicamente ocorre nos armazéns. Logo, uma das vantagens do cross-docking é a redução dos custos de armazenamento e de manipulação de produtos nos centros de distribuição, o que leva a uma redução nos custos operacionais de distribuição, em comparação aos armazéns. Em resumo, na estratégia de cross-docking não se trabalha com estoque, apenas admitem-se estoques temporários que, no entanto, possuem um custo de armazanamento. Terminais dedicados às operações de cross-docking são chamados cross-docks (Belle, Valckenaers e Cattrysse (2012)) e são compostos por docas de descarregamento (em que entregas são feitas) e docas de carregamento (em que coletas são captadas). Devido a sua relevância econômica, vários autores têm estudado estratégias para o projeto e gerenciamento das operações de cross-docking. Revisões recentes sobre o tema foram apresentadas em Buijs, Vis e Carlo (2014) e Belle, Valckenaers e Cattrysse (2012).

Esta dissertação de mestrado tem por objetivo estudar o problema de cross-docking em que as cargas a serem descarregadas (entregas) e as cargas a serem compostas/carregadas (coletas) têm janelas de tempo para suas operações. Além disso, é imposto um limite para o estoque de produtos e custos de transferência entre cross-docks são contabilizados. O objetivo é encontrar um plano de distribuição que minimize os custos de transporte e de estoque. A possibilidade de múltiplas docas não é tratada de forma detalhada.

A revisão bibliográfica aponta que existem lacunas na literatura com relação aos modelos, 
desta forma foi proposto um modelo baseado no modelo de Javanmard, Vahdani e TavakkoliMoghaddam (2014), cobrindo as lacunas identificadas e que gerou o artigo Miyazaki-Tenório, Toledo e Armentano (2015). Dados os bons resultados obtidos foi realizado o estudo da calibração dos parâmetros do software CPLEX, que retornou resultados de melhor qualidade. Com a falta de instâncias disponíveis na literatura para o problema foi criado um conjunto de instâncias (benchmark), disponível à comunidade científica em Miyazaki-Tenório e Toledo (2016). Como este é um problema NP-difícil (Lim et al. (2005), Chen et al. (2006), Ma et al. (2011), Miao et al. (2012)) um método heurístico foi proposto para sua resolução. Os testes computacionais indicaram que a heurística apresenta resultados competitivos com o software utilizado, principalmente para cenários em que há diferentes proporções de entregas e coletas no problema.

O texto está estruturado como segue. No Capítulo 2, o problema estudado é descrito e há uma breve revisão bibliográfica no contexto de cross-docking, assim como a ideia principal para o desenvolvimento do modelo proposto nesse trabalho. No Capítulo 3, um modelo matemático para representação do problema estudado é proposto. O Capítulo 4 é destinado a testes computacionais comparando modelos e de calibração do software comercial utilizado, buscando melhoria das soluções. A proposta de uma heurística é apresentada no Capítulo 5 e os resultados computacionais acerca da heurística são apresentados e discutidos no Capítulo 6. Por fim, no Capítulo 7, são apresentadas as conclusões do trabalho desenvolvido e perspectivas de trabalhos futuros. 



\section{DEFINIÇÃO DO PROBLEMA E REVISÃO BIBLIOGRÁFICA}

A estratégia de cross-docking consiste em um sistema de distribuição intermediário entre fornecedores e consumidores. A ideia central é transferir cargas através de uma instalação logística intermediária da forma mais direta possível, ou seja, sem armazenagem entre os processos (Belle, Valckenaers e Cattrysse (2012)), ou buscando manter um estoque pelo menor tempo possível. O objetivo é efetuar o processo de entrega, organização e coleta de produtos com custo mínimo de transporte e armazenagem.

A Figura 2 ilustra um centro de distribuição composto por um único cross-dock, com docas de recebimento em que os entregadores devem descarregar seus produtos e docas de carregamento destinadas aos captadores. Na ilustração, há três entregadores e dois captadores efetuando as operações destacadas (recebimento/descarregamento da carga dos entregadores, separação das cargas para compor o carregamento das coletas realizadas pelos captadores).

Figura 2 - Cross-docking com cross-dock único.

\section{Centro de distribuicão}

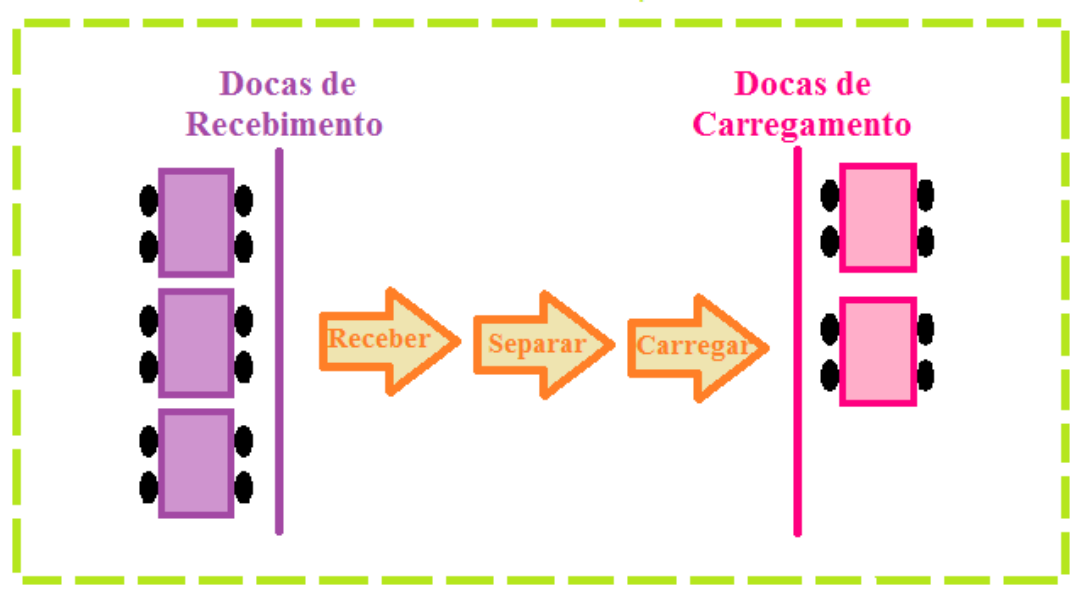

Fonte: Adaptado de Yu e Egbelu (2008). 
A Figura 3 ilustra um centro de distribuição composto por três cross-docks, em que as distâncias entre os cross-docks são destacadas. Para o problema abordado é importante citar que as distâncias entre os cross-docks não podem ser muito grandes, uma vez que se considera que transferências entre os cross-docks podem ocorrer em cerca de uma hora.

Figura 3 - Centro de distribuição (cross-docking) com três cross-docks.

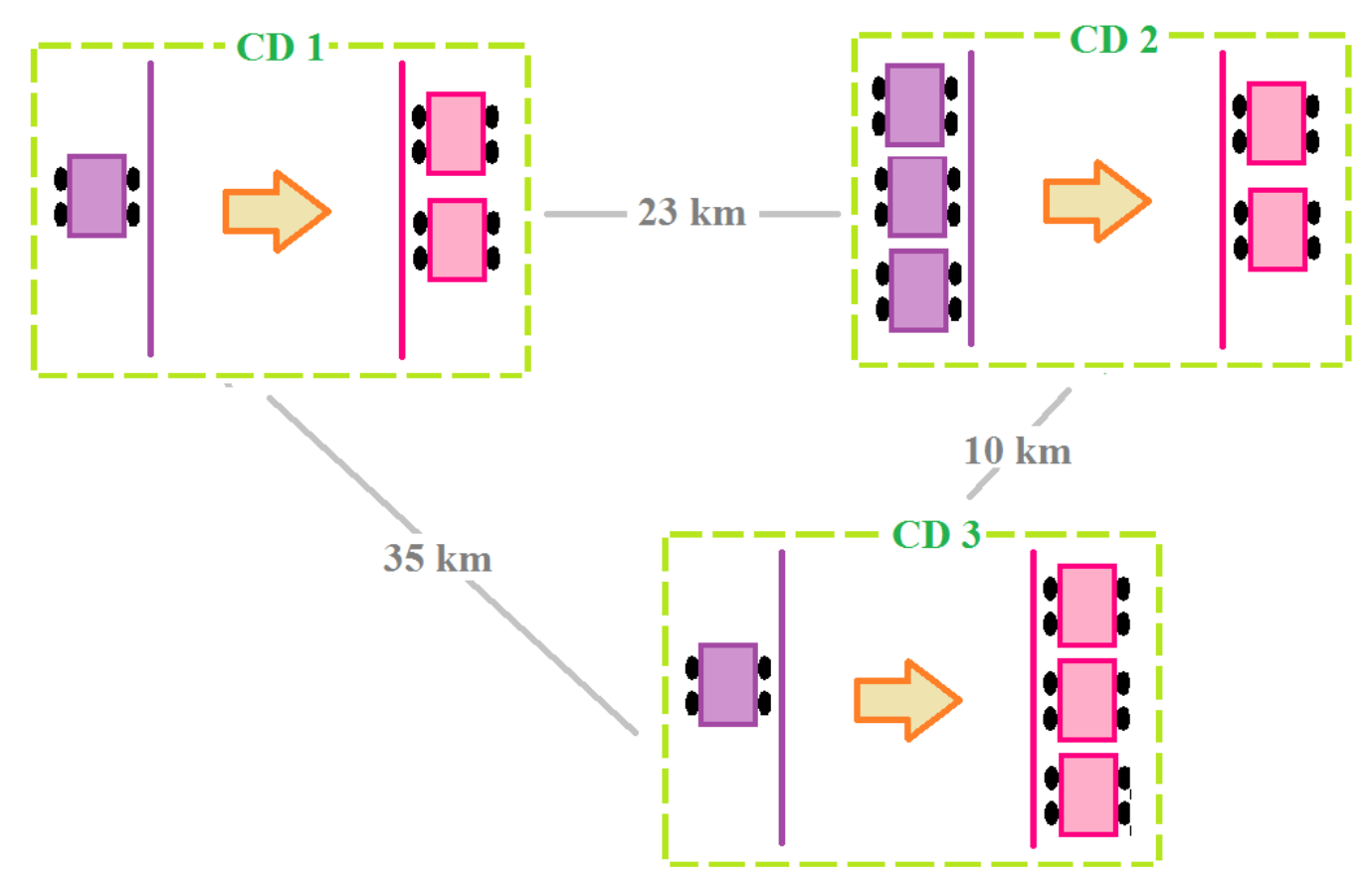

Fonte: própria.

Em geral, os centros de distribuição são compostos por um ou mais cross-docks que contém várias docas de recebimento e várias docas de carregamento. Como dito no Capítulo 1, a operação de armazenagem é uma das mais caras dentro de uma estratégia de distribuição, o que torna importante o estudo da estratégia de cross-docking. Segundo Belle, Valckenaers e Cattrysse (2012), as principais vantagens de se utilizar a estratégia de cross-docking com relação aos outros tipos de centros de distribuição são: redução de custos (carregamento, descarregamento, manuseio nos armazéns e armazenagem), entregas mais rápidas (muitas vezes entregas são descarregadas e os produtos são imediatamente direcionados a compor a carga das coletas), redução do espaço de armazenagem e redução do risco de perdas (no caso de produtos perecíveis), devido ao tempo de estoque limitado.

Uma das principais aplicações práticas para esta estratégia é encontrada nas redes de varejo de todo o mundo, em que os produtos chegam a um centro de distribuição de uma rede (por exemplo, a matriz) e devem ser carregados para envio a filiais ou diretamente para os consumidores. Ladier e Alpan (2015) citam o Wal-Mart como um dos pioneiros na utilização de cross-docking, tendo implementado a estratégia por volta de 1980. No Brasil, empresas de logística utilizam o cross-docking e também algumas redes de supermercado têm usado a estratégia combinada à estratégia de warehouses, alguns exemplos são Maroni (2013), Carraro (2008), Covisi (2016). 
Segundo Buijs, Vis e Carlo (2014), na estratégia de cross-docking, três elementos são recorrentes: as operações básicas, os objetivos a serem atingidos; e o número de docas disponíveis. As operações básicas realizadas são: o descarregamento da carga, a classificação dos produtos com base em seu destino, a movimentação dos produtos, e o despacho imediato para coleta. Dentre os objetivos, os autores destacam: minimizar o tempo de atraso no despacho das mercadorias, minimizar o tempo de espera para entregas e coletas, e minimizar o manuseio dos produtos no interior das instalações. A restrição mais comum é quanto ao tempo limite de armazenamento dos produtos, por exemplo, 24 horas. Também o número de docas disponíveis no cross-dock é relevante pois, em muitos casos, é importante haver capacidade para tratar o descarregamento de várias cargas simultaneamente, o que permite que o despacho de mercadorias seja mais ágil e as cargas sejam melhor consolidadas.

O problema de cross-docking pode ser dividido em classes, que são: problemas locais e problemas da rede de distribuição. Problemas locais se restringem a um cross-dock, enquanto problemas de rede estão relacionados a uma rede de cross-docks. Estes problemas são subdivididos de acordo com seu nível de tomada de decisão, isto é, estratégico, tático e operacional, como ilustra a Figura 4 (ver Buijs, Vis e Carlo (2014)).

Figura 4 - Organização de problemas de Cross-docking.

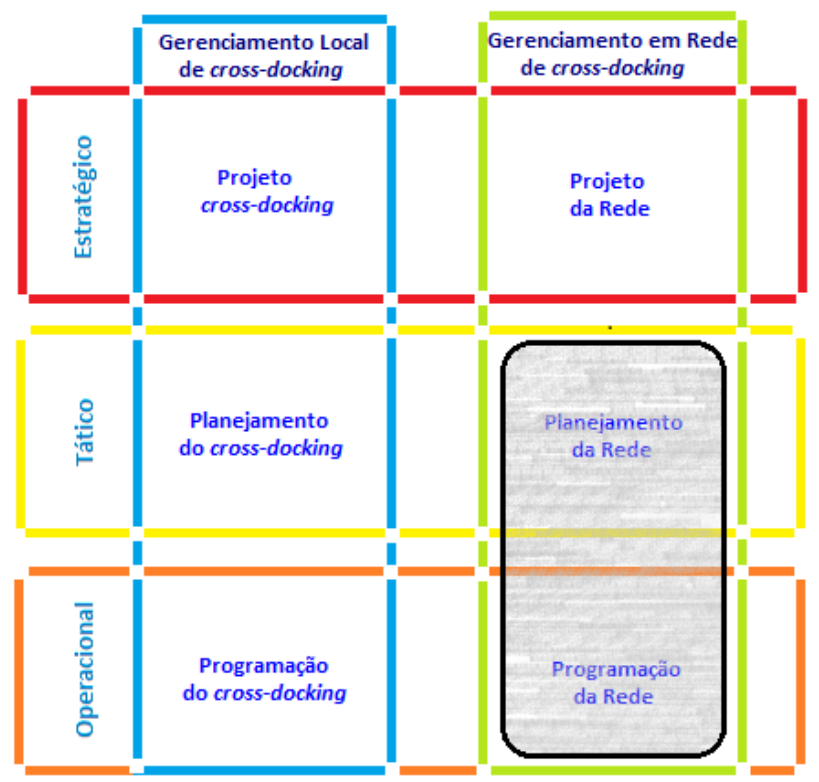

Fonte: adaptado de Buijs, Vis e Carlo (2014).

De acordo com Buijs, Vis e Carlo (2014), no gerenciamento local de cross-docking, a classe de Projeto de cross-docking especifica as configurações do centro de distribuição como, por exemplo, determinar o número de docas a ser utilizado (planejamento estratégico). Na classe de Planejamento de cross-docking são definidas as operações das docas (planejamento tático). Um objetivo comum nessa classe é minimizar o manuseio de material nas docas, enquanto a classe de Programação de cross-docking especifica o planejamento das operações internas do 
cross-dock no dia-a-dia (planejamento operacional).

As decisões associadas ao gerenciamento da rede de cross-docking são similares às do gerenciamento local de cross-docking. Assim, a classe de Projeto de Rede determina a infraestrutura física da rede de cross-docking (por exemplo, número de cross-docks), de forma a atender a demanda com o menor custo possível, a classe de Planejamento da Rede aloca e utiliza configurações logísticas de forma a economizar e atender às demandas, e a Programação de Rede considera restrições de tempo, respeitando as janelas de tempo para os serviços de transporte da rede.

De acordo com esta classificação, o problema abordado nessa dissertação é um problema de integração do planejamento e da programação de uma rede de distribuição, região destacada em cinza na Figura 4. O foco principal, entretanto, está no nível operacional, uma vez que se deseja programar a ordem e o instante de início das operações de entregas e coletas. Desta forma, a revisão bibliográfica apresentada se restringe aos artigos relacionados ao problema estudado. Uma revisão mais ampla sobre o tema pode ser encontrada em Boysen e Fliedner (2010), Belle, Valckenaers e Cattrysse (2012), Buijs, Vis e Carlo (2014) e Ladier e Alpan (2015) que também apresentam uma boa descrição do problema e algumas classificações para o mesmo.

\subsection{Problema de integração do planejamento e da pro- gramação de uma rede de distribuição}

O problema de integração do planejamento e da programação de uma rede de distribuição consiste em determinar a ordem e o instante para início das operações de descarregamento de entregas e carregamento de coletas em um ou mais cross-docks de um centro de distribuição. $\mathrm{O}$ foco principal é sincronizar os carregamentos e os descarregamentos de forma que a soma dos custos de distribuição e de armazenagem sejam minimizados. Como mencionado na introdução deste capítulo, a revisão aqui apresentada se restringe aos artigos relacionados a esta classe de problemas de cross-docking.

Lim et al. (2005) apresentam uma comparação entre os modelos propostos para o problema de cross-docking sem janelas de tempo e terminam por dar foco aos cross-dockings com janelas de tempo. Além disso, os autores classificaram o problema com relação a sua programação: rígida (quando os tempos são fixos), flexível (quando os tempos de entrada e saída são flexíveis) e mista (junção da programação rígida e da programação flexível).

Chen et al. (2006) destacam que o planejamento das operações de cross-docking é extremamente complexo, exigindo de fornecedores, consumidores e distribuidores um alto grau de coordenação. Em especial, a sincronização dos tempos de chegada e saída de cargas é crucial para que as operações de distribuição sejam eficazes. Sendo assim, os autores focam na política "just-in-time", ou seja, os produtos que chegam às docas devem ser despachados, evitando, 
assim, os custos de armazenamento. Além disso, é desenvolvido um modelo matemático para o problema de cross-docking considerando janelas de tempo para entregadores (deliveries) e captadores (pickups, que realizam as coletas), de forma que os atrasos são penalizados (as janelas de tempo devem ser respeitadas). Os autores provaram que o problema é de difícil solução exata e desenvolveram métodos heurísticos (heurística gulosa, Simulated Annealing, Tabu Search e Simulated Annealing com Tabu Search) para a resolução de 40 instâncias geradas por eles. As soluções obtidas foram comparadas às melhores soluções obtidas pelo software ILOG CPLEX 8.0. Tabu Search (TS) e Simulated Annealing com Tabu Search (SA+TS) obtiveram, em média, as melhores soluções, uma vez que encontraram valores mais próximos da solução do software CPLEX em mais instâncias. Comparando-se somente TS e SA+TS, concluiu-se que SA+TS é a melhor abordagem para os problemas tratados, uma vez que SA+TS encontra mais soluções próximas das melhores soluções do software CPLEX que TS.

Ma et al. (2011) seguem uma abordagem semelhante a de Chen et al. (2006), porém, em sua proposta apenas um tipo de produto compõe a carga e os entregadores são, também, os captadores. Desta forma, em alguns casos, os cross-docks nem chegam a ser utilizados. Quando há a necessidade de cross-docking, os produtos são descarregados nas docas e recarregados, respeitando as janelas de tempo de entregadores e de captadores. O objetivo do problema é reduzir os custos de transporte, manuseio dos produtos dentro dos cross-docks e estoque. Os autores mostram que o problema é NP-completo e por isso desenvolvem duas heurísticas para sua resolução: fluxos em redes com squeaky wheel optimization (NF+SWO) e fluxos em redes com genetic algorithm (NF+GA). Foram resolvidas 24 instâncias de testes, geradas aleatoriamente pelos autores, e comparadas às soluções dadas pelo software CPLEX (os autores não informam a versão) em um tempo limite (2700s). Respeitando o tempo limite, o software CPLEX não obteve a solução ótima para nenhuma das instâncias avaliadas, os gaps obtidos foram de no mínimo 6,6\% e no máximo 21,9\%. A heurística NF+SWO resolveu as instâncias em no máximo 41,8s, e teve gaps entre $8,1 \%$ e $22,5 \%$, enquanto a heurística NF+GA teve seu tempo limitado em 133,5 s e gaps entre $8,0 \%$ e 20,1\%. Assim, analisando-se os gráficos comparativos e os resultados obtidos, em geral, as heurísticas (principalmente NF+GA) tiveram melhor desempenho que o software CPLEX com relação ao tempo computacional, além de apresentarem soluções de qualidade similar às soluções encontradas pelo software.

Miao et al. (2012) seguem a mesma linha que Ma et al. (2011), considerando cargas com apenas um tipo de produto. Porém, Miao et al. (2012) sugerem uma nova abordagem para as janelas de tempo dos captadores, em que elas são divididas em dois tipos: janelas de tempo flexíveis (soft time windows) e janelas de tempo rígidas (hard time windows). As janelas de tempo flexíveis representam o período em que se deseja que as coletas sejam carregadas, e as janelas de tempo rígidas representam o período em que os captadores devem ser atendidos. As janelas de tempo flexíveis não precisam, necessariamente, ser atendidas. Já as janelas de tempo rígidas precisam, necessariamente, ser atendidas. Como o problema é NP-completo (Lim et al. (2005)), os autores desenvolvem meta-heurísticas para sua resolução. As meta-heurísticas 
propostas foram: busca tabu adaptativa (BTA) e algoritmo genético adaptativo (AGA). Foram utilizados 8 grupos de instâncias de testes de pequeno porte (cada um com 4 instâncias), geradas aleatoriamente seguindo uma distribuição uniforme, e 8 grupos de instâncias de teste para problemas de grande porte, gerados da mesma forma que os problemas de pequeno porte também com 4 instâncias cada grupo. Os resultados obtidos foram comparados aos resultados obtidos utilizando o software ILOG CPLEX 11.0 com tempo limitado a 3600s. A BTA teve melhores tempos computacionais que os demais, e a AGA teve os melhores gaps; porém, para os problemas de grande escala, a BTA obteve gaps e tempos computacionais melhores. Desta forma, através de uma análise de sensibilidade, os autores mostram que, na maioria dos casos, a BTA tem um desempenho superior a AGA, principalmente para instâncias de grande porte. Como esperado, as duas meta-heurísticas possuem um tempo computacional muito menor que o utilizado pelo software CPLEX e para quase todas as instâncias testadas os gaps do software foram maiores que os encontrados pelas meta-heurísticas propostas.

Marjani, Husseini e Karimi (2012) também seguem a mesma linha de problemas que Ma et al. (2011), porém, permitindo o transporte de múltiplos tipos de produtos, transporte entre cross-docks e atraso para alguns captadores (com penalidade na função objetivo). Além destas características, os autores permitem que o estoque inicial de cada cross-dock seja não-nulo, e o problema é tratado como bi-objetivo, em que os objetivos são: minimizar o custo total (de manuseio, transporte dos entregadores, dos captadores, e entre cross-docks) e minimizar o atraso permitido. Os autores propõem três meta-heurísticas para o problema: busca em vizinhança variável (ou variable neiborhood search - VNS), busca tabu (TS) e simulated annealing híbrido (HSA). Foram geradas 24 instâncias de teste, e as meta-heurísticas foram implementadas em Matlab 7.0. Desta forma, a partir dos resultados, o algoritmo VNS mostrou melhor desempenho que os demais (menores valores de função objetivo), porém TS se mostrou mais rápida e mantendo soluções próximas de VNS.

Javanmard, Vahdani e Tavakkoli-Moghaddam (2014), uma extensão de Chen et al. (2006), também abordam problemas com múltiplos tipos de produtos, múltiplos cross-docks e janelas de tempo tanto para entregadores quanto para captadores, porém cada entrega ou coleta pode passar por até um cross-dock por tipo de produto. Os autores, após mostrar que o problema é NP-difícil, propõem uma heurística imperialista, Imperialist Competitive Algorithm (ICA), para resolução do problema. Este método é semelhante aos algoritmos genéticos e, comparando seus resultados aos resultados obtidos utilizando a linguagem GAMS 22.9 (com tempo limite de $2 \mathrm{~h}$ ), a heurística chega a soluções de boa qualidade (com gaps inferiores a $2 \%$, quando comparadas as soluções ótimas do GAMS às soluções encontradas pela heurística) para as 40 instâncias geradas e encontra soluções factíveis para as instâncias maiores, para as quais o software GAMS não encontrou solução. 


\subsection{Considerações}

Como visto no desenvolver deste capítulo, os problemas de cross-docking têm grande importância na área de distribuição de produtos. Na Tabela 1 é apresentado um breve resumo dos principais aspectos dos problemas abordados pelos autores anteriormente citados. Embora possa ocorrer na prática, nota-se que em nenhum dos artigos todos os aspectos (vários cross-docks, vários produtos, estoque limitado, janelas de tempo para entregadores e captadores (rígidas e flexíveis), podendo passar por mais de um cross-dock e com transporte entre cross-docks) são abordados simultaneamente. Identificou-se, portanto, uma lacuna na literatura que será estudada neste trabalho e destacado na última coluna da tabela.

Tabela 1 - Resumo dos artigos.

\begin{tabular}{|c|c|c|c|c|c|c|}
\hline Modelo & Chen et al. (2006) & Ma et al. (2011) & Miao et al. (2012) & Marjani et al. (2012) & $\begin{array}{c}\text { Javanmard et al. } \\
(2014)\end{array}$ & $\begin{array}{c}\text { Miyazaki-Tenório e } \\
\text { Toledo (2015) }\end{array}$ \\
\hline Cross-docks & Vários & Vários & Vários & Vários & Vários & Vários \\
\hline Tipo de carga & Heterogênea & Homogênea & Homogênea & Heterogênea & Heterogênea & Heterogênea \\
\hline $\begin{array}{c}\text { Janelas de } \\
\text { tempo }\end{array}$ & $\begin{array}{c}\text { Rigidas para } \\
\text { entregas e coletas }\end{array}$ & $\begin{array}{c}\text { Rígidas para } \\
\text { entregas e coletas }\end{array}$ & $\begin{array}{l}\text { Rígidas para } \\
\text { entregas e rígidas } \\
\text { e flexíveis para } \\
\text { coletas }\end{array}$ & $\begin{array}{c}\text { Rígidas para } \\
\text { entregas e coletas }\end{array}$ & $\begin{array}{c}\text { Rígidas para } \\
\text { entregas e coletas }\end{array}$ & $\begin{array}{l}\text { Rigidas para } \\
\text { entregas e rígidas e } \\
\text { flexíveis para } \\
\text { coletas }\end{array}$ \\
\hline $\begin{array}{c}\text { Pode passar por } \\
\text { quantos cross- } \\
\text { docks }\end{array}$ & Somente um & Somente um & Somente um & Somente um & $\begin{array}{l}\text { Vários (até um para } \\
\text { cada tipo de } \\
\text { produto) }\end{array}$ & $\begin{array}{l}\text { Vários (até um para } \\
\text { cada tipo de } \\
\text { produto) }\end{array}$ \\
\hline $\begin{array}{c}\text { Transporte entre } \\
\text { cross-docks }\end{array}$ & Não & Não & Não & Sim & Não & Sim \\
\hline Objetivo & $\begin{array}{l}\text { Minimizar custos de } \\
\text { transporte e estoque }\end{array}$ & $\begin{array}{l}\text { Minimizar custos } \\
\text { de transporte e } \\
\text { estoque }\end{array}$ & $\begin{array}{l}\text { Minimizar custos } \\
\text { de transporte, } \\
\text { estoque e } \\
\text { penalizações por } \\
\text { não cumprir as } \\
\text { janelas de tempo } \\
\text { flexíveis das } \\
\text { coletas }\end{array}$ & $\begin{array}{c}\text { Minimizar cutos de } \\
\text { estoque, transpoete } \\
\text { e transferências e } \\
\text { Minimizar o atraso } \\
\text { permitido }\end{array}$ & $\begin{array}{l}\text { Minimizar custos de } \\
\text { transporte e estoque }\end{array}$ & $\begin{array}{c}\text { Minimizar custos de } \\
\text { transporte, estoque, } \\
\text { tranferências e } \\
\text { penalizações por } \\
\text { não cumprir as } \\
\text { janelas de tempo } \\
\text { flexíveis das coletas }\end{array}$ \\
\hline
\end{tabular}

Fonte: própria.

Uma solução para um exemplo deste problema é ilustrada na Figura 5. No exemplo são considerados 2 cross-docks (CD1 e CD2), 2 entregadores (F1 e F2), 3 captadores (C1, C2 e C3) e 3 tipos de produtos, ilustrados pelas setas de cores amarela, vermelha e azul. Os valores $(\mathrm{P} ; \mathrm{Q} ; \mathrm{T})$ representam, respectivamente, o tipo de produto da carga, a quantidade e o instante de início da operação (entrega, coleta ou transferência), as setas indicam a direção da operação.

Figura 5 - Uma solução para um exemplo do problema estudado.

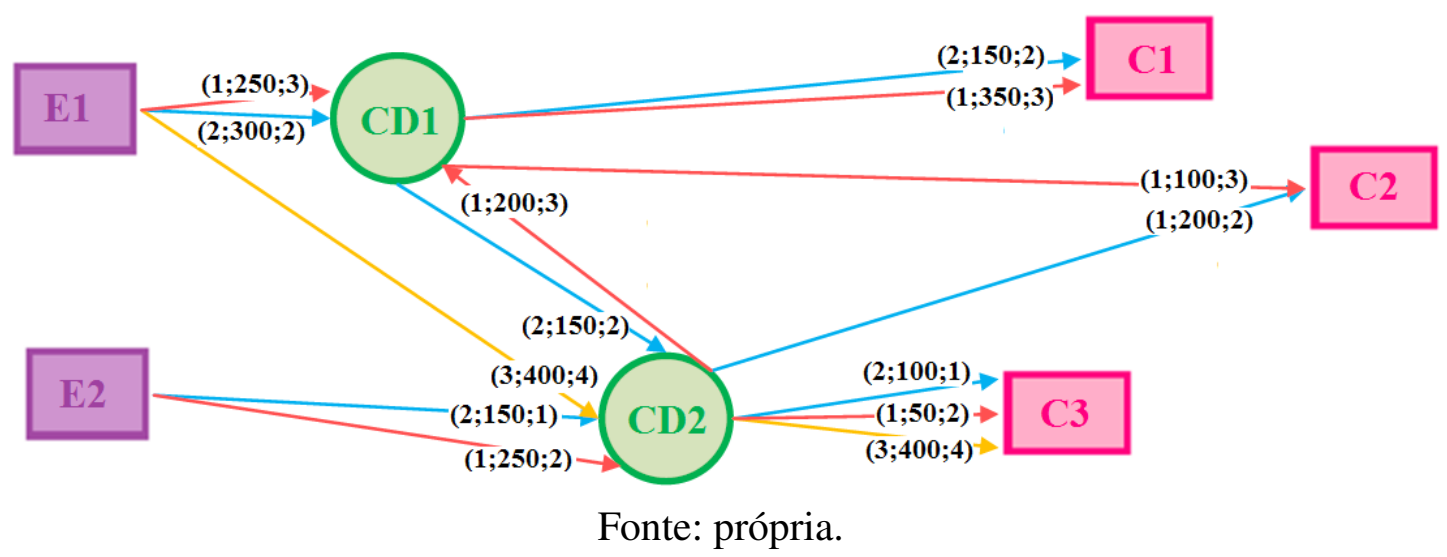

Por hipótese, admite-se a utilização de um período de tempo para cada operação seja 
ela descarregamento, transferência ou carregamento. No exemplo da Figura 5, no período 3, o cross-dock 1 recebe uma carga com 250 itens do produto 1 e outra carga com 200 itens do mesmo produto vinda do cross-dock 2.

A Figura 6 ilustra o horizonte de planejamento do exemplo exibido na Figura 5. Na figura é apresentada uma linha de tempo para cada produto, respectivamente, tipo 1 (vermelho), tipo 2 (azul) e tipo 3 (amarelo).

Figura 6 - Horizonte de planejamento do exemplo da Figura 5
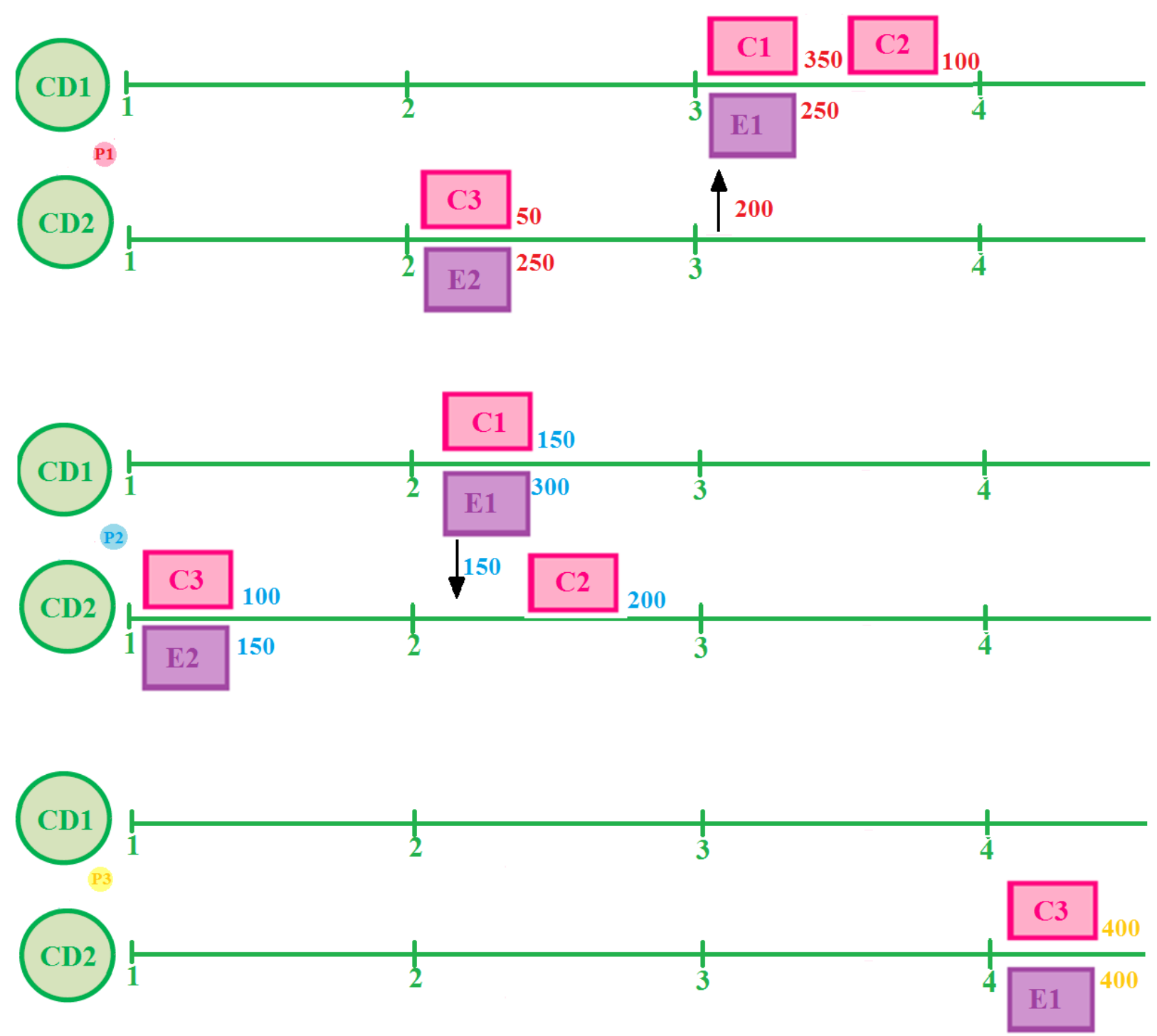

Fonte: própria.

Para os produtos do tipo 1, o entregador E1 inicia sua entrega de 250 itens no instante 2 no cross-dock CD2 e 50 itens são direcionados a compor a carga do captador C3, deixando ao final do período 2 um estoque de 200 itens. No instante 3, os 200 itens em estoque são transferidos de CD 2 para CD1 e Cd1 recebe 250 itens de E1. Dos 450 itens recebidos 350 são direcionados a $\mathrm{C} 1$ e 100 para $\mathrm{C} 2$. O estoque de produtos do tipo 1 ao final do período 3 é nulo em ambos os cross-docks. 
Os produtos do tipo 2 são entregues no instante 1 por E2 e 100 itens são redirecionados à carga de $\mathrm{C} 3$, deixando um estoque no cross-dock $\mathrm{CD} 2$ de 50 itens ao final do período 1 . No instante 2, E1 inicia a entrega de 300 itens em CD1 dos quais 150 são carregados em C1, enquanto 150 são tranferidos para CD2. Em CD2, 200 itens passam a compor a carga de C2. O estoque final de CD1 e de CD2 ao final do período 2 é nulo.

Por fim, os produtos do tipo 3 possuem entrega de 400 itens iniciada no instante 4 no cross-dock $\mathrm{CD} 2$ que instantaneamente passam a compor a coleta $\mathrm{C} 3$, deixando um estoque nulo ao final do período 4. 

O problema de cross-docking estudado neste trabalho é, conforme definido em Buijs, Vis e Carlo (2014), um problema de integração do planejamento e da programação de uma rede de distribuição. Ele consiste em determinar a ordem e o instante em que entregas são destinadas a dar início ao descarregamento e as coletas são destinadas a iniciar os carregamentos em algum dos cross-docks de um centro de distribuição. O foco principal é sincronizar os descarregamentos e os carregamentos de cargas de forma que a soma dos custos de distribuição e de estoque sejam minimizados. Este problema é frequente em centros de distribuição de produtos como, por exemplo, em grandes empresas de eletrodomésticos e em redes de lojas de varejo como o clássico exemplo do Wal-Mart (Simchi-Levi, Kaminsky e Simchi-Levi (2003) e Miranda (2015)). No Brasil, esta estratégia de distribuição é frequente em redes de logística como Maroni (2013), Carraro (2008), Covisi (2016) e no crescente $e$-commerce, como mencionado em CARGOBR (2013).

Neste trabalho, é abordado o problema integrado de planejamento e da programação da distribuição com as seguintes características: vários cross-docks e múltiplos tipos de produto (cargas heterogêneas), tanto para entregas quanto para coletas, transferência de cargas entre cross-docks de um mesmo centro de distribuição, entregadores e captadores podem passar por até um cross-dock para cada tipo de produto e janelas de tempo para entregas e coletas. Além disso, são tratados dois tipos de janelas de tempo para as coletas: janelas de tempo rígidas e janelas de tempo desejáveis (ou flexíveis). As janelas de tempo rígidas devem, obrigatoriamente, ser respeitadas; já as janelas de tempo flexíveis representam o período desejável para que cada coleta inicie a operação de carregamento.

Este mesmo problema, exceto pela transferência de cargas entre cross-docks de um mesmo centro de distribuição e janelas de tempo flexíveis para os consumidores, foi abordado por Javanmard, Vahdani e Tavakkoli-Moghaddam (2014). Desta forma, o modelo aqui proposto é uma extensão do trabalho desses autores que é descrito a seguir. 


\subsection{Modelo da literatura}

O problema estudado por Javanmard, Vahdani e Tavakkoli-Moghaddam (2014) possui as seguintes características:

- as cargas de entregas e de coletas podem ser compostas por mais de um tipo de produto, ou seja, são cargas heterogêneas;

- todas as demandas das coletas devem ser atendidas;

- cada cross-dock possui capacidade limitada, ou seja, o estoque ao final de cada período de tempo não deve ultrapassar sua capacidade de armazenagem;

- o estoque inicial de cada cross-dock é nulo;

- entregas e coletas têm janelas de tempo que devem ser respeitadas, ou seja, os carregamentos e descarregamentos devem ser (obrigatoriamente) iniciados nos cross-docks dentro destas janelas;

- entregadores e captadores podem passar por mais de um cross-dock, mais especificamente, podem passar por até um cross-dock para cada tipo de produto, não sendo proibido fazer as operações de carga e descarga de mais de um tipo de produto.

Em geral, o horizonte de planejamento para problemas deste tipo não ultrapassa 24 horas e usualmente é subdividido em períodos de uma hora. Para a modelagem, considera-se que o horizonte de planejamento é discretizado e subdividido em períodos e que apenas um carregamento (descarregamento) é realizado por coleta (entrega) a cada período. Também se considera que uma vez que uma entrega seja destinada a um determinado cross-dock, ela deve ser inteiramente descarregada, ou seja, não se admite a entrega parcial de uma carga por um determinado entregador. O objetivo é minimizar os custos de estoque e de transporte. O modelo proposto pelos autores é dado por (3.1) - (3.9), em que:

Índices:

- $i \in\{1,2, \ldots, I\}$ - em que $I$ é o total de tipos de produtos;

- $k \in\{1,2, \ldots, K\}$ - em que $K$ é o total de cross-docks disponíveis no centro de distribuição;

- $t \in\{1, \ldots, T\}$ - em que $T$ é o total de períodos do horizonte de planejamento;

- $e \in\{1,2, \ldots, E\}$ - em que $E$ é o total de entregadores;

- $c \in\{1,2, \ldots, C\}$ - em que $C$ é o total de captadores. 
- $H C_{i k}$ - penalidade por período por unidade do produto $i$ em estoque no cross-dock $k$;

- $E T C_{i k}^{e}$ - custo de transporte do produto $i$ da entrega $e$ até o cross-dock $k$;

- $C T C_{i k}^{c}$ - custo de transporte do produto $i$ da coleta $c$ a partir do cross-dock $k$;

- $T I^{e}\left(T F^{e}\right)$ - limitante inferior (superior) da janela de tempo da entrega $e$;

- $T I^{c}\left(T F^{c}\right)$ - limitante inferior (superior) da janela de tempo da coleta $c$;

- $C A P_{k}$ - capacidade de armazenagem do cross-dock $k$, dado em termos de itens;

- $M_{i}^{e}$ - quantidade do produto $i$ na entrega $e$;

- $M_{i}^{c}$ - demanda do produto $i$ na coleta $c$.

Variáveis:

- $x_{i k t}^{e}= \begin{cases}1, & \text { se o produto } i \text { da entrega } e \text { é descarregado no } c r o s s-d o c k ~ k \text { no instante } t, \\ 0, & \text { caso contrário; }\end{cases}$

- $y_{i k t}^{c}= \begin{cases}1, & \text { se o produto } i \text { da coleta } c \text { é carregado no cross-dock } k \text { no instante } t \\ 0, & \text { caso contrário; }\end{cases}$

- $s_{i k t}=$ a quantidade do produto $i$ em estoque no cross-dock $k$ ao final do período iniciado no instante $t$. 


$$
\begin{aligned}
\text { Minimizar } & \sum_{i=1}^{I} \sum_{k=1}^{K} \sum_{t=1}^{T} H C_{i k} s_{i k t}+\sum_{i=1}^{I} \sum_{k=1}^{K} \sum_{t=1}^{T} \sum_{e=1}^{E} E T C_{i k}^{e} x_{i k t}^{e} \\
& +\sum_{i=1}^{I} \sum_{k=1}^{K} \sum_{t=1}^{T} \sum_{c=1}^{C} C T C_{i k}^{c} y_{i k t}^{c}
\end{aligned}
$$

Sujeito a:

$$
\begin{array}{lr}
\sum_{k=1}^{K}\left(\sum_{t=1}^{T I^{e}-1} x_{i k t}^{e}+\sum_{t=T F^{e}+1}^{T} x_{i k t}^{e}\right)=0, & \forall i, e \\
\sum_{k=1}^{K}\left(\sum_{t=1}^{T I^{c}-1} y_{i k t}^{c}+\sum_{t=T F^{c}+1}^{T} y_{i k t}^{c}\right)=0, & \forall i, c \\
\sum_{k=1}^{K} \sum_{t=T I^{e}}^{T F^{e}} x_{i k t}^{e} \leq 1, & \forall i, e \\
\sum_{k=1}^{K} \sum_{t=T I^{c}}^{T F^{c}} y_{i k t}^{c}=1, & \forall i, c \\
\sum_{i=1}^{I} s_{i k t} \leq C A P_{k}, & \forall k, t \\
s_{i k t}=s_{i k, t-1}+\sum_{e=1}^{E} x_{i k t}^{e} M_{i}^{e}-\sum_{c=1}^{C} y_{i k t}^{c} M_{i}^{c}, & \forall i, k, t \\
s_{i k, 0}=0, & \forall i, k \\
s_{i k t} \in \mathbb{Z}_{+} ; x_{i k t}^{e} \in \mathbb{B} ; y_{i k t}^{c} \in \mathbb{B} & \forall i, k, t, e, c
\end{array}
$$

A função objetivo (3.1) consiste em minimizar a soma dos custos de estoque de produtos nos cross-docks, dos custos de transporte dos produtos dos entregadores para os cross-docks e dos custos de transporte dos produtos dos cross-docks dos captadores. As restrições (3.2) determinam que um entregador não pode chegar a um cross-dock fora de sua janela de tempo, enquanto as restrições (3.4) garantem que se houver entrega ela terá início dentro de sua janela de tempo. De forma análoga, as restrições (3.3) asseguram que as janelas de tempo das coletas são satisfeitas. As restrições (3.5) garantem o atendimento da demanda das coletas. As restrições (3.6) impõem que a capacidade de armazenamento dos cross-docks é respeitada em todos os períodos. As restrições (3.7) representam o balanço de estoque de produtos nos cross-docks, enquanto as restrições (3.8) determinam, sem perda de generalidade, que o estoque inicial nos cross-docks é nulo. Por fim, as restrições (3.9) definem o domínio das variáveis.

\subsection{Modelo proposto}

Em Miao et al. (2012), os autores estudam dois tipos de janelas de tempo: desejável (isto é, flexível) e obrigatória (isto é, rígida). A janela de tempo desejável, definida apenas para os captadores, é o período mais apropriado para o serviço. Os autores tratam esta característica penalizando na função objetivo o serviço iniciado fora da janela de tempo desejável. Vale destacar 
que as janelas de tempo obrigatórias devem ser respeitadas tanto pelos entregadores quanto pelos captadores.

No problema estudado são abordadas janelas de tempo flexíveis (desejáveis) e rígidas para coletas como em Miao et al. (2012), em que as janelas de tempo rígidas são as mesmas utilizadas anteriormente, ou seja, $\left[T I^{c}, T F^{c}\right]$. Já as janelas de tempo flexíveis constituem um período em que se deseja que o captador inicie atendimento no cross-docking, caso contrário, impõe-se uma penalidade à função objetivo. Definem-se, então, os dados:

- $P C^{c}$ - o custo por não atender a janela de tempo flexível da coleta $c$;

- $F I^{c}$ - o limitante inferior da janela de tempo flexível da coleta $c$;

- $F F^{c}$ - o limitante superior da janela de tempo flexível da coleta $c$.

A Figura 7 ilustra a diferença entre as janelas de tempo, ou seja, a janela de tempo flexível (em azul) está contida na janela de tempo rígida (em vinho), uma vez que a janela de tempo flexível representa o período preferível para atendimento do captador e a janela de tempo rígida representa o período em que há a obrigação de atendimento da coleta.

Figura 7 - Ilustração das janelas de tempo, flexível e rígida.

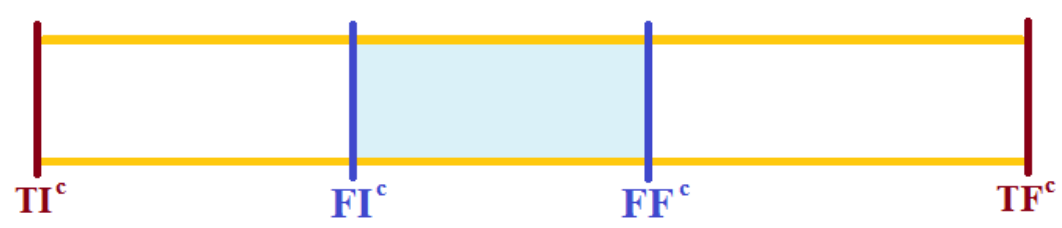

Fonte: própria.

Para adicionar a restrição desejada, define-se, também, a variável binária:

- $\delta^{c}= \begin{cases}1, & \text { se a janela de tempo desejável da coleta } c \text { é atendida, } \\ 0, & \text { caso contrário; }\end{cases}$

Assim, novas restrições para determinar se as janelas de tempo desejáveis são ou não atendidas são adicionadas ao problema:

$$
\begin{gathered}
\sum_{k=1}^{K} \sum_{t=F I^{c}}^{F F^{c}} y_{i k t}^{c} \leq \delta_{c}, \quad \forall i, c \\
\boldsymbol{\delta}_{c \in \mathbb{B},}
\end{gathered}
$$

e adiciona-se à função objetivo uma penalidade caso o consumidor seja atendido fora da janela de tempo flexível, logo a nova função objetivo é dada por:

$$
\begin{array}{r}
\sum_{i=1}^{I} \sum_{k=1}^{K} \sum_{t=1}^{T} H C_{i k} s_{i k t}+\sum_{i=1}^{I} \sum_{k=1}^{K} \sum_{t=1}^{T} \sum_{e=1}^{E} F T C_{i k}^{e} x_{i k t}^{e} \\
+\sum_{i=1}^{I} \sum_{k=1}^{K} \sum_{t=1}^{T} \sum_{c=1}^{C} C T C_{i k}^{c} y_{i k t}^{c}+\sum_{i=1}^{I} \sum_{c=1}^{C} P C^{c}\left(1-\delta_{i}^{c}\right) .
\end{array}
$$


Deseja-se agora, permitir o transporte de produtos entre cross-docks, como em Marjani, Husseini e Karimi (2012). Assim, é necessário conhecer $T C_{i k k^{\prime}}$ - o custo de transportar uma unidade de um produto de tipo $i$ do cross-dock $k$ para o cross-dock $k^{\prime}$. Definimos, também, as variáveis:

- $z_{k k^{\prime} t}= \begin{cases}1, & \text { se há transferência de produtos do cross-dock } k \text { para } k^{\prime} \text { no período } t \\ 0, & \text { caso contrário; }\end{cases}$

- $w_{i k k^{\prime} t}=$ a quantidade transferida do produto $i$ do $c r o s s-d o c k k$ para $k^{\prime}$ no período $t$.

As restrições (3.7), de atualização de estoque, são, então, substituídas por:

$$
s_{i k t}=s_{i k, t-1}+\sum_{e=1}^{E} x_{i k t}^{e} M_{i}^{e}-\sum_{c=1}^{C} y_{i k t}^{c} M_{i}^{c}+\sum_{k^{\prime}=1, k^{\prime} \neq k}^{K} w_{k^{\prime} k t}^{i}-\sum_{k^{\prime}=1, k^{\prime} \neq k}^{K} w_{k k^{\prime} t}^{i}, \quad \forall i, k, t
$$

em que a parcela $\sum_{k^{\prime}=1, k^{\prime} \neq k}^{K} w_{k^{\prime} k t}^{i}$ representa os produtos que chegaram ao cross-dock $k$ transferidos de outros cross-docks e $\sum_{k^{\prime}=1, k^{\prime} \neq k}^{K} w_{k k^{\prime} t}^{i}$ representa os produtos que foram transferidos de $k$ para outros cross-docks no instante $t$. Além disso, são adicionadas as restrições:

$$
\sum_{i=1}^{I} w_{i k k^{\prime} t} \leq \min \left\{C A P_{k}, C A P_{k^{\prime}}\right\} z_{k k^{\prime} t}, \forall k, k^{\prime} \neq k, t
$$

que validam as variáveis $z_{k k^{\prime} t}$, responsáveis pelo custo adicionado à função objetivo quando há transferência de produtos entre cross-docks.

Como não é permitido estoque negativo e como são dependentes somente de variáveis inteiras, o domínio das variáveis $w_{k k^{\prime} t}^{i}$ é dado por:

$$
w_{k k^{\prime} t}^{i} \in \mathbb{R}_{+}, \quad \forall i, k, k^{\prime}, t
$$

O modelo proposto é, então, dado por (3.10)-(3.16). 


$$
\begin{aligned}
\text { Minimizar } & \sum_{t=1}^{T} \sum_{k=1}^{K}\left(\sum_{i=1}^{I} H C_{i k} s_{i k t}+\sum_{e=1}^{E} \sum_{i=1}^{I} F T C_{i k}^{e} x_{i k t}^{e}+\sum_{c=1}^{C} \sum_{i=1}^{I} C T C_{i k}^{c} y_{i k t}^{c}\right) \\
& +\sum_{c=1}^{C} P C^{c}\left(1-\delta^{c}\right)+\sum_{k=1}^{K} \sum_{k^{\prime}=1, k^{\prime} \neq k}^{K} \sum_{i=1}^{I} T C_{i k k^{\prime}} \sum_{t=1}^{T} z_{k k^{\prime} t}
\end{aligned}
$$

Sujeito a:

$$
\begin{aligned}
& \text { (3.2) - (3.6) } \\
& s_{i k t}=s_{i k, t-1}+\sum_{e=1}^{E} x_{i k t}^{e} M_{i}^{e}-\sum_{c=1}^{C} y_{i k t}^{c} M_{i}^{c} \\
& +\sum_{k^{\prime}=1, k^{\prime} \neq k}^{K} w_{i k^{\prime} k t}-\sum_{k^{\prime}=1, k^{\prime} \neq k}^{K} w_{i k k^{\prime} t}, \quad \forall i, k, t \\
& \sum_{k=1}^{K} \sum_{t=F I^{c}}^{F F^{c}} y_{i k t}^{c} \leq \delta^{c}, \quad \forall i, c \\
& \sum_{i=1}^{I} w_{i k k^{\prime} t} \leq \min \left\{C A P_{k}, C A P_{k^{\prime}}\right\} z_{k k^{\prime} t}, \quad \forall k, k^{\prime} \neq k, t \\
& s_{i k, 0}=0 \text {, } \\
& \forall i, k \\
& x_{i k t}^{e}, y_{i k t}^{c}, z_{k k^{\prime} t}, \delta^{c} \in \mathbb{B} ; s_{i k t} \in \mathbb{Z}_{+} \\
& \forall i, k, t, c, e \\
& w_{i k k^{\prime} t} \in \mathbb{R}_{+} \text {, } \\
& \forall i, k, k^{\prime}, t \text {. }
\end{aligned}
$$

A função objetivo (3.10) visa minimizar a soma dos custos de estoque de produtos nos cross-docks, dos custos de transporte das entregas e das coletas, das penalidades caso as janelas de tempo desejáveis das coletas não sejam atendidas e custos de transferência de produtos entre cross-docks.

As equações (3.11) representam o balanço de estoque de produtos nos cross-docks, incluindo as quantidades de produtos transferidas para outros cross-docks e recebidas de outros cross-docks. Essas restrições foram adaptadas do modelo de Javanmard, Vahdani e TavakkoliMoghaddam (2014) para permitir a transferência de produtos entre cross-docks. Nas restrições (3.12), cada uma das variáveis $\delta^{c}$ assume o valor um se a janela de tempo flexível a ela associada for atendida. Essas restrições foram adaptadas de Miao et al. (2012). Nas restrições (3.13), cada uma das variáveis $z_{k k^{\prime} t}$ assume o valor um se existir transferência do cross-dock $k$ para o $k^{\prime}$ no tempo $t$. Sem perda de generalidade, as restrições (3.14) impõem que o estoque inicial dos produtos nos cross-docks é nulo. Finalmente, as restrições (3.15) - (3.16) definem o domínio das variáveis do modelo. 

Neste capítulo são apresentados resultados computacionais referentes aos modelos descritos no Capítulo 3. Os testes computacionais foram realizados utilizando-se o software comercial ILOG CPLEX 12.6 em um computador Intel(R) Core(TM) Xeon (2.00GHz), com 32 GB de memória RAM, 24 núcleos e sistema operacional Linux. Além de resultados utilizando-se a configuração padrão do software, também são reportados resultados obtidos a partir do estudo da calibração de seus parâmetros. Como na literatura não há benchmark de instâncias disponível para o problema estudado, foram geradas instâncias como descrito na Seção 4.1.

\subsection{Geração de instâncias}

O conjunto de instâncias gerado para os testes aqui apresentados está disponível em Miyazaki-Tenório e Toledo (2016).

Para avaliar a influência do número de entregas e de coletas, decidiu-se gerar três cenários:

Cenário 1. mesma proporção de entregas e coletas;

Cenário 2. muitas entregas e poucas coletas;

Cenário 3. poucas entregas e muitas coletas.

Com base nos dados de Chen et al. (2006) e seguindo uma distribuição uniforme (U[a,b]), foram gerados os parâmetros:

- demanda de produtos por entrega: U[200,500] itens;

- custo unitário de estoque: U[2,10] por item por período de tempo;

- custo de transporte de uma carga (tanto para entregas quanto para coletas): U[1000,2000];

- capacidade de estoque dos cross-docks: U[600,1500] itens. 
A demanda das coletas foi gerada a partir dos valores das entregas, isto é, entre $50 \%$ e 95\% das entregas e possuem U[200,500] itens. Além disso, como não há custo de transferência entre cross-docks em Chen et al. (2006), a geração destes custos foi baseada em uma visita técnica realizada durante a pesquisa. Assim, assumiu-se que o custo de transporte interno (entre crossdocks) é menor que o custo de transporte externo (entre a origem e cross-dock e entre cross-dock e destino), ou seja, o custo de transferência é gerado uniformemente entre U[500,1000].

Considera-se um horizonte de planejamento com 24 períodos em que cada período equivale a 1 hora. A geração das janelas de tempo fixas e flexíveis foi adaptada de Miao et al. (2012). Assim, o início da janela de tempo da entrega $e$ está entre U[1,3] e que o fim está entre $\mathrm{U}\left[3+P^{e}, 22\right]$, em que $P^{e}$ é a quantidade de tipos de produtos da entrega $e$. Para as coletas, o início da janela de tempo fixa $\left(T I^{c}\right)$ está entre U[2,6] e o fim $\left(T F^{c}\right)$ está entre U[21,24]. Já o início da janela de tempo flexível da coleta $c$ está entre U[TI $\left.I^{c}+2, T I^{c}+3\right]$ e o fim está entre $\mathrm{U}\left[T F^{c}-3, T F^{c}-2\right]$.

A quantidade de coletas (C), quantidade de entregas (E), número de cross-docks (K) e número de tipos de produtos (I) foram fixados, e as combinações utilizadas são ilustradas na Tabela 2. Cada linha da tabela representa um grupo de instâncias, para o qual foram geradas 5 instâncias-teste. Desta forma, há 40 instâncias para cada Cenário, totalizando 120 instânciasteste geradas. As duas últimas colunas da tabela representam, respectivamente, a quantidade de variáveis (\#var) e a quantidade de restrições (\#rest), a menos das restrições do domínio das variáveis, no modelo proposto MPJT.

\subsection{Comparação entre os modelos}

As instâncias de teste geradas foram resolvidas utilizando-se o software comercial CPLEX com sua configuração padrão. A fim de avaliar a redução de custos que pode ser obtida ao se permitir transferências entre cross-docks, as instâncias-teste foram resolvidas pelo modelo de Javanmard, Vahdani e Tavakkoli-Moghaddam (2014), em que transferências entre crossdocks não são permitidas, e pelo modelo proposto, primeiramente, sem considerar as restrições referentes às janelas de tempo flexíveis e em seguida considerando essa possibilidade.

As Tabelas 3 - 5 apresentam os resultados para os três modelos, sendo: JVTM o modelo da literatura, MP o modelo proposto sem janelas de tempo flexíveis e com a possibilidade de transferência de produtos entre cross-docks e MPJT o modelo proposto com transferência de produtos entre cross-docks e janelas de tempo flexíveis para as coletas. As instâncias são representadas por $(t, k, i, e, c)$, com $t$ o tamanho do horizonte de planejamento (em horas), $k \mathrm{o}$ número de cross-docks, $i$ o número de tipos de produtos, $e$ o número de entregas disponíveis e $c$ o número de coletas a realizar.

Na Tabela 3, são apresentados os resultados para o Cenário 1, enquanto as Tabelas 4 e 5 exibem os resultados para os Cenários 2 e 3, respectivamente. Para cada modelo é apresentado 
Tabela 2 - Grupos de instâncias gerados e quantidade de variáveis correspondentes.

\begin{tabular}{|c|c|c|c|c|c|c|}
\hline & I & $\mathbf{K}$ & $\mathbf{E}$ & C & \#var & \#rest \\
\hline \multirow{8}{*}{ 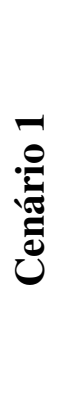 } & 5 & 3 & 10 & 10 & 8434 & 841 \\
\hline & 5 & 3 & 20 & 20 & 15644 & 1091 \\
\hline & 5 & 4 & 10 & 10 & 11818 & 1134 \\
\hline & 5 & 4 & 20 & 20 & 21428 & 1384 \\
\hline & 10 & 3 & 10 & 10 & 16714 & 1466 \\
\hline & 10 & 3 & 20 & 20 & 31124 & 1966 \\
\hline & 10 & 4 & 10 & 10 & 23338 & 1884 \\
\hline & 10 & 4 & 20 & 20 & 42548 & 2384 \\
\hline \multirow{8}{*}{ Uֶ } & 5 & 3 & 5 & 10 & 6634 & 791 \\
\hline & 5 & 3 & 5 & 20 & 10244 & 941 \\
\hline & 5 & 4 & 5 & 10 & 9418 & 1084 \\
\hline & 5 & 4 & 5 & 20 & 14228 & 1234 \\
\hline & 10 & 3 & 5 & 10 & 13114 & 1366 \\
\hline & 10 & 3 & 5 & 20 & 20324 & 1666 \\
\hline & 10 & 4 & 5 & 10 & 18538 & 1784 \\
\hline & 10 & 4 & 5 & 20 & 28148 & 2084 \\
\hline \multirow{8}{*}{ שֶّ } & 5 & 3 & 10 & 5 & 6629 & 766 \\
\hline & 5 & 3 & 20 & 5 & 10229 & 866 \\
\hline & 5 & 4 & 10 & 5 & 9413 & 1059 \\
\hline & 5 & 4 & 20 & 5 & 14213 & 1159 \\
\hline & 10 & 3 & 10 & 5 & 13109 & 1316 \\
\hline & 10 & 3 & 20 & 5 & 20309 & 1516 \\
\hline & 10 & 4 & 10 & 5 & 18533 & 1734 \\
\hline & 10 & 4 & 20 & 5 & 28133 & 1934 \\
\hline
\end{tabular}

Fonte: própria.

o valor da melhor solução encontrada (Sol) respeitando o tempo limite de 1800s, o tempo de resolução dado em segundos (Ti) e o desvio percentual desta solução para seu limite inferior (LI) fornecido pelo CPLEX e dado em porcentagem $\left(G A P=\frac{(S o l-L I)}{S o l} * 100\right)$. Para MP há, ainda, a diferença com relação ao modelo JVTM (D1) dado em porcentagem $\left(D 1=\frac{\left(\text { Sol }_{M P}-\text { Sol }_{J V T M}\right)}{\text { Sol JVTM }_{J V}} * 100\right)$. A melhor solução e o menor GAP encontrados pelos modelos é destacada em negrito, NIS significa que nenhuma solução foi encontrada no tempo limite e, consequentemente, o GAP não é apresentado (-).

Na Tabela 3 para 32 das 40 instâncias MP teve melhores soluções que Javanmard, sendo que para 6 dessas o modelo da literatura não retornou solução inteira factível no tempo limite. $\mathrm{O}$ modelo MP, como esperado, resulta em soluções de menor custo, apesar de ter GAPs mais altos. Como se nota pela diferença $D 1$, com média $-4,09 \%$, em geral, há um ganho na qualidade da solução quando se utiliza o modelo proposto MP.

Na Tabela 4 para 23 das 40 instâncias MP teve melhores soluções que Javanmard e para 
Tabela 3 - Resultados dos modelos para mesma proporção de entregas e coletas.

\begin{tabular}{|c|c|c|c|c|c|c|c|c|c|c|}
\hline & \multicolumn{3}{|c|}{ JVTM } & \multicolumn{4}{|c|}{ MP } & \multicolumn{3}{|c|}{ MPJT } \\
\hline & Sol & $\mathbf{T i}$ & GAP & Sol & $\mathbf{T i}$ & GAP & D1 & Sol & $\mathbf{T i}$ & GAP \\
\hline$(24,3,5,10,10) \_1$ & 77421 & 1806 & 39,56 & 74669 & 1803 & 40,49 & $-3,55$ & 74630 & 1804 & 40,46 \\
\hline$(24,3,5,10,10) \_2$ & 50458 & 1802 & 20,14 & 48605 & 1805 & 25,99 & $-3,67$ & 48361 & 1808 & 25,71 \\
\hline$(24,3,5,10,10) \_3$ & 59504 & 1803 & 14,09 & 58242 & 1805 & 21,05 & $-2,12$ & 58138 & 1806 & 20,82 \\
\hline$(24,3,5,10,10) \_4$ & 48579 & 1803 & 16,97 & 46514 & 1804 & 21,70 & $-4,25$ & 46981 & 1806 & 22,48 \\
\hline$(24,3,5,10,10) \_5$ & 52126 & 1802 & 19,10 & 49573 & 1807 & 22,09 & $-4,90$ & 51170 & 1809 & 24,59 \\
\hline$(24,3,5,20,20) \_1$ & 120923 & 1807 & 17,74 & 115724 & 1803 & 8,02 & $-4,30$ & 114990 & 1806 & 7,46 \\
\hline$(24,3,5,20,20) \_2$ & 114043 & 1803 & 21,33 & 97432 & 1805 & $\mathbf{9 , 0 7}$ & $-14,57$ & 97577 & 1805 & 9,21 \\
\hline$(24,3,5,20,20) \_3$ & 97098 & 1805 & 18,77 & 85652 & 1807 & 10,42 & $-11,79$ & 87385 & 1805 & 12,23 \\
\hline$(24,3,5,20,20) \_4$ & 100129 & 1807 & 15,98 & 90411 & 1807 & 9,09 & $-9,71$ & 88998 & 1806 & 7,63 \\
\hline$(24,3,5,20,20) \_5$ & 84382 & 1803 & 10,16 & 82577 & 1805 & 10,74 & $-2,14$ & 82587 & 1806 & 10,74 \\
\hline$(24,4,5,10,10) \_1$ & 35800 & 1804 & 13,19 & 34971 & 1807 & 20,05 & $-2,32$ & 35355 & 1808 & 19,97 \\
\hline$(24,4,5,10,10) \_2$ & 52108 & 1804 & 9,73 & 54356 & 1805 & 33,72 & 4,31 & 54300 & 1805 & 33,64 \\
\hline$(24,4,5,10,10) \_3$ & 52643 & 1803 & 34,06 & 52040 & 1806 & 44,33 & $-1,15$ & 52064 & 1805 & 44,35 \\
\hline$(24,4,5,10,10) \_4$ & 65773 & 1803 & 8,01 & 66087 & 1806 & 59,68 & 0,48 & 66433 & 1807 & 60,91 \\
\hline$(24,4,5,10,10) \_5$ & 47520 & 1804 & 8,99 & 47137 & 1806 & 12,10 & $-0,81$ & 47197 & 1807 & 12,22 \\
\hline$(24,4,5,20,20) \_1$ & 78589 & 1803 & 18,00 & 75418 & 1808 & 17,28 & $-4,03$ & 75180 & 1806 & 17,01 \\
\hline$(24,4,5,20,20) \_2$ & 97737 & 1806 & 20,27 & 84182 & 1805 & 9,69 & $-13,87$ & 4132 & 1807 & 9,63 \\
\hline 0,20$) \_3$ & 100105 & 1806 & 18,05 & 95742 & 1808 & 15,45 & $-4,36$ & 90273 & 1806 & 10,33 \\
\hline$(24,4,5,20,20) \_4$ & 129797 & 1806 & 27,01 & 103897 & 1808 & 10,66 & $-19,95$ & 103488 & 1808 & 10,31 \\
\hline$(24,4,5,20,20) \_5$ & 125945 & 1804 & 34,40 & 98108 & 1807 & 18,81 & $-22,10$ & 103186 & 1808 & 22,79 \\
\hline$(24,3,10,10,10) \_1$ & 98721 & 1803 & 24,30 & 99754 & 1806 & 32,47 & 1,05 & 99760 & 1806 & 32,47 \\
\hline$(24,3,10,10,10) \_2$ & 121406 & 1801 & 36,80 & 116423 & 1807 & 45,32 & $-4,10$ & 120856 & 1807 & 47,32 \\
\hline$(24,3,10,10,10) \_3$ & 101703 & 1802 & 10,74 & 99161 & 1804 & 38,91 & $-2,50$ & 99161 & 1804 & 38,90 \\
\hline$(24,3,10,10,10) \_4$ & 118857 & 1804 & 15,81 & 112639 & 1807 & 48,49 & $-5,23$ & 111984 & 1805 & 48,18 \\
\hline$(24,3,10,10,10) \_5$ & 105422 & 1802 & 18,30 & 96320 & 1805 & 17,90 & $-8,63$ & 96760 & 1807 & 18,15 \\
\hline$(24,3,10,20,20) \_1$ & NIS & 1802 & - & 179707 & 1807 & 16,97 & - & 180410 & 1807 & 17,30 \\
\hline$(24,3,10,20,20) \_2$ & NIS & 1802 & - & 168625 & 1808 & 15,36 & - & 166128 & 1807 & 14,09 \\
\hline$(24,3,10,20,20) \_3$ & 185574 & 1803 & 21,18 & 178667 & 1805 & 20,68 & $-3,72$ & 173947 & 1803 & 18,09 \\
\hline$(24,3,10,20,20) \_4$ & NIS & 1802 & - & 183710 & 1808 & 14,64 & - & 181240 & 1807 & 13,48 \\
\hline$(24,3,10,20,20) \_5$ & NIS & 1802 & - & 160461 & 1805 & 9,20 & - & 159472 & 1808 & 8,64 \\
\hline$(24,4,10,10,10) \_1$ & 5955 & 1802 & 23,20 & 126964 & 1809 & 33,51 & 0,80 & 127340 & 1807 & 33,70 \\
\hline$(24,4,10,10,10) \_2$ & 103271 & 1801 & 17,25 & 106301 & 1808 & 45,36 & 2,93 & 106301 & 1808 & 45,36 \\
\hline$(24,4,10,10,10) \_3$ & 112736 & 1803 & 29,32 & 114957 & 1806 & 47,63 & 1,97 & 115123 & 1809 & 47,70 \\
\hline$(24,4,10,10,10) \_4$ & 90194 & 1804 & 21,67 & 92317 & 1809 & 38,60 & 2,35 & 92317 & 1810 & 38,60 \\
\hline$(24,4,10,10,10) \_5$ & 140261 & 1805 & 31,76 & 137570 & 1806 & 50,90 & $-1,92$ & 136686 & 1808 & 50,57 \\
\hline$(24,4,10,20,20) \_1$ & NIS & 1803 & 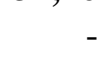 & 187036 & 1806 & 24,32 & - & 193080 & 1808 & 26,69 \\
\hline$(24,4,10,20,20) \_2$ & 150418 & 1802 & 21,20 & 146910 & 1808 & 21,92 & $-2,33$ & 144646 & 1806 & 20,70 \\
\hline$(24,4,10,20,20) \_3$ & 158989 & 1802 & 17,43 & 185495 & 1806 & 31,23 & 16,67 & 171316 & 1808 & 25,54 \\
\hline$(24,4,10,20,20) \_4$ & 179049 & 1802 & 22,80 & 158059 & 1809 & 13,82 & $-11,72$ & 158470 & 1809 & 14,05 \\
\hline$(24,4,10,20,20) \_5$ & NIS & 1807 & - & 173861 & 1807 & 20,15 & 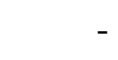 & 171753 & 1809 & 19,17 \\
\hline 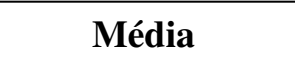 & 99507 & & & 107157 & & & $-4,09$ & 106729 & & \\
\hline Mínimo & 35800 & & & 34971 & & & $-22,10$ & 35355 & & \\
\hline Máximo & 185574 & & & 187036 & & & 16,67 & 193080 & & \\
\hline
\end{tabular}


Tabela 4 - Resultados dos modelos para muitas entregas e poucas coletas.

\begin{tabular}{|c|c|c|c|c|c|c|c|c|c|c|}
\hline & \multicolumn{3}{|c|}{ JVTM } & \multicolumn{4}{|c|}{ MP } & \multicolumn{3}{|c|}{ MPJT } \\
\hline & Sol & $\mathbf{T i}$ & GAP & Sol & $\mathbf{T i}$ & GAP & D1 & Sol & $\mathbf{T i}$ & GAP \\
\hline$(24,3,5,10,5) \_1$ & 53960 & 1805 & 18,73 & 50676 & 1807 & 24,23 & $-6,09$ & 50054 & 1807 & 23,77 \\
\hline$(24,3,5,10,5) \_2$ & 41079 & 786 & 0,01 & 39446 & 1805 & 15,38 & $-3,98$ & 39446 & 1804 & 15,38 \\
\hline$(24,3,5,10,5) \_3$ & 43641 & 1804 & 6,90 & 44016 & 1807 & 28,08 & 0,86 & 44016 & 1807 & 28,07 \\
\hline$(24,3,5,10,5) \_4$ & 35241 & 1803 & 14,40 & 34414 & 1807 & 25,47 & $-2,35$ & 34414 & 1805 & 25,47 \\
\hline$(24,3,5,10,5) \_5$ & 32407 & 1804 & 1,54 & 31586 & 1807 & 28,65 & $-2,53$ & 31606 & 1808 & 28,70 \\
\hline$(24,3,5,20,5) \_1$ & 41225 & 1803 & 19,56 & 40764 & 1803 & 21,75 & $-1,12$ & 41239 & 1804 & 22,55 \\
\hline$(24,3,5,20,5) \_2$ & 30564 & 1803 & 7,62 & 31086 & 1805 & 13,60 & 1,71 & 31682 & 1808 & 15,17 \\
\hline$(24,3,5,20,5) \_3$ & 48231 & 1802 & 41,77 & 48524 & 1805 & 48,94 & 0,61 & 49700 & 1808 & 50,15 \\
\hline$(24,3,5,20,5) \_4$ & 31642 & 1802 & 18,27 & 29613 & 1805 & 21,85 & $-6,41$ & 29613 & 1809 & 21,84 \\
\hline$(24,3,5,20,5) \_5$ & 34489 & 1802 & 10,05 & 34299 & 1804 & 21,99 & $-0,55$ & 34299 & 1805 & 21,99 \\
\hline$(24,4,5,10,5) \_1$ & 35375 & 37 & $\mathbf{0 , 0 0}$ & 34431 & 1808 & 34,50 & $-2,67$ & 34431 & 1807 & 34,51 \\
\hline$(24,4,5,10,5) \_2$ & 31601 & 1806 & 22,50 & 31715 & 1807 & 38,46 & 0,36 & 31715 & 1806 & 38,46 \\
\hline$(24,4,5,10,5) \_3$ & 54315 & 1331 & 0,01 & 54231 & 1805 & 54,69 & $-0,15$ & 54342 & 1807 & 54,79 \\
\hline$(24,4,5,10,5) \_4$ & 41609 & 1804 & 13,97 & 38764 & 1805 & 39,84 & $-6,84$ & 39182 & 1807 & 40,48 \\
\hline$(24,4,5,10,5) \_5$ & 45897 & 1806 & 23,31 & 46438 & 1804 & 44,61 & 1,18 & 46574 & 1806 & 45,21 \\
\hline$(24,4,5,20,5) \_1$ & 25063 & 646 & $\mathbf{0 , 0 1}$ & 26356 & 1806 & 31,93 & 5,16 & 26421 & 1804 & 32,12 \\
\hline$(24,4,5,20,5) \_2$ & 36922 & 1804 & 16,52 & 36079 & 1808 & 19,54 & $-2,28$ & 36079 & 1808 & 19,54 \\
\hline$(24,4,5,20,5) \_3$ & 33477 & 1802 & $\mathbf{9 , 8 7}$ & 32672 & 1807 & 36,76 & $-2,40$ & 32672 & 1806 & 36,76 \\
\hline$(24,4,5,20,5) \_4$ & 31304 & 1803 & 3,97 & 31822 & 1807 & 17,32 & 1,65 & 31947 & 1807 & 18,18 \\
\hline$(24,4,5,20,5) \_5$ & 20839 & 569 & 0,01 & 22809 & 1806 & 41,12 & 9,45 & 24647 & 1806 & 45,58 \\
\hline$(24,3,10,10,5) \_1$ & 62503 & 1690 & 0,01 & 59240 & 1806 & 18,29 & $-5,22$ & 59308 & 1807 & 18,53 \\
\hline$(24,3,10,10,5) \_2$ & 90520 & 1806 & 2,34 & 88701 & 1806 & 34,92 & $-2,01$ & 88649 & 1806 & 34,80 \\
\hline$(24,3,10,10,5) \_3$ & 113037 & 1803 & 22,39 & 112024 & 1807 & 61,38 & $-0,90$ & 111813 & 1807 & 61,30 \\
\hline$(24,3,10,10,5) \_4$ & 77208 & 1802 & 8,19 & 80023 & 1804 & 28,60 & 3,65 & 80197 & 1806 & 28,75 \\
\hline$(24,3,10,10,5) \_5$ & 66602 & 1803 & 2,63 & 66404 & 1805 & 38,10 & $-0,30$ & 66404 & 1805 & 38,11 \\
\hline$(24,3,10,20,5) \_1$ & 64273 & 403 & $\mathbf{0 , 0 1}$ & 65897 & 1806 & 48,86 & 2,53 & 64238 & 1806 & 46,51 \\
\hline$(24,3,10,20,5) \_2$ & 68040 & 1427 & $\mathbf{0 , 0 1}$ & 69630 & 1805 & 53,00 & 2,34 & 68925 & 1805 & 52,66 \\
\hline$(24,3,10,20,5) \_3$ & 78819 & 1805 & 19,43 & 78597 & 1807 & 28,42 & $-0,28$ & 80554 & 1806 & 30,16 \\
\hline$(24,3,10,20,5) \_4$ & 86977 & 1804 & 24,89 & 93907 & 1806 & 42,16 & 7,97 & 93147 & 1807 & 41,69 \\
\hline$(24,3,10,20,5) \_5$ & 86920 & 1805 & 39,14 & 83179 & 1806 & 45,33 & $-4,30$ & 83179 & 1806 & 45,33 \\
\hline$(24,4,10,10,5) \_1$ & 59222 & 1803 & 12,92 & 59004 & 1807 & 41,85 & $-0,37$ & 58883 & 1807 & 41,73 \\
\hline$(24,4,10,10,5) \_2$ & 60670 & 1804 & 2,64 & 59590 & 1802 & 35,41 & $-1,78$ & 59590 & 1804 & 35,41 \\
\hline$(24,4,10,10,5) \_3$ & 73193 & 1803 & 17,24 & 70482 & 1806 & 28,07 & $-3,70$ & 70540 & 1807 & 28,13 \\
\hline$(24,4,10,10,5) \_4$ & 74716 & 1806 & 3,99 & 73384 & 1806 & 39,38 & $-1,78$ & 73988 & 1807 & 39,89 \\
\hline$(24,4,10,10,5) \_5$ & 62123 & 1804 & 16,41 & 62667 & 1805 & 43,11 & 0,88 & 62992 & 1805 & 43,41 \\
\hline$(24,4,10,20,5) \_1$ & 69384 & 1804 & 16,49 & 69384 & 1802 & 37,20 & 0,00 & 69384 & 1803 & 37,20 \\
\hline$(24,4,10,20,5) \_2$ & 62674 & 1804 & 12,94 & 63151 & 1808 & 45,81 & 0,76 & 62319 & 1807 & 45,09 \\
\hline$(24,4,10,20,5) \_3$ & 75280 & 1903 & 28,36 & 84217 & 1805 & 57,12 & 11,87 & 84217 & 1804 & 57,12 \\
\hline$(24,4,10,20,5) \_4$ & 60531 & 1806 & 16,26 & 61983 & 1808 & 45,45 & 2,40 & 62479 & 1807 & 45,86 \\
\hline$(24,4,10,20,5) \_5$ & 57022 & 1802 & 17,20 & 59154 & 1806 & 41,03 & 3,74 & 59154 & 1807 & 41,03 \\
\hline Média & 54965 & & & 55009 & & & $-0,02$ & 55101 & & \\
\hline Mínimo & 20839 & & & 22809 & & & $-6,84$ & 24647 & & \\
\hline Máximo & 113037 & & & 112024 & & & 11,87 & 111813 & & \\
\hline
\end{tabular}


Tabela 5 - Resultados dos modelos para poucas entregas e muitas coletas

\begin{tabular}{|c|c|c|c|c|c|c|c|c|c|c|}
\hline & \multicolumn{3}{|c|}{ JVTM } & \multicolumn{4}{|c|}{ MP } & \multicolumn{3}{|c|}{ MPJT } \\
\hline & Sol & $\mathbf{T i}$ & GAP & Sol & $\mathbf{T i}$ & GAP & D1 & Sol & $\mathbf{T i}$ & GAP \\
\hline$(24,3,5,5,10) \_1$ & 86564 & 1642 & $\mathbf{0 , 0 1}$ & 84425 & 1806 & 49,20 & $-2,47$ & 84425 & 1807 & 45,67 \\
\hline$(24,3,5,5,10) \_2$ & 49089 & 4 & 0,00 & 48630 & 195 & 0,01 & $-0,94$ & 48630 & 196 & 0,01 \\
\hline$(24,3,5,5,10) \_3$ & 55845 & 1807 & 13,21 & 53671 & 1807 & 20,18 & $-3,89$ & 54005 & 1806 & 20,63 \\
\hline$(24,3,5,5,10) \_4$ & 82196 & 47 & 0,01 & 79571 & 1805 & 4,57 & $-3,19$ & 79571 & 1805 & 4,57 \\
\hline$(24,3,5,5,10) \_5$ & 40135 & 459 & 0,01 & 39191 & 1805 & 18,60 & $-2,35$ & 39593 & 1807 & 19,36 \\
\hline$(24,3,5,5,20) \_1$ & 80119 & 1803 & 16,45 & 77703 & 1807 & 33,23 & $-3,02$ & 77368 & 1808 & 39,03 \\
\hline$(24,3,5,5,20) \_2$ & 82164 & 1803 & 1,34 & 82612 & 1802 & 7,77 & 0,55 & 82200 & 1808 & 6,72 \\
\hline$(24,3,5,5,20) \_3$ & 89198 & 689 & $\mathbf{0 , 0 1}$ & 88126 & 1808 & 6,95 & $-1,20$ & 88198 & 1809 & 6,96 \\
\hline$(24,3,5,5,20) \_4$ & 57321 & 1805 & 8,53 & 54301 & 1805 & 12,54 & $-5,27$ & 54364 & 1808 & 12,64 \\
\hline$(24,3,5,5,20) \_5$ & 53681 & 1806 & 11,06 & 51813 & 1806 & 16,92 & $-3,48$ & 51813 & 1808 & 16,95 \\
\hline$(24,4,5,5,10) \_1$ & 63123 & 1803 & 21,70 & 60501 & 1805 & 24,22 & $-4,15$ & 60750 & 1807 & 24,53 \\
\hline$(24,4,5,5,10) \_2$ & 53012 & 1806 & 10,63 & 48165 & 1806 & 18,73 & $-9,14$ & 48165 & 1807 & 18,73 \\
\hline$(24,4,5,5,10) \_3$ & 58180 & 1804 & 5,88 & 57529 & 1805 & 40,16 & $-1,12$ & 57476 & 1804 & 40,11 \\
\hline$(24,4,5,5,10) \_4$ & 57372 & 1803 & 16,93 & 55596 & 1809 & 31,07 & $-3,10$ & 55459 & 1805 & 31,16 \\
\hline$(24,4,5,5,10) \_5$ & 56293 & 1803 & 11,68 & $\mathbf{5 5 7 7 7}$ & 1806 & 33,54 & $-0,92$ & $\mathbf{5 5 7 7 7}$ & 1806 & 33,54 \\
\hline$(24,4,5,5,20) \_1$ & 49586 & 1805 & 7,33 & 49082 & 1805 & 18,71 & $-1,02$ & 49082 & 1806 & 18,71 \\
\hline$(24,4,5,5,20) \_2$ & 64875 & 1807 & 21,84 & 61942 & 1806 & 22,71 & $-4,52$ & 61807 & 1805 & 22,54 \\
\hline$(24,4,5,5,20) \_3$ & 60634 & 1807 & 13,78 & 58403 & 1807 & 30,00 & $-3,68$ & 58288 & 1808 & 29,87 \\
\hline$(24,4,5,5,20) \_4$ & 50048 & 1806 & 16,35 & 49470 & 1807 & 18,09 & $-1,15$ & 49470 & 1807 & 18,09 \\
\hline$(24,4,5,5,20) \_5$ & 57251 & 1112 & 0,01 & 56321 & 1806 & 20,68 & $-1,62$ & 56218 & 1807 & 20,53 \\
\hline$(24,3,10,5,10) \_1$ & 94136 & 1803 & 18,42 & 87134 & 1806 & 35,63 & $-7,44$ & 87134 & 1806 & 35,62 \\
\hline$(24,3,10,5,10) \_2$ & 179658 & 1805 & 5,27 & 178481 & 1807 & 36,85 & $-0,66$ & 178481 & 1807 & 36,85 \\
\hline$(24,3,10,5,10) \_3$ & 82053 & 1803 & 2,76 & 80096 & 1805 & 28,53 & $-2,39$ & 80522 & 1808 & 28,68 \\
\hline$(24,3,10,5,10) \_4$ & 152869 & 1703 & $\mathbf{0 , 0 1}$ & 146566 & 1807 & 40,01 & $-4,12$ & 146566 & 1808 & 40,02 \\
\hline$(24,3,10,5,10) \_5$ & 158794 & 1803 & 1,64 & 156314 & 1805 & 53,79 & $-1,56$ & 155840 & 1806 & 54,52 \\
\hline$(24,3,10,5,20) \_1$ & 90962 & 1803 & 17,19 & 88419 & 1806 & 29,70 & $-2,80$ & 88199 & 1805 & 29,52 \\
\hline$(24,3,10,5,20) \_2$ & 100399 & 1805 & 11,46 & 101856 & 1807 & 19,75 & 1,45 & 101919 & 1805 & 20,42 \\
\hline$(24,3,10,5,20) \_3$ & 145559 & 1803 & 23,15 & 133860 & 1808 & 28,89 & $-8,04$ & 134525 & 1806 & 29,24 \\
\hline$(24,3,10,5,20) \_4$ & 116393 & 1802 & 21,79 & 110173 & 1805 & 33,84 & $-5,34$ & 109582 & 1805 & 32,90 \\
\hline$(24,3,10,5,20) \_5$ & 166604 & 1803 & $\mathbf{9 , 5 2}$ & 161152 & 1806 & 40,37 & $-3,27$ & 161152 & 1807 & 40,87 \\
\hline$(24,4,10,5,10) \_1$ & 91990 & 1803 & 2,30 & 88676 & 1806 & 42,28 & $-3,60$ & 88676 & 1807 & 42,15 \\
\hline$(24,4,10,5,10) \_2$ & 122869 & 1804 & 12,72 & 121368 & 1807 & 29,77 & $-1,22$ & 121368 & 1807 & 29,77 \\
\hline$(24,4,10,5,10) \_3$ & 66655 & 1804 & 9,15 & 66679 & 1808 & 38,93 & 0,04 & 66679 & 1807 & 38,92 \\
\hline$(24,4,10,5,10) \_4$ & 80272 & 1803 & 0,71 & 75218 & 1807 & 30,72 & $-6,30$ & 75271 & 1807 & 30,77 \\
\hline$(24,4,10,5,10) \_5$ & 73134 & 1398 & $\mathbf{0 , 0 1}$ & 71358 & 1807 & 28,14 & $-2,43$ & 71191 & 1805 & 27,98 \\
\hline$(24,4,10,5,20) \_1$ & 73536 & 1803 & 15,62 & 71896 & 1805 & 33,88 & $-2,23$ & 71500 & 1807 & 33,54 \\
\hline$(24,4,10,5,20) \_2$ & 80993 & 1806 & 11,50 & 77205 & 1807 & 43,19 & $-4,68$ & 77841 & 1805 & 49,78 \\
\hline$(24,4,10,5,20) \_3$ & 102150 & 1803 & 3,75 & 100583 & 1805 & 26,20 & $-1,53$ & 98448 & 1804 & 27,74 \\
\hline$(24,4,10,5,20) \_4$ & 64299 & 1803 & 4,79 & 62364 & 1806 & 37,05 & $-3,01$ & 62364 & 1807 & 37,06 \\
\hline$(24,4,10,5,20) \_5$ & 93878 & 1803 & 5,32 & 93494 & 1803 & 39,05 & $-0,41$ & 93235 & 1803 & 38,88 \\
\hline Média & 84597 & & & 82143 & & & $-2,88$ & 82079 & & \\
\hline Mínimo & 40135 & & & 39191 & & & $-9,14$ & 39593 & & \\
\hline Máximo & 179658 & & & 178481 & & & 1,45 & 178481 & & \\
\hline
\end{tabular}


1 instância encontrou solução de mesmo valor. As soluções de MP são de melhor qualidade com média de diferença de -0,02\% apesar dos GAPs superiores aos do modelo de Javanmard, Vahdani e Tavakkoli-Moghaddam (2014). E na Tabela 5 para 37 das 40 instâncias MP teve melhores soluções que Javanmard e a diferença média de $-2,88 \%$ também indica que o modelo MP retorna soluções que superam as de Javanmard.

Comparando-se os modelos propostos com e sem janela de tempo desejável para os captadores, na Tabela 3 para 19 instâncias MPJT teve melhores soluções e para 3 instâncias obteve soluções iguais. 8 soluções das apresentadas na Tabela 4 para MPJT são de melhor qualidade, enquanto que em 15 instâncias a solução encontrada pelo modelo MPJT foi de qualidade igual à encontrada por MP. Para 14 das 40 instâncias da Tabela 5 MPJT teve melhores soluções e para 16 teve soluções iguais às de MP. A diferença média de solução apresentada entre os modelos MPJT e MP é de $-0,13 \%, 0,34 \%$ e $-0,05 \%$ para os cenários 1,2 e 3, respectivamente.

Nos Cenários 1, 2 e 3 as soluções de menor custo foram obtidas pelo modelo proposto com janelas de tempo desejáveis (MPJT) e os melhores GAPs encontrados foram para o modelo da literatura. Os GAPs médios de MP e MPJT são muito próximos (menos de 1,0\% de diferença), porém as soluções de MPJT são de melhor qualidade para todos os cenários. Apenas para uma das 120 instâncias dos 3 cenários $\left((24,3,5,5,10) \_2\right)$, os três modelos encontraram solução ótima.

Em geral, para todas as instâncias o modelo proposto com janelas de tempo flexíveis retornou as melhores soluções, mas apresentando GAPs relativamente altos quando comparados ao modelo de Javanmard, Vahdani e Tavakkoli-Moghaddam (2014). O modelo da literatura apresentou os melhores GAPs, porém a qualidade das soluções dos modelos propostos foi melhor. Desta forma, mostramos que o modelo proposto (inserindo a transferência entre crossdocks e, até mesmo com as janelas de tempo desejáveis - que às vezes representam aumento no custo da função objetivo) pode auxiliar a encontrar soluções de melhores qualidades.

As Figuras 8 e 9 ilustram, respectivamente, os resultados do modelo de Javanmard, Vahdani e Tavakkoli-Moghaddam (2014) e do modelo proposto MPJT para um problema de pequena dimensão, com 2 cross-docks, 5 entregadores (veículos roxos), 6 captadores (veículos rosa) e 4 tipos de produto. $\mathrm{O}$ valor da solução encontrada pelo modelo da literatura é de 65062,70 (encontrada em 3,20s) e em MPJT é de 63207,00 (encontrada em 1,80s), ou seja, há melhoria na qualidade da solução. A Figura 9 mostra que o ganho foi, principalmente, ao se permitir a transferência de produtos do tipo 1 e do tipo 4 (representada por setas vermelhas).

\subsection{Calibração do CPLEX para o MPJT}

A fim de buscar melhores resultados para o modelo proposto, foi realizada a calibração dos parâmetros do software comercial ILOG CPLEX 12.6. Desta forma, buscou-se obter melhores configurações para resolver as instâncias geradas para o problema de cross-docking. $\mathrm{Na}$ 
Figura 8 - Ilustração do resultado de uma instância pequena a partir do modelo de Javanmard, Vahdani e TavakkoliMoghaddam (2014).

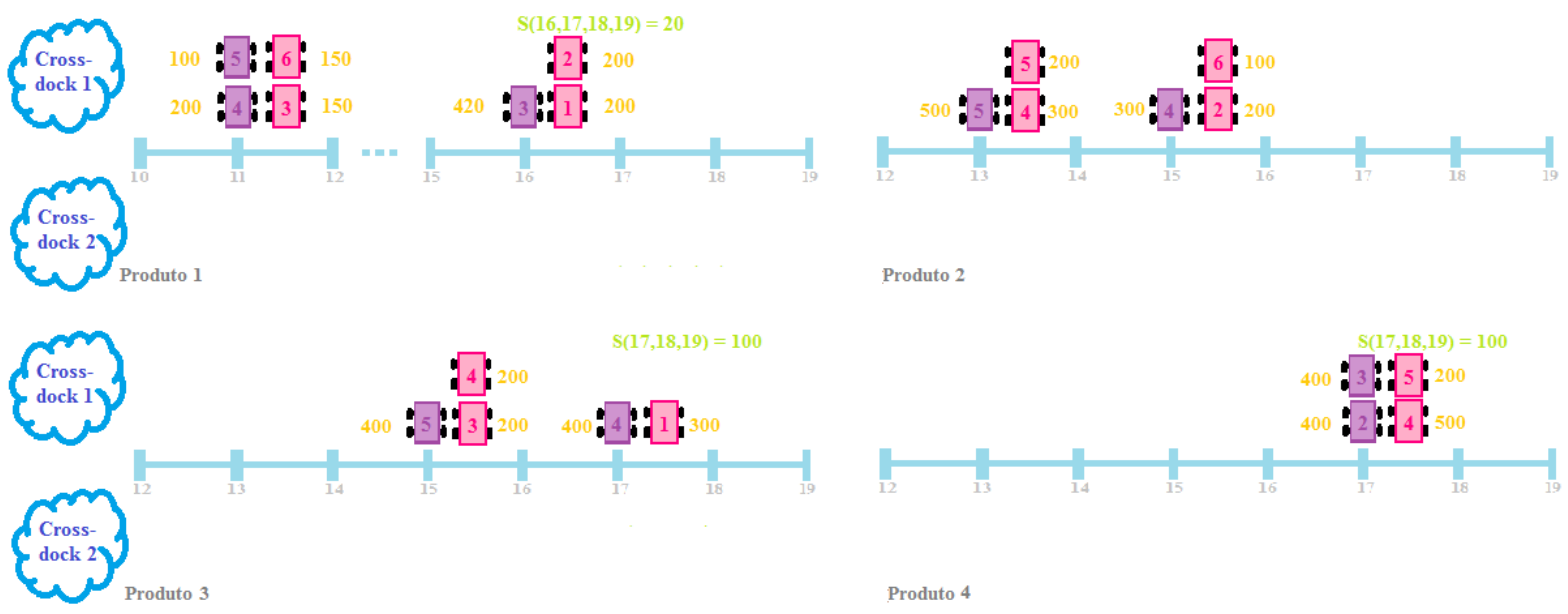

Fonte: própria.

Figura 9 - Ilustração do resultado de uma instância pequena a partir do modelo proposto MPJT.

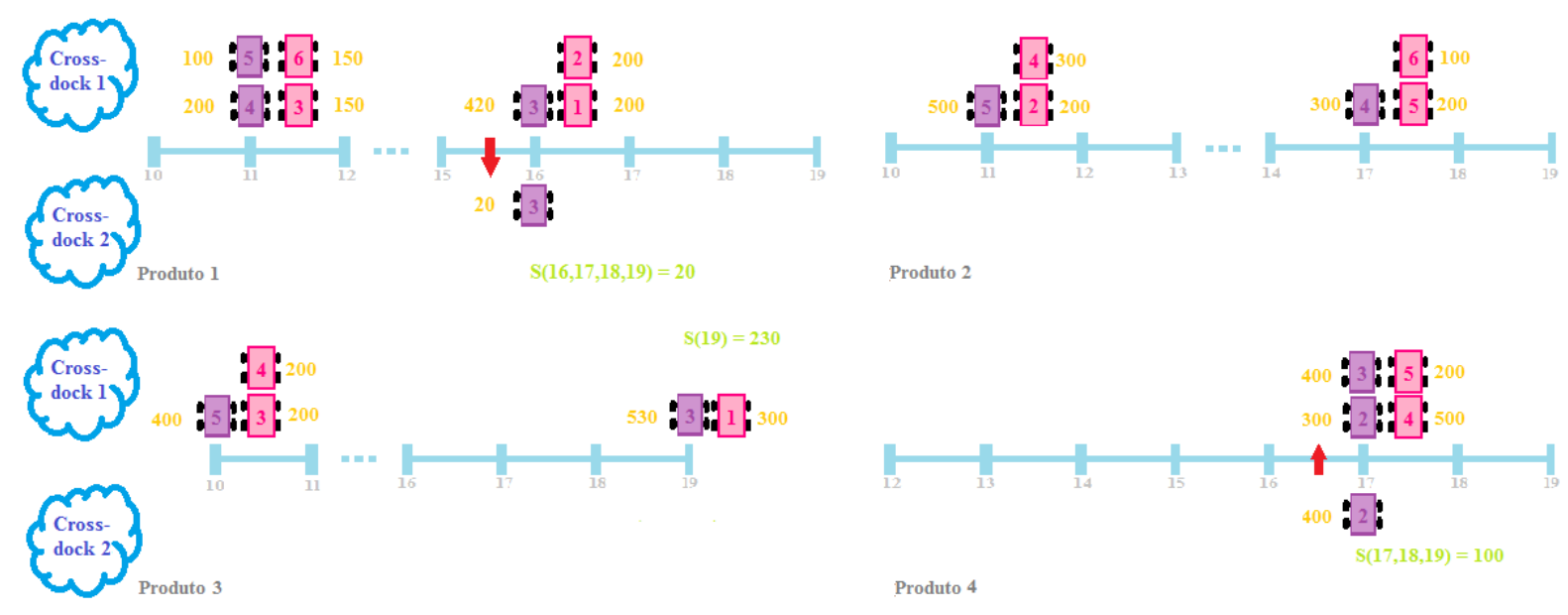

Fonte: própria.

versão utilizada do software CPLEX existe a possibilidade de realizar a calibração automática dos parâmetros. A escolha dos parâmetros testados individualmente foi baseada no conhecimento prévio do problema e com base dos parâmetros mais modificados usualmente. A definição dos parâmetros, bem como seus valores são apresentados no Manual do software.

Das 120 instâncias geradas na Seção 4.1, 15 instâncias de pequena dimensão foram selecionadas e executadas com tempo limite de execução de 1800s com o software na configuração padrão. Na seleção das 15 instâncias, foram escolhidas 5 de cada um dos 3 cenários descritos. As soluções obtidas são resumidas na Tabela 6. Para a calibração (automática e manual), foram selecionadas as 10 piores soluções (com maiores GAPs, destacadas em negrito) uma vez que para todas as instâncias não foi possível encontrar a melhor solução dentro do tempo limite estipulado.

Para a calibração do software CPLEX, fixou-se um tempo limite de 600s de execução 
Tabela 6 - Resultados de instâncias para calibração do CPLEX, com tempo limite de 30min.

\begin{tabular}{|c|c|c|c|}
\hline & Sol & $\mathbf{T}$ & GAP \\
\hline$(24,3,5,10,10) \_1$ & 74630 & 1804 & 40,46 \\
\hline$(24,3,5,10,10) \_2$ & 48361 & 1808 & 25,71 \\
\hline$(24,3,5,10,10) \_3$ & 58138 & 1806 & 20,82 \\
\hline$(24,3,5,10,10) \_4$ & 46981 & 1806 & 22,48 \\
\hline$(24,3,5,10,10) \_5$ & 51170 & 1809 & 24,59 \\
\hline$(24,3,5,5,20) \_1$ & 77368 & 1808 & 39,03 \\
\hline$(24,3,5,5,20) \_2$ & 82200 & 1808 & 6,72 \\
\hline$(24,3,5,5,20) \_3$ & 88198 & 1809 & 6,96 \\
\hline$(24,3,5,5,20) \_4$ & 54364 & 1808 & 12,64 \\
\hline$(24,3,5,5,20) \_5$ & 51813 & 1808 & 16,95 \\
\hline$(24,3,5,20,5) \_1$ & 41239 & 1804 & 22,55 \\
\hline$(24,3,5,20,5) \_2$ & 31682 & 1808 & 15,17 \\
\hline$(24,3,5,20,5) \_3$ & 49700 & 1808 & 50,15 \\
\hline$(24,3,5,20,5) \_4$ & 29613 & 1809 & 21,84 \\
\hline$(24,3,5,20,5) \_5$ & 34299 & 1805 & 21,99 \\
\hline
\end{tabular}

Fonte: própria.

para cada uma das instâncias em cada configuração testada. Na Tabela 7, são apresentadas as soluções das 10 instâncias-teste selecionadas no passo anterior, com tempo limite de execução de 600s. A solução média apresentada na tabela é 52229,7 e o GAP médio é 31,06.

Tabela 7 - Melhores soluções encontradas para as instâncias-teste de calibração do CPLEX com 10min com os parâmetros padrão do software.

\begin{tabular}{|c|c|c|c|}
\hline & & Sol & GAP \\
\hline $\mathrm{I} 1$ & $(24,3,5,10,10) \_1$ & 75691 & 41,40 \\
\hline $\mathrm{I} 2$ & $(24,3,5,10,10) \_2$ & 48978 & 26,81 \\
\hline $\mathrm{I} 3$ & $(24,3,5,10,10) \_3$ & 60527 & 27,24 \\
\hline I4 & $(24,3,5,10,10) \_4$ & 47257 & 23,09 \\
\hline I5 & $(24,3,5,10,10) \_5$ & 51170 & 24,75 \\
\hline I6 & $(24,3,5,5,20) \_1$ & 77969 & 39,71 \\
\hline I7 & $(24,3,5,20,5) \_1$ & 46712 & 31,94 \\
\hline I8 & $(24,3,5,20,5) \_3$ & 49840 & 50,45 \\
\hline I9 & $(24,3,5,20,5) \_4$ & 29749 & 22,71 \\
\hline \multirow[t]{2}{*}{$\mathrm{I} 10$} & $(24,3,5,20,5) \_5$ & 34404 & 22,51 \\
\hline & Média & & 31,06 \\
\hline
\end{tabular}

Através da calibração automática do CPLEX, nota-se que todos os parâmetros devem ser mantidos em seus valores padrão, exceto pelo parâmetro mircuts, que deve assumir o valor 1 (moderado). As soluções obtidas para as 10 instâncias-teste com a configuração sugerida após a calibração automática do CPLEX são exibidas na Tabela 8 . O valor médio das soluções encontradas é de 51709,4 e o GAP médio de 31,88\%, ou seja, há redução no valor das soluções 
e aumento de $0,82 \%$ no GAP médio.

Tabela 8 - Soluções encontradas para as instâncias-teste de calibração após calibração automática do CPLEX com 10 min de execução.

\begin{tabular}{rrr}
\hline & Sol & GAP \\
\hline I1 & 77354 & 43,53 \\
I2 & $\mathbf{4 8 2 8 9}$ & 26,15 \\
I3 & 60527 & 33,49 \\
I4 & $\mathbf{4 6 9 0 8}$ & 22,99 \\
I5 & $\mathbf{4 9 7 0 6}$ & 22,27 \\
I6 & $\mathbf{7 7 6 0 8}$ & 39,07 \\
I7 & $\mathbf{4 1 6 6 8}$ & 23,86 \\
I8 & $\mathbf{4 7 2 2 5}$ & 48,24 \\
I9 & 31085 & 26,17 \\
I10 & 36724 & 33,01 \\
\hline \multicolumn{2}{c}{ Média } & $\mathbf{3 1 , 8 8}$ \\
\hline \multicolumn{2}{l}{ Fonte· própria. }
\end{tabular}

Fonte: própria.

Foi realizada, também, a calibração manual com tempo limite de 600s para cada instância e variando alguns parâmetros. O primeiro parâmetro analisado é a ênfase de resolução, os resultados obtidos são ilustrados na Tabela 9. As Tabelas 9-20 apresentam as soluções para cada um dos valores que o parâmetro pode assumir. A primeira coluna é o parâmetro padrão do CPLEX, e as melhores soluções e os melhores GAPs são destacados em negrito. É apresentada na última linha de cada tabela a média de soluções e as melhores médias são destacadas em negrito. O parâmetro selecionado é o que tiver melhor solução média, uma vez que buscamos soluções de melhor qualidade.

Tabela 9 - Soluções das instâncias-teste de calibração para o parâmetro de ênfase com 10min de execução.

\begin{tabular}{rrrrrrrrrrr}
\hline & \multicolumn{3}{c}{ balance (0) } & \multicolumn{2}{c}{ feasibility (1) } & \multicolumn{2}{c}{ optimality (2) } & \multicolumn{2}{c}{ best bound (3) } & \multicolumn{2}{c}{ hidden (4) } \\
& Sol & GAP & Sol & GAP & Sol & GAP & Sol & GAP & Sol & GAP \\
\hline I1 & 75634 & $\mathbf{4 1 , 3 5}$ & 76653 & 45,26 & 80530 & 44,74 & 76223 & 42,33 & $\mathbf{7 4 1 2 0}$ & 40,75 \\
I2 & 48978 & 26,81 & 48972 & 28,01 & 50964 & 29,27 & 51109 & $\mathbf{1 9 , 0 5}$ & $\mathbf{4 8 2 9 4}$ & 26,08 \\
I3 & 58931 & 27,62 & $\mathbf{5 8 1 6 3}$ & 34,58 & 60459 & 32,00 & 59491 & $\mathbf{1 4 , 4 3}$ & 58917 & 15,72 \\
I4 & 46832 & 22,39 & $\mathbf{4 6 1 0 4}$ & 23,97 & 47335 & 23,19 & 46273 & $\mathbf{1 5 , 1 5}$ & 46512 & 21,75 \\
I5 & 52101 & 26,02 & $\mathbf{5 0 4 0 3}$ & 22,48 & 51499 & 24,97 & 50662 & $\mathbf{1 8 , 6 6}$ & 50771 & 23,61 \\
I6 & 78099 & 39,81 & 77610 & 40,67 & 78673 & 33,76 & 78119 & $\mathbf{1 3 , 7 4}$ & $\mathbf{7 7 4 5 1}$ & 34,95 \\
I7 & 44950 & 29,28 & 41548 & 26,27 & 49086 & 34,98 & 41551 & $\mathbf{1 9 , 6 6}$ & $\mathbf{4 0 7 1 8}$ & 21,86 \\
I8 & 49450 & 50,06 & $\mathbf{4 7 7 0 6}$ & 51,11 & 49913 & 50,19 & 48562 & $\mathbf{2 5 , 2 7}$ & 49053 & 49,66 \\
I9 & $\mathbf{2 9 7 4 9}$ & 22,70 & 31146 & 30,53 & 29613 & 21,46 & 30000 & $\mathbf{1 3 , 3 7}$ & 29842 & 23,33 \\
I10 & $\mathbf{3 4 4 0 4}$ & 22,50 & 34946 & 28,36 & 38473 & 30,25 & 36724 & $\mathbf{1 7 , 8 1}$ & 36917 & 27,66 \\
\hline & 51913 & & 51325 & & 53655 & & 51871 & & $\mathbf{5 1 2 6 0}$ & \\
\hline
\end{tabular}

Fonte: própria.

Para o parâmetro ênfase, o valor selecionado (que possui melhores soluções) é o hidden 
feasible solutions (3). Com média de soluções de 51260 e GAP médio de 28,54\% (redução de 2,52\% quando comparadas com as soluções da Tabela 7).

Fixado o parâmetro ênfase, o próximo parâmetro verificado foi o de método de programação linear, cujas soluções são apresentadas na Tabela 10. Nota-se, então, que o valor padrão 0 - automatic, apresenta a melhor solução, com soluções de menor custo para 6 instâncias, além de melhores GAPs para 4 instâncias.

As soluções obtidas para o parâmetro de escolha de variáveis são apresentadas na Tabela 11. A seleção por pseudo-custos (2-pseudo costs) apresentou as melhores soluções, com médias de 50994 para a solução e 30,38\% para o GAP.

Os próximos parâmetros verificados são heurísticas. As heurísticas verificadas foram: Limitante Inferior (LB), RINS e Feasibility Pump (FP). Para a heurística LB, os resultados são resumidos na Tabela 12. A solução média encontrada é de 50938 e o GAP médio é de 29,74\% para o valor yes.

Para a heurística RINS, os resultados são resumidos na Tabela 13. Verifica-se que as melhores soluções mantém o valor padrão para esse parâmetro.

Finalmente, para a heurística FP, os resultados são exibidos na Tabela 14. A melhor média de solução é 50829 para o valor -1 (do not generate), com GAP médio 29,64.

Também foram analisados os parâmetros de cortes e, para tal, dividimos esta verificação em duas etapas:

Etapa 1: todos os cortes ao mesmo tempo; e

Etapa 2: cada um dos cortes mais adequados ao problema individualmente (cliques, covers, flow covers e flow path).

Os resultados obtidos quando se verificam todos os cortes ao mesmo tempo (Etapa 1) são apresentados na Tabela 15. As melhores soluções obtidas são com o valor -1 (do not generate), com médias de 50789 para solução e 34,21\% para GAP.

Na Etapa 2, foram testados, nesta ordem, os parâmetros de corte: cliques, covers, flow covers e flow path. Seus resultados são apresentados nas Tabelas 16-19.

Os resultados apresentados na Tabela 16, quando comparados com os resultados da Tabela 14, mantém-se com a melhor média de soluções no valor padrão.

Já na Tabela 17, os melhores valores encontrados para média de solução e GAP médio são 50518 e 14,33\%, respectivamente. Ou seja, há uma redução de 15,31\% quando comparado ao GAP médio da Tabela 16. Como o valor 2-aggressive para o parâmetro de cortes covers apresentou mais soluções de boa qualidade, este foi o valor selecionado para a calibração.

Na Tabela 18, o parâmetro flow covers cuts apresentou melhores resultados com o valor 1-moderate, com solução média de 50446 e GAP médio de 12,52\% (redução de 1,82\% quando 


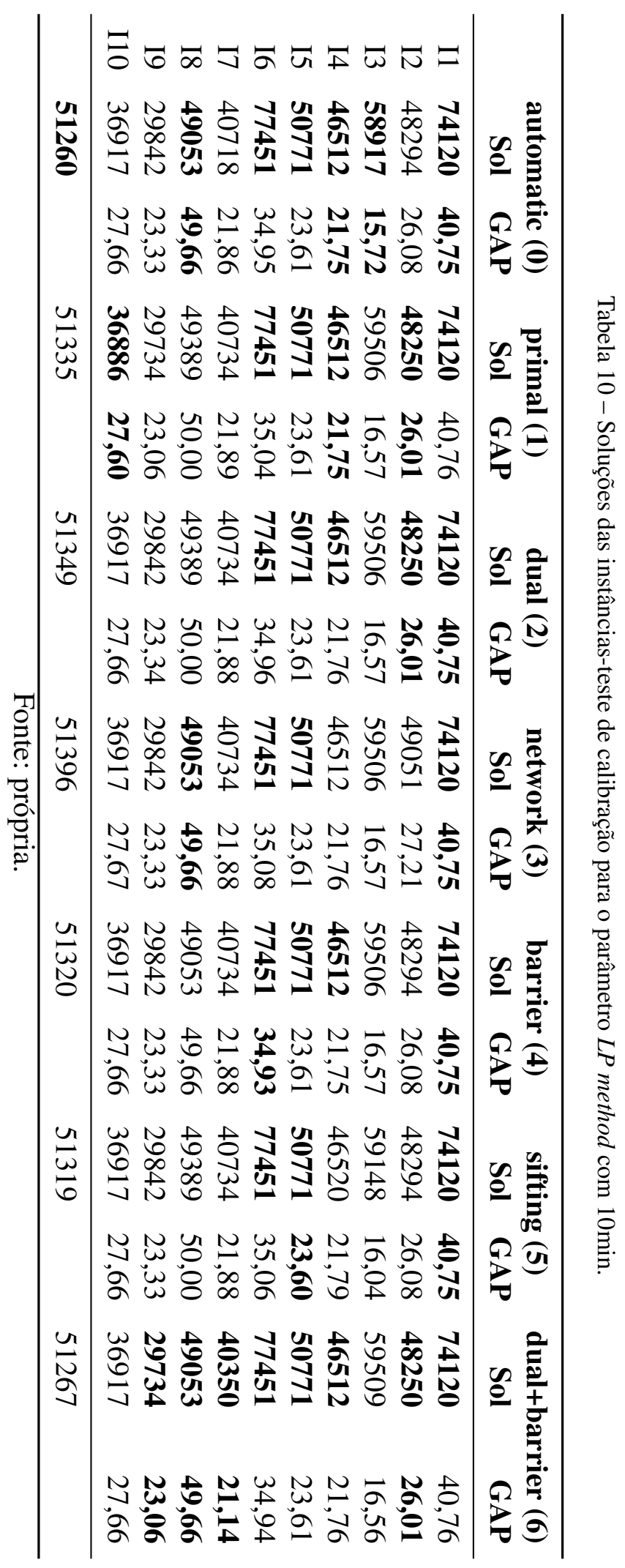




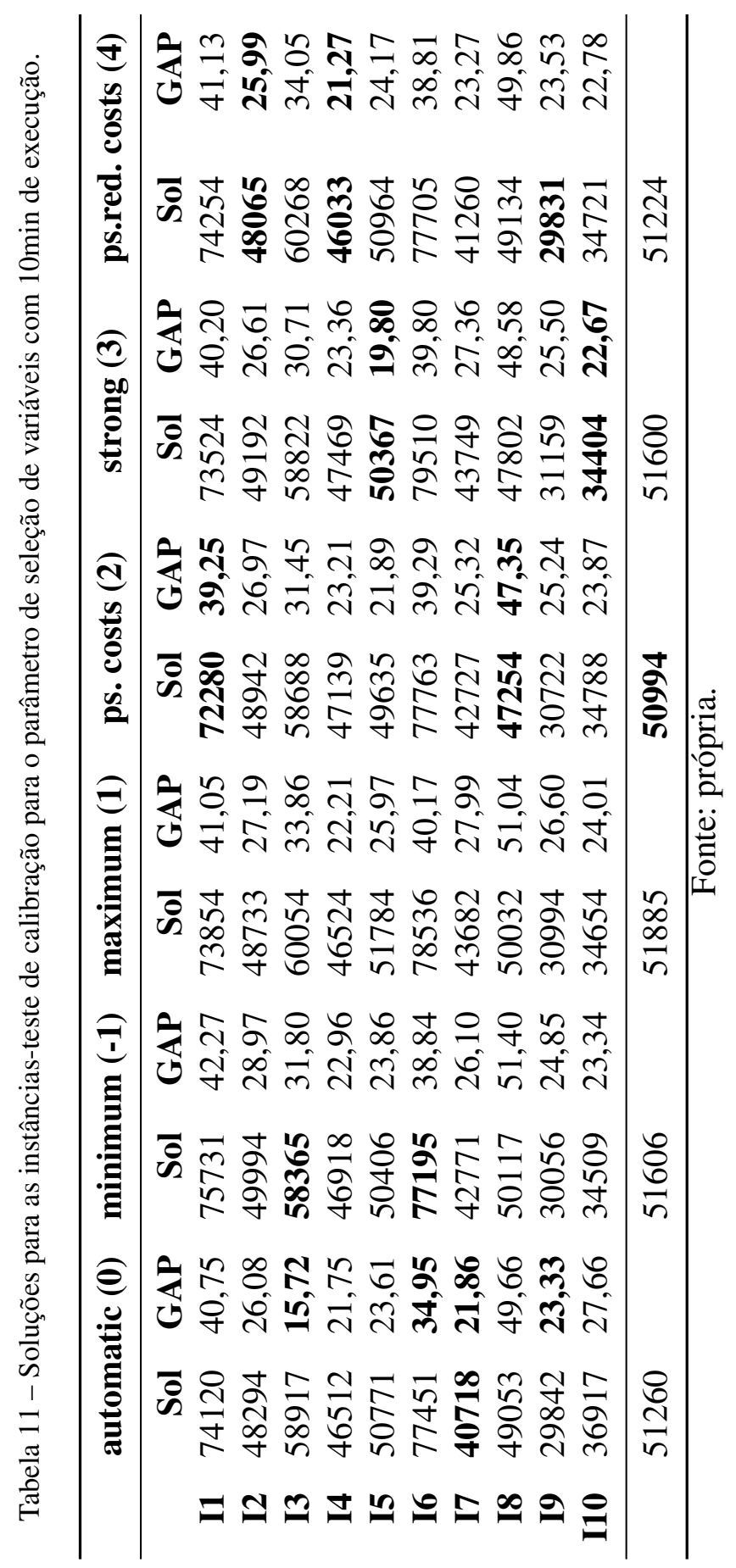


Tabela 12 - Soluções das instâncias-teste de calibração para a heurística LB com 10min de execução.

\begin{tabular}{rrrrr}
\hline & \multicolumn{2}{c}{ no } & \multicolumn{2}{c}{ yes } \\
& Sol & GAP & Sol & GAP \\
\hline I1 & $\mathbf{7 2 2 8 0}$ & 39,25 & 73277 & $\mathbf{3 8 , 8 3}$ \\
I2 & 48942 & 26,97 & $\mathbf{4 8 2 4 4}$ & $\mathbf{2 5 , 5 2}$ \\
I3 & $\mathbf{5 8 6 8 8}$ & 31,45 & 58936 & $\mathbf{2 9 , 2 2}$ \\
I4 & 47139 & 23,21 & $\mathbf{4 6 5 1 9}$ & $\mathbf{2 1 , 7 5}$ \\
I5 & 49635 & $\mathbf{2 1 , 8 9}$ & $\mathbf{4 9 5 7 3}$ & 22,11 \\
I6 & $\mathbf{7 7 7 6 3}$ & 39,29 & 77864 & $\mathbf{3 8 , 7 2}$ \\
I7 & 42727 & 25,32 & $\mathbf{4 1 1 8 9}$ & $\mathbf{2 2 , 4 8}$ \\
I8 & $\mathbf{4 7 2 5 4}$ & $\mathbf{4 7 , 3 5}$ & 47562 & 48,20 \\
I9 & $\mathbf{3 0 7 2 2}$ & $\mathbf{2 5 , 2 4}$ & 31302 & 26,85 \\
I10 & $\mathbf{3 4 7 8 8}$ & 23,87 & 34911 & $\mathbf{2 3 , 7 0}$ \\
\hline \multicolumn{4}{c}{$\mathbf{5 0 9 3 8}$} \\
\hline
\end{tabular}

Fonte: própria.

Tabela 13 - Soluções das instâncias-teste de calibração para a heurística RINS com 10min de execução.

\begin{tabular}{|c|c|c|c|c|}
\hline & \multicolumn{2}{|c|}{ automatic (0) } & \multicolumn{2}{|c|}{ none $(-1)$} \\
\hline & Sol & GAP & Sol & GAP \\
\hline I1 & 73277 & $\mathbf{3 8 , 8 3}$ & 79085 & 44,26 \\
\hline I2 & 48244 & 25,52 & 54982 & 34,92 \\
\hline I3 & 58936 & 29,22 & 59232 & 22,41 \\
\hline I4 & 46519 & 21,75 & 52687 & 31,19 \\
\hline I5 & 49573 & 22,11 & 52356 & 26,47 \\
\hline I6 & 77864 & 38,72 & 79377 & 40,01 \\
\hline I7 & 41189 & 22,48 & 46698 & 31,63 \\
\hline I8 & 47562 & 48,20 & 50113 & 50,43 \\
\hline I9 & 31302 & 26,85 & 31832 & 27,67 \\
\hline I10 & 34911 & 23,70 & 34489 & 27,10 \\
\hline & 50938 & & 85 & \\
\hline
\end{tabular}

Fonte: própria.

comparado ao GAP obtido na Tabela 17).

A Tabela 19 apresenta os resultados para o parâmetro flow path cuts que obteve as melhores soluções para o valor -1 (do not generate), com solução média de 50437 e GAP médio de 12,50 .

Assim, na Tabela 20, exibimos a comparação entre os resultados obtidos pela calibração automática do software CPLEX, a calibração manual com a Etapa 1, a calibração manual com a Etapa 2 e a configuração padrão do CPLEX. Para 6 das 10 instâncias-teste, a calibração manual com cortes pela Etapa 1 obteve melhores soluções que a calibração automática do CPLEX. Enquanto para 9 das 10 instâncias-teste, a calibração manual com cortes pela Etapa 2 obteve melhores soluções que a calibração automática. 
Tabela 14 - Soluções das instâncias-teste de calibração para a heurística FP (Feasibility Pump) com 10min de execução.

\begin{tabular}{rrrrrrrrr}
\hline & \multicolumn{2}{c}{ automatic (0) } & \multicolumn{2}{c}{ none $\mathbf{( - 1 )}$} & \multicolumn{2}{c}{ feasibility (1) } & \multicolumn{2}{c}{ both (2) } \\
& Sol & GAP & Sol & GAP & Sol & GAP & Sol & GAP \\
\hline I1 & $\mathbf{7 3 2 7 7}$ & $\mathbf{3 8 , 8 3}$ & 73417 & 39,95 & 74550 & 40,91 & 75232 & 41,09 \\
I2 & 48244 & 25,52 & $\mathbf{4 7 7 9 4}$ & $\mathbf{2 4 , 8 2}$ & 48581 & 26,39 & 48883 & 26,89 \\
I3 & 58936 & 29,22 & $\mathbf{5 8 6 5 4}$ & 28,90 & 58920 & $\mathbf{2 8 , 3 5}$ & 60067 & 33,02 \\
I4 & $\mathbf{4 6 5 1 9}$ & 21,75 & $\mathbf{4 6 5 1 9}$ & 21,75 & 46805 & 22,04 & 46550 & $\mathbf{2 1 , 6 5}$ \\
I5 & $\mathbf{4 9 5 7 3}$ & $\mathbf{2 2 , 1 1}$ & $\mathbf{4 9 5 7 3}$ & $\mathbf{2 2 , 1 1}$ & 50200 & 23,09 & 50768 & 24,13 \\
I6 & 77864 & $\mathbf{3 8 , 7 2}$ & 77864 & $\mathbf{3 8 , 7 2}$ & 77802 & 39,24 & $\mathbf{7 7 6 2 2}$ & 39,02 \\
I7 & 41189 & 22,48 & $\mathbf{4 1 1 0 4}$ & $\mathbf{2 2 , 2 9}$ & 42931 & 25,64 & 44973 & 29,38 \\
I8 & 47562 & 48,20 & $\mathbf{4 7 4 9 0}$ & $\mathbf{4 8 , 1 2}$ & 51814 & 52,27 & 50404 & 51,20 \\
I9 & 31302 & 26,85 & $\mathbf{3 0 9 6 8}$ & $\mathbf{2 6 , 0 6}$ & 31442 & 27,22 & 32329 & 29,17 \\
I10 & $\mathbf{3 4 9 1 1}$ & 23,70 & $\mathbf{3 4 9 1 1}$ & 23,69 & $\mathbf{3 4 9 1 1}$ & $\mathbf{2 3 , 1 2}$ & 37169 & 28,35 \\
\hline \multicolumn{10}{c}{} & $\mathbf{5 0 8 2 9}$ & & 51796 & & 52400 & \\
\hline
\end{tabular}

Fonte: própria.

Tabela 15 - Soluções das instâncias-teste de calibração para todos os cortes ao mesmo tempo com 10min de execução.

\begin{tabular}{rrrrrrrrr}
\hline & \multicolumn{2}{c}{ automatic (0) } & \multicolumn{2}{c}{ do not (-1) } & \multicolumn{2}{c}{ moderate (1) } & \multicolumn{2}{c}{ aggressive (2) } \\
& Sol & GAP & Sol & GAP & Sol & GAP & Sol & GAP \\
\hline I1 & $\mathbf{7 3 4 1 7}$ & 39,95 & 73941 & 43,29 & 73973 & 41,44 & 75033 & $\mathbf{2 7 , 8 2}$ \\
I2 & $\mathbf{4 7 7 9 4}$ & 24,82 & 48410 & 27,15 & 48192 & 25,44 & 48071 & $\mathbf{1 7 , 0 2}$ \\
I3 & 58654 & 28,90 & $\mathbf{5 8 4 0 4}$ & 35,60 & 59709 & 33,36 & 58437 & $\mathbf{6 , 9 0}$ \\
I4 & 46519 & 21,75 & $\mathbf{4 5 7 3 8}$ & 23,25 & 46934 & 23,24 & 46359 & $\mathbf{1 3 , 4 6}$ \\
I5 & $\mathbf{4 9 5 7 3}$ & 22,11 & 50771 & 26,23 & 50212 & 24,17 & 50497 & $\mathbf{1 5 , 3 2}$ \\
I6 & 77864 & 38,72 & 78536 & 45,07 & 77795 & 39,52 & $\mathbf{7 7 3 0 6}$ & $\mathbf{2 , 6 9}$ \\
I7 & 41104 & 22,29 & 40350 & 24,15 & 40744 & 22,45 & $\mathbf{4 0 1 1 4}$ & $\mathbf{1 3 , 8 3}$ \\
I8 & 47490 & 48,12 & 47389 & 51,07 & 50696 & 51,59 & $\mathbf{4 6 9 5 3}$ & $\mathbf{9 , 8 8}$ \\
I9 & 30968 & 26,06 & $\mathbf{3 0 0 4 9}$ & 26,93 & 30871 & 26,52 & 31207 & $\mathbf{1 6 , 2 9}$ \\
I10 & 34911 & 23,69 & $\mathbf{3 4 2 9 9}$ & 39,32 & 35025 & 24,64 & 34489 & $\mathbf{1 3 , 5 4}$ \\
\hline & 50829 & & $\mathbf{5 0 7 8 9}$ & & 51415 & & 50847 & \\
\hline
\end{tabular}

Fonte: própria. 
Tabela 16 - Resultados da calibração das instâncias-teste dos cortes por cliques com 10min de execução.

\begin{tabular}{rrrrrrrrrrr}
\hline & $\begin{array}{r}\text { automatic (0) } \\
\text { Sol }\end{array}$ & GAP & So not & Sol & GAP & moderate (1) & \multicolumn{2}{c}{ aggressive (2) } & \multicolumn{2}{c}{ very aggr. (3) } \\
& GAP & Sol & GAP & Sol & GAP \\
\hline I1 & 73417 & 39,95 & $\mathbf{7 3 2 7 7}$ & $\mathbf{3 8 , 8 3}$ & $\mathbf{7 3 2 7 7}$ & $\mathbf{3 8 , 8 3}$ & 76676 & 42,84 & 76676 & 42,84 \\
I2 & $\mathbf{4 7 7 9 4}$ & $\mathbf{2 4 , 8 2}$ & 48019 & 25,19 & 48019 & 25,19 & 48882 & 26,77 & 48882 & 26,77 \\
I3 & 58654 & $\mathbf{2 8 , 9 0}$ & 58936 & 29,36 & 59257 & 29,80 & $\mathbf{5 8 2 8 5}$ & 31,68 & 58693 & 32,03 \\
I4 & 46519 & 21,75 & $\mathbf{4 6 2 6 9}$ & $\mathbf{2 1 , 0 8}$ & 46898 & 22,38 & 46867 & 22,31 & 46877 & 22,33 \\
I5 & $\mathbf{4 9 5 7 3}$ & 22,11 & $\mathbf{4 9 5 7 3}$ & 22,10 & $\mathbf{4 9 5 7 3}$ & 22,10 & $\mathbf{4 9 5 7 3}$ & $\mathbf{2 1 , 9 9}$ & $\mathbf{4 9 5 7 3}$ & $\mathbf{2 1 , 9 9}$ \\
I6 & 77864 & $\mathbf{3 8 , 7 2}$ & 77887 & 38,74 & 77887 & 38,74 & $\mathbf{7 7 1 9 5}$ & $\mathbf{3 8 , 7 2}$ & 77610 & 39,05 \\
I7 & $\mathbf{4 1 1 0 4}$ & $\mathbf{2 2 , 2 9}$ & $\mathbf{4 1 1 0 4}$ & $\mathbf{2 2 , 2 9}$ & $\mathbf{4 1 1 0 4}$ & 22,31 & 42600 & 25,15 & 42600 & 25,15 \\
I8 & 47490 & 48,12 & $\mathbf{4 7 4 4 4}$ & $\mathbf{4 8 , 0 7}$ & 47562 & 48,20 & 48822 & 49,41 & 48822 & 49,41 \\
I9 & $\mathbf{3 0 9 6 8}$ & $\mathbf{2 6 , 0 6}$ & 31038 & 26,23 & 31038 & 26,23 & 31311 & 26,95 & 31736 & 27,93 \\
I10 & 34911 & 23,69 & 34911 & 23,70 & 34911 & 23,70 & $\mathbf{3 4 4 8 9}$ & $\mathbf{2 2 , 4 9}$ & $\mathbf{3 4 4 8 9}$ & $\mathbf{2 2 , 4 9}$ \\
\hline & $\mathbf{5 0 8 2 9}$ & & 50846 & & 50953 & & 51470 & & 51596 & \\
\hline
\end{tabular}

Fonte: própria.

Tabela 17 - Resultados das instâncias-teste de calibração para o parâmetro de cortes covers com 10min de execução.

\begin{tabular}{rrrrrrrrrrr}
\hline & \multicolumn{2}{c}{ automatic (0) } & \multicolumn{2}{c}{ do not(-1) } & \multicolumn{2}{c}{ moderate (1) } & \multicolumn{2}{c}{ aggressive (2) } & \multicolumn{2}{c}{ very aggr. (3) } \\
& Sol & GAP & Sol & GAP & Sol & GAP & Sol & GAP & Sol & GAP \\
\hline I1 & 73417 & 39,95 & 74735 & 41,49 & 73960 & 40,17 & $\mathbf{7 2 9 5 5}$ & $\mathbf{3 3 , 3 2}$ & $\mathbf{7 2 9 5 5}$ & $\mathbf{3 3 , 3 2}$ \\
I2 & $\mathbf{4 7 7 9 4}$ & 24,82 & 49885 & 28,25 & 49008 & 27,09 & 48948 & $\mathbf{1 7 , 3 8}$ & 48948 & 17,39 \\
I3 & 58654 & 28,90 & $\mathbf{5 8 2 0 9}$ & 31,32 & $\mathbf{5 8 2 0 9}$ & 31,32 & 58484 & $\mathbf{6 , 3 6}$ & 58484 & $\mathbf{6 , 3 6}$ \\
I4 & 46519 & 21,75 & 46421 & 21,55 & 46421 & 21,55 & $\mathbf{4 5 8 8 0}$ & $\mathbf{1 2 , 3 9}$ & 45924 & 12,47 \\
I5 & $\mathbf{4 9 5 7 3}$ & 22,11 & 51191 & 25,15 & 51191 & 25,15 & 50403 & $\mathbf{1 5 , 9 6}$ & 50403 & $\mathbf{1 5 , 9 6}$ \\
I6 & 77864 & 38,72 & 77958 & 39,53 & 77643 & 39,20 & $\mathbf{7 7 1 9 5}$ & 3,16 & $\mathbf{7 7 1 9 5}$ & $\mathbf{3 , 1 5}$ \\
I7 & 41104 & 22,29 & 41224 & 22,62 & 41224 & 22,62 & $\mathbf{4 0 2 2 1}$ & $\mathbf{1 5 , 3 4}$ & $\mathbf{4 0 2 2 1}$ & $\mathbf{1 5 , 3 4}$ \\
I8 & 47490 & 48,12 & 49820 & 50,55 & 49820 & 50,55 & $\mathbf{4 6 9 3 4}$ & $\mathbf{1 6 , 6 2}$ & $\mathbf{4 6 9 3 4}$ & $\mathbf{1 6 , 6 2}$ \\
I9 & 30968 & 26,06 & 30187 & 24,26 & 30925 & 25,92 & $\mathbf{2 9 8 6 4}$ & $\mathbf{1 0 , 8 0}$ & $\mathbf{2 9 8 6 4}$ & 10,81 \\
I10 & 34911 & 23,69 & 34911 & 23,63 & 34911 & 23,63 & $\mathbf{3 4 2 9 9}$ & $\mathbf{1 2 , 0 1}$ & $\mathbf{3 4 2 9 9}$ & $\mathbf{1 2 , 0 1}$ \\
\hline & 50829 & & 51454 & & 51331 & & $\mathbf{5 0 5 1 8}$ & & 50523 & \\
\hline
\end{tabular}

Fonte: própria.

A calibração manual com cortes pela Etapa 2 apresentou melhores resultados, até mesmo quanto às médias, com o menor valor para solução (50437) e o menor valor para GAP (12,50\%). Ainda assim, há uma redução de 19,00\% quando comparados às soluções do padrão do CPLEX. Portanto a melhor solução encontrada é: calibração manual utilizando a Etapa 2, ou seja, mudando os parâmetros:

- ênfase 3 (hidden feasibe solutions),

- escolha de variáveis 2 (pseudo costs),

- heurística LB yes,

- heurística FP 1 (do not generate), 
Tabela 18 - Resultados das instâncias-teste de calibraccão para o parâmetro de cortes flow covers com 10min de execução.

\begin{tabular}{rrrrrrrrr}
\hline & \multicolumn{2}{c}{ automatic (0) } & \multicolumn{2}{c}{ do not (-1) } & \multicolumn{2}{c}{ moderate (1) } & \multicolumn{2}{c}{ aggressive (2) } \\
& Sol & GAP & Sol & GAP & Sol & GAP & Sol & GAP \\
\hline I1 & 72955 & 33,32 & $\mathbf{7 1 1 1 0}$ & $\mathbf{2 3 , 2 4}$ & 71541 & 25,60 & 71541 & 25,60 \\
I2 & 48948 & 17,38 & 48003 & 16,18 & $\mathbf{4 7 9 7 1}$ & $\mathbf{1 6 , 1 6}$ & $\mathbf{4 7 9 7 1}$ & $\mathbf{1 6 , 1 6}$ \\
I3 & 58484 & $\mathbf{6 , 3 6}$ & 59317 & 18,11 & $\mathbf{5 8 4 4 0}$ & 7,14 & $\mathbf{5 8 4 4 0}$ & 7,14 \\
I4 & 45880 & 12,39 & 45587 & $\mathbf{1 0 , 7 0}$ & $\mathbf{4 5 2 9 2}$ & 11,20 & $\mathbf{4 5 2 9 2}$ & 11,20 \\
I5 & $\mathbf{5 0 4 0 3}$ & 15,96 & 51054 & 18,50 & 51868 & $\mathbf{1 4 , 5 4}$ & 52168 & 14,97 \\
I6 & 77195 & 3,16 & 77449 & 18,37 & $\mathbf{7 7 1 9 1}$ & $\mathbf{3 , 0 6}$ & $\mathbf{7 7 1 9 1}$ & 3,11 \\
I7 & $\mathbf{4 0 2 2 1}$ & 15,34 & 40223 & 15,20 & 40835 & 15,07 & 40767 & $\mathbf{1 4 , 9 8}$ \\
I8 & $\mathbf{4 6 9 3 4}$ & 16,62 & 47316 & 17,93 & 46985 & $\mathbf{9 , 1 9}$ & 46985 & $\mathbf{9 , 1 9}$ \\
I9 & 29864 & 10,80 & 29668 & 11,06 & $\mathbf{2 9 6 1 3}$ & $\mathbf{1 0 , 1 0}$ & $\mathbf{2 9 6 1 3}$ & $\mathbf{1 0 , 1 0}$ \\
I10 & $\mathbf{3 4 2 9 9}$ & $\mathbf{1 2 , 0 1}$ & 34489 & 12,29 & 34721 & 13,13 & 34721 & 13,13 \\
\hline \multicolumn{8}{c}{50422} & \multicolumn{5}{c}{ Fonte: própria. } \\
\hline
\end{tabular}

Tabela 19 - Resultados das instâncias-teste de calibração para o parâmetro de cortes flow path com 10min de execução.

\begin{tabular}{rrrrrrrrr}
\hline & \multicolumn{2}{c}{ automatic (0) } & \multicolumn{2}{c}{ do not $\mathbf{( - 1 )}$} & \multicolumn{2}{c}{ moderate (1) } & \multicolumn{2}{c}{ aggressive (2) } \\
& Sol & GAP & Sol & GAP & Sol & GAP & Sol & GAP \\
\hline I1 & $\mathbf{7 1 5 4 1}$ & $\mathbf{2 5 , 6 0}$ & $\mathbf{7 1 5 4 1}$ & $\mathbf{2 5 , 6 0}$ & $\mathbf{7 1 5 4 1}$ & $\mathbf{2 5 , 6 0}$ & $\mathbf{7 1 5 4 1}$ & $\mathbf{2 5 , 6 0}$ \\
I2 & $\mathbf{4 7 9 7 1}$ & $\mathbf{1 6 , 1 6}$ & $\mathbf{4 7 9 7 1}$ & $\mathbf{1 6 , 1 6}$ & $\mathbf{4 7 9 7 1}$ & $\mathbf{1 6 , 1 6}$ & 49179 & 18,19 \\
I3 & $\mathbf{5 8 4 4 0}$ & 7,14 & $\mathbf{5 8 4 4 0}$ & 7,14 & $\mathbf{5 8 4 4 0}$ & 7,14 & $\mathbf{5 8 4 4 0}$ & $\mathbf{7 , 0 9}$ \\
I4 & $\mathbf{4 5 2 9 2}$ & $\mathbf{1 1 , 2 0}$ & $\mathbf{4 5 2 9 2}$ & $\mathbf{1 1 , 2 0}$ & $\mathbf{4 5 2 9 2}$ & $\mathbf{1 1 , 2 0}$ & $\mathbf{4 5 2 9 2}$ & $\mathbf{1 1 , 2 0}$ \\
I5 & $\mathbf{5 1 8 6 8}$ & $\mathbf{1 4 , 5 4}$ & $\mathbf{5 1 8 6 8}$ & $\mathbf{1 4 , 5 4}$ & 52168 & 14,97 & 52418 & 15,85 \\
I6 & $\mathbf{7 7 1 9 1}$ & $\mathbf{3 , 0 6}$ & $\mathbf{7 7 1 9 1}$ & $\mathbf{3 , 0 6}$ & $\mathbf{7 7 1 9 1}$ & 3,11 & $\mathbf{7 7 1 9 1}$ & 3,07 \\
I7 & 40835 & 15,07 & 40744 & 14,88 & 40835 & 15,07 & $\mathbf{4 0 7 3 3}$ & $\mathbf{1 4 , 8 5}$ \\
I8 & $\mathbf{4 6 9 8 5}$ & $\mathbf{9 , 1 9}$ & $\mathbf{4 6 9 8 5}$ & $\mathbf{9 , 1 9}$ & $\mathbf{4 6 9 8 5}$ & $\mathbf{9 , 1 9}$ & $\mathbf{4 6 9 8 5}$ & $\mathbf{9 , 1 9}$ \\
I9 & $\mathbf{2 9 6 1 3}$ & 10,10 & $\mathbf{2 9 6 1 3}$ & 10,10 & $\mathbf{2 9 6 1 3}$ & 10,10 & $\mathbf{2 9 6 1 3}$ & $\mathbf{1 0 , 0 9}$ \\
I10 & $\mathbf{3 4 7 2 1}$ & 13,13 & $\mathbf{3 4 7 2 1}$ & 13,13 & $\mathbf{3 4 7 2 1}$ & 13,13 & $\mathbf{3 4 7 2 1}$ & $\mathbf{1 3 , 1 1}$ \\
\hline & 50446 & & $\mathbf{5 0 4 3 7}$ & & 50476 & & 50611 & \\
\hline
\end{tabular}

Fonte: própria. 
- covers 2 (aggressive),

- flow covers 1 (do not generate), e

- flow path 1 (do not generate).

Tabela 20 - Comparação entre os resultados da calibração automática, das calibrações manuais e o padrão do software com 10min de execução.

\begin{tabular}{rrrrrrrrr}
\hline & \multicolumn{2}{c}{ automático } & \multicolumn{2}{c}{ manual + Etapa 1 } & \multicolumn{2}{c}{ manual + Etapa 2 } & \multicolumn{2}{c}{ padrão } \\
& Sol & GAP & Sol & GAP & Sol & GAP & Sol & GAP \\
\hline I1 & 77354 & 43,53 & 73941 & 43,29 & $\mathbf{7 1 5 4 1}$ & $\mathbf{2 5 , 6 0}$ & 75691 & 41,40 \\
I2 & 48289 & 26,15 & 48410 & 27,15 & $\mathbf{4 7 9 7 1}$ & $\mathbf{1 6 , 1 6}$ & 48978 & 26,81 \\
I3 & 60527 & 33,49 & $\mathbf{5 8 4 0 4}$ & 35,60 & $\mathbf{5 8 4 4 0}$ & $\mathbf{7 , 1 4}$ & 59099 & 27,24 \\
I4 & 46908 & 22,99 & 45738 & 23,25 & $\mathbf{4 5 2 9 2}$ & $\mathbf{1 1 , 2 0}$ & 47257 & 23,09 \\
I5 & $\mathbf{4 9 7 0 6}$ & 22,27 & 50770 & 26,23 & 51868 & $\mathbf{1 4 , 5 4}$ & 51170 & 24,75 \\
I6 & 77608 & 39,07 & 78536 & 45,07 & $\mathbf{7 7 1 9 1}$ & $\mathbf{3 , 0 6}$ & 77969 & 39,71 \\
I7 & 41668 & 23,86 & $\mathbf{4 0 3 5 0}$ & 24,15 & 40744 & $\mathbf{1 4 , 8 8}$ & 46712 & 31,94 \\
I8 & 47225 & 48,24 & 47389 & 51,07 & $\mathbf{4 6 9 8 5}$ & $\mathbf{9 , 1 9}$ & 49840 & 50,45 \\
I9 & 31085 & 26,17 & 30049 & 26,93 & $\mathbf{2 9 6 1 3}$ & $\mathbf{1 0 , 1 0}$ & 29749 & 22,71 \\
I10 & 36724 & 33,01 & $\mathbf{3 4 2 9 9}$ & 39,32 & 34721 & $\mathbf{1 3 , 1 3}$ & 34404 & 22,51 \\
\hline Média & 51709 & 31,88 & 50789 & 34,21 & $\mathbf{5 0 4 3 7}$ & $\mathbf{1 2 , 5 0}$ & 52087 & 31,06 \\
\hline
\end{tabular}

Fonte: própria.

\subsection{Conclusões da calibração}

Nesta seção são apresentados os resultados obtidos resolvendo as instâncias-teste pelo CPLEX com os parâmetros definidos como proposto na Seção 4.3. Os resultados obtidos são exibidos nas Tabelas 21 - 23, em que o tempo máximo de execução é de 1800s. MPJT representam os resultados do software na configuração padrão, enquanto MPJT* representam a resolução utilizando a configuração proposta.

A Tabela 21 mostra que houve uma redução média de 12,10\% no GAP quando utilizada a configuração de parâmetros proposta, além de apresentar 34 soluções de melhor qualidade quando comparadas às encontradas utilizando o CPLEX. Na Tabela 22 nota-se uma redução de 28,05\% no GAP médio e uma melhoria na qualidade de 37 das 40 instâncias testadas neste grupo. Por fim, na Tabela 23 nota-se uma redução de 20,47\% no GAP médio e uma melhoria na qualidade de 34 instâncias.

Ou seja, em geral, houve uma redução média de $20,21 \%$ do GAP e uma melhoria na qualidade de 105 das 120 instâncias-teste utilizando-se a calibração manual do CPLEX. 
Tabela 21 - Resultados após a calibração do modelo proposto para instâncias com mesma proporção de entregas e coletas com 10min de execução.

\begin{tabular}{|c|c|c|c|c|c|c|}
\hline & \multicolumn{3}{|c|}{ MPJT } & \multicolumn{3}{|c|}{ MPJT* } \\
\hline & Sol & $\mathbf{T}$ & GAP & Sol & $\mathbf{T}$ & GAP \\
\hline$(24,3,5,10,10) \_1$ & 74630 & 1804 & 40,46 & 71541 & 1804 & 24,97 \\
\hline$(24,3,5,10,10) \_2$ & 48361 & 1808 & 25,71 & 47971 & 1806 & 15,57 \\
\hline$(24,3,5,10,10) \_3$ & 58138 & 1806 & 20,82 & 58121 & 1804 & 6,22 \\
\hline$(24,3,5,10,10) \_4$ & 46981 & 1806 & 22,48 & 45139 & 1805 & 10,17 \\
\hline$(24,3,5,10,10) \_5$ & 51170 & 1809 & 24,59 & 49573 & 1806 & 7,19 \\
\hline$(24,3,5,20,20) \_1$ & 114990 & 1806 & 7,46 & 114324 & 1808 & 6,28 \\
\hline$(24,3,5,20,20) \_2$ & 97577 & 1805 & 9,21 & 96012 & 1808 & 7,49 \\
\hline$(24,3,5,20,20) \_3$ & 87385 & 1805 & 12,23 & 85230 & 1805 & 9,55 \\
\hline$(24,3,5,20,20) \_4$ & 88998 & 1806 & 7,63 & 89696 & 1807 & 8,23 \\
\hline$(24,3,5,20,20) \_5$ & 82587 & 1806 & 10,74 & 81296 & 1806 & 8,45 \\
\hline$(24,4,5,10,10) \_1$ & 35355 & 1808 & 19,97 & 35413 & 1806 & 14,38 \\
\hline$(24,4,5,10,10) \_2$ & 54300 & 1805 & 33,64 & 51696 & 1807 & 8,69 \\
\hline$(24,4,5,10,10) \_3$ & 52064 & 1805 & 44,35 & 49662 & 1807 & 30,27 \\
\hline$(24,4,5,10,10) \_4$ & 66433 & 1807 & 60,91 & 64231 & 1807 & 8,15 \\
\hline$(24,4,5,10,10) \_5$ & 47197 & 1807 & 12,22 & 48185 & 1807 & 12,65 \\
\hline$(24,4,5,20,20) \_1$ & 75180 & 1806 & 17,01 & 73040 & 1806 & 13,59 \\
\hline$(24,4,5,20,20) \_2$ & 84132 & 1807 & 9,63 & 83796 & 1807 & 8,90 \\
\hline$(24,4,5,20,20) \_3$ & 90273 & 1806 & 10,33 & 89182 & 1806 & 8,91 \\
\hline$(24,4,5,20,20) \_4$ & 103488 & 1808 & 10,31 & 102178 & 1807 & 8,55 \\
\hline$(24,4,5,20,20) \_5$ & 103186 & 1808 & 22,79 & 98564 & 1805 & 17,53 \\
\hline$(24,3,10,10,10) \_1$ & 99760 & 1806 & 32,47 & 93967 & 1804 & 13,77 \\
\hline$(24,3,10,10,10) \_2$ & 120856 & 1807 & 47,32 & 115449 & 1803 & 15,23 \\
\hline$(24,3,10,10,10) \_3$ & 99161 & 1804 & 38,90 & 99832 & 1800 & 8,57 \\
\hline$(24,3,10,10,10) \_4$ & 111984 & 1805 & 48,18 & 111401 & 1808 & 5,21 \\
\hline$(24,3,10,10,10) \_5$ & 96760 & 1807 & 18,15 & 95814 & 1807 & 12,15 \\
\hline$(24,3,10,20,20) \_1$ & 180410 & 1807 & 17,30 & 175438 & 1800 & 13,43 \\
\hline$(24,3,10,20,20) \_2$ & 166128 & 1807 & 14,09 & 163338 & 1800 & 11,73 \\
\hline$(24,3,10,20,20) \_3$ & 173947 & 1803 & 18,09 & 172167 & 1806 & 20,01 \\
\hline$(24,3,10,20,20) \_4$ & 181240 & 1807 & 13,48 & 177403 & 1805 & 11,54 \\
\hline$(24,3,10,20,20) \_5$ & 159472 & 1808 & 8,64 & 164632 & 1806 & 12,12 \\
\hline$(24,4,10,10,10) \_1$ & 127340 & 1807 & 33,70 & 119184 & 1804 & 20,02 \\
\hline$(24,4,10,10,10) \_2$ & 106301 & 1808 & 45,36 & 98186 & 1800 & 12,71 \\
\hline$(24,4,10,10,10) \_3$ & 115123 & 1809 & 47,70 & 106150 & 1800 & 18,43 \\
\hline$(24,4,10,10,10) \_4$ & 92317 & 1810 & 38,60 & 86939 & 1800 & 13,01 \\
\hline$(24,4,10,10,10) \_5$ & 136686 & 1808 & 50,57 & 130602 & 1800 & 18,40 \\
\hline$(24,4,10,20,20) \_1$ & 193080 & 1808 & 26,69 & 165179 & 1809 & 13,34 \\
\hline$(24,4,10,20,20) \_2$ & 144646 & 1806 & 20,70 & 146463 & 1800 & 21,25 \\
\hline$(24,4,10,20,20) \_3$ & 171316 & 1808 & 25,54 & 143573 & 1805 & 10,78 \\
\hline$(24,4,10,20,20) \_4$ & 158470 & 1809 & 14,05 & 156547 & 1808 & 14,11 \\
\hline$(24,4,10,20,20) \_5$ & 171753 & 1809 & 19,17 & 166252 & 1806 & 15,70 \\
\hline Média & 106729 & & & 103084 & & \\
\hline Mínimo & 35355 & & & 35413 & & \\
\hline Máximo & 193080 & & & 177403 & & \\
\hline
\end{tabular}


Tabela 22 - Resultados após a calibração do modelo proposto para instâncias com muitas entregas e poucas coletas.

\begin{tabular}{|c|c|c|c|c|c|c|}
\hline & \multicolumn{3}{|c|}{ MPJT } & \multicolumn{3}{|c|}{ MPJT* } \\
\hline & Sol & $\mathbf{T}$ & GAP & Sol & $\mathbf{T}$ & GAP \\
\hline$(24,3,5,10,5) \_1$ & 50054 & 1807 & 23,77 & 50054 & 1806 & 13,74 \\
\hline$(24,3,5,10,5) \_2$ & 39446 & 1804 & 15,38 & 39249 & 1806 & 3,32 \\
\hline$(24,3,5,10,5) \_3$ & 44016 & 1807 & 28,07 & 44016 & 1803 & 6,30 \\
\hline$(24,3,5,10,5) \_4$ & 34414 & 1805 & 25,47 & 34333 & 1807 & 16,04 \\
\hline$(24,3,5,10,5) \_5$ & 31606 & 1808 & 28,70 & 31357 & 100 & $\mathbf{0 , 0 1}$ \\
\hline$(24,3,5,20,5) \_1$ & 41239 & 1804 & 22,55 & 40114 & 1805 & 12,76 \\
\hline$(24,3,5,20,5) \_2$ & 31682 & 1808 & 15,17 & 31005 & 1805 & $\mathbf{9 , 8 1}$ \\
\hline$(24,3,5,20,5) \_3$ & 49700 & 1808 & 50,15 & 46934 & 1800 & 5,33 \\
\hline$(24,3,5,20,5) \_4$ & 29613 & 1809 & 21,84 & 29613 & 1808 & 9,27 \\
\hline$(24,3,5,20,5) \_5$ & 34299 & 1805 & 21,99 & 34721 & 1809 & 12,99 \\
\hline$(24,4,5,10,5) \_1$ & 34431 & 1807 & 34,51 & 34401 & 1185 & $\mathbf{0 , 0 1}$ \\
\hline$(24,4,5,10,5) \_2$ & 31715 & 1806 & 38,46 & 31496 & 1806 & 9,38 \\
\hline$(24,4,5,10,5) \_3$ & 54342 & 1807 & 54,79 & 53953 & 1807 & 6,92 \\
\hline$(24,4,5,10,5) \_4$ & 39182 & 1807 & 40,48 & 38764 & 1800 & 3,56 \\
\hline$(24,4,5,10,5) \_5$ & 46574 & 1806 & 45,21 & 46424 & 1807 & 10,54 \\
\hline$(24,4,5,20,5) \_1$ & 26421 & 1804 & 32,12 & 25591 & 1800 & 13,74 \\
\hline$(24,4,5,20,5) \_2$ & 36079 & 1808 & 19,54 & 36065 & 1805 & 17,06 \\
\hline$(24,4,5,20,5) \_3$ & 32672 & 1806 & 36,76 & 32811 & 1806 & 4,53 \\
\hline$(24,4,5,20,5) \_4$ & 31947 & 1807 & 18,18 & 30861 & 1806 & 10,32 \\
\hline$(24,4,5,20,5) \_5$ & 24647 & 1806 & 45,58 & 20839 & 1536 & $\mathbf{0 , 0 1}$ \\
\hline$(24,3,10,10,5) \_1$ & 59308 & 1807 & 18,53 & 59240 & 1800 & 1,48 \\
\hline$(24,3,10,10,5) \_2$ & 88649 & 1806 & 34,80 & 87978 & 1805 & 15,33 \\
\hline$(24,3,10,10,5) \_3$ & 111813 & 1807 & 61,30 & 111669 & 233 & $\mathbf{0 , 0 1}$ \\
\hline$(24,3,10,10,5) \_4$ & 80197 & 1806 & 28,75 & 77324 & 1808 & 5,63 \\
\hline$(24,3,10,10,5) \_5$ & 66404 & 1805 & 38,11 & 65303 & 168 & $\mathbf{0 , 0 1}$ \\
\hline$(24,3,10,20,5) \_1$ & 64238 & 1806 & 46,51 & 62380 & 348 & $\mathbf{0 , 0 1}$ \\
\hline$(24,3,10,20,5) \_2$ & 68925 & 1805 & 52,66 & 67320 & 1800 & 6,97 \\
\hline$(24,3,10,20,5) \_3$ & 80554 & 1806 & 30,16 & 76772 & 1808 & 10,96 \\
\hline$(24,3,10,20,5) \_4$ & 93147 & 1807 & 41,69 & 82299 & 1808 & 9,78 \\
\hline$(24,3,10,20,5) \_5$ & 83179 & 1806 & 45,33 & 76714 & 1806 & 10,75 \\
\hline$(24,4,10,10,5) \_1$ & 58883 & 1807 & 41,73 & 57611 & 1800 & 8,68 \\
\hline$(24,4,10,10,5) \_2$ & 59590 & 1804 & 35,41 & 59722 & 1806 & 10,67 \\
\hline$(24,4,10,10,5) \_3$ & 70540 & 1807 & 28,13 & 68121 & 1800 & 1,64 \\
\hline$(24,4,10,10,5) \_4$ & 73988 & 1807 & 39,89 & 72940 & 1800 & 7,86 \\
\hline$(24,4,10,10,5) \_5$ & 62992 & 1805 & 43,41 & 59928 & 1800 & 5,15 \\
\hline$(24,4,10,20,5) \_1$ & 69384 & 1803 & 37,20 & 62048 & 1800 & 7,89 \\
\hline$(24,4,10,20,5) \_2$ & 62319 & 1807 & 45,09 & 58430 & 1800 & 9,47 \\
\hline$(24,4,10,20,5) \_3$ & 84217 & 1804 & 57,12 & 73397 & 1800 & 5,44 \\
\hline$(24,4,10,20,5) \_4$ & 62479 & 1807 & 45,86 & 59361 & 1800 & 6,78 \\
\hline$(24,4,10,20,5) \_5$ & 59154 & 1807 & 41,03 & 55990 & 1808 & 19,55 \\
\hline & 55101 & & & 53179 & & \\
\hline Mínimo & 24647 & & & 20839 & & \\
\hline Máximo & 111813 & & & 111669 & & \\
\hline
\end{tabular}


Tabela 23 - Resultados após a calibração do modelo proposto para instâncias com poucas entregas e muitas coletas.

\begin{tabular}{|c|c|c|c|c|c|c|}
\hline & \multicolumn{3}{|c|}{ MPJT } & \multicolumn{3}{|c|}{ MPJT* } \\
\hline & Sol & $\mathbf{T}$ & GAP & Sol & $\mathbf{T}$ & GAP \\
\hline$(24,3,5,5,10) \_1$ & 84425 & 1807 & 45,67 & 84425 & 1806 & 1,77 \\
\hline$(24,3,5,5,10) \_2$ & 48630 & 196 & 0,01 & 48630 & 34 & $\mathbf{0 , 0 0}$ \\
\hline$(24,3,5,5,10) \_3$ & 54005 & 1806 & 20,63 & 53671 & 1808 & 12,23 \\
\hline$(24,3,5,5,10) \_4$ & 79571 & 1805 & 4,57 & 79571 & 64 & $\mathbf{0 , 0 1}$ \\
\hline$(24,3,5,5,10) \_5$ & 39593 & 1807 & 19,36 & 39165 & 187 & $\mathbf{0 , 0 1}$ \\
\hline$(24,3,5,5,20) \_1$ & 77368 & 1808 & 39,03 & 77191 & 1804 & 2,31 \\
\hline$(24,3,5,5,20) \_2$ & 82200 & 1808 & 6,72 & 81629 & 1800 & 0,25 \\
\hline$(24,3,5,5,20) \_3$ & 88198 & 1809 & 6,96 & 88105 & 1806 & 6,69 \\
\hline$(24,3,5,5,20) \_4$ & 54364 & 1808 & 12,64 & 54007 & 1808 & 9,30 \\
\hline$(24,3,5,5,20) \_5$ & 51813 & 1808 & 16,95 & 51813 & 1800 & 0,24 \\
\hline$(24,4,5,5,10) \_1$ & 60750 & 1807 & 24,53 & 60701 & 1806 & 20,11 \\
\hline$(24,4,5,5,10) \_2$ & 48165 & 1807 & 18,73 & 48177 & 1805 & $\mathbf{6 , 5 8}$ \\
\hline$(24,4,5,5,10) \_3$ & 57476 & 1804 & 40,11 & 57179 & 1806 & 3,52 \\
\hline$(24,4,5,5,10) \_4$ & 55459 & 1805 & 31,16 & 55085 & 1807 & 4,01 \\
\hline$(24,4,5,5,10) \_5$ & 55777 & 1806 & 33,54 & 55777 & 1807 & 16,89 \\
\hline$(24,4,5,5,20) \_1$ & 49082 & 1806 & 18,71 & 49590 & 1806 & 10,79 \\
\hline$(24,4,5,5,20) \_2$ & 61807 & 1805 & 22,54 & 61702 & 1807 & 23,29 \\
\hline$(24,4,5,5,20) \_3$ & 58288 & 1808 & 29,87 & 57939 & 1806 & 8,17 \\
\hline$(24,4,5,5,20) \_4$ & 49470 & 1807 & 18,09 & 49064 & 1806 & 10,98 \\
\hline$(24,4,5,5,20) \_5$ & 56218 & 1807 & 20,53 & 56321 & 1806 & 12,23 \\
\hline$(24,3,10,5,10) \_1$ & 87134 & 1806 & 35,62 & 86076 & 1806 & 5,23 \\
\hline$(24,3,10,5,10) \_2$ & 178481 & 1807 & 36,85 & 178522 & 1807 & 6,33 \\
\hline$(24,3,10,5,10) \_3$ & 80522 & 1808 & 28,68 & 79552 & 1342 & $\mathbf{0 , 0 1}$ \\
\hline$(24,3,10,5,10) \_4$ & 146566 & 1808 & 40,02 & 146566 & 1807 & 1,68 \\
\hline$(24,3,10,5,10) \_5$ & 155840 & 1806 & & 155700 & 1806 & 3,82 \\
\hline$(24,3,10,5,20) \_1$ & 88199 & 1805 & 29,52 & 87052 & 1807 & 10,52 \\
\hline$(24,3,10,5,20) \_2$ & 101919 & 1805 & 20,42 & 99125 & 1800 & 5,60 \\
\hline$(24,3,10,5,20) \_3$ & 134525 & 1806 & 29,24 & 133761 & 1803 & 12,57 \\
\hline$(24,3,10,5,20) \_4$ & 109582 & 1805 & 32,90 & 109831 & 1805 & 12,04 \\
\hline$(24,3,10,5,20) \_5$ & 161152 & 1807 & 40,87 & 161097 & 182 & $\mathbf{0 , 0 1}$ \\
\hline$(24,4,10,5,10) \_1$ & 88676 & 1807 & 42,15 & 87914 & 1800 & $\mathbf{7 , 8 5}$ \\
\hline$(24,4,10,5,10) \_2$ & 121368 & 1807 & 29,77 & 118387 & 1800 & 1,07 \\
\hline$(24,4,10,5,10) \_3$ & 66679 & 1807 & 38,92 & 65450 & 1800 & 9,93 \\
\hline$(24,4,10,5,10) \_4$ & 75271 & 1807 & 30,77 & 75218 & 1800 & 1,89 \\
\hline$(24,4,10,5,10) \_5$ & 71191 & 1805 & 27,98 & 71025 & 1804 & 5,36 \\
\hline$(24,4,10,5,20) \_1$ & 71500 & 1807 & 33,54 & 69216 & 1803 & 14,55 \\
\hline$(24,4,10,5,20) \_2$ & 77841 & 1805 & 49,78 & 77663 & 1800 & 12,32 \\
\hline$(24,4,10,5,20) \_3$ & 98448 & 1804 & 27,74 & 100889 & 1805 & 28,98 \\
\hline$(24,4,10,5,20) \_4$ & 62364 & 1807 & 37,06 & 61632 & 1800 & 5,77 \\
\hline$(24,4,10,5,20) \_5$ & 93235 & 1803 & 38,88 & 88130 & 1805 & 21,98 \\
\hline Média & 82079 & & & 81564 & & \\
\hline Mínimo & 39593 & & & 39165 & & \\
\hline Máximo & 178481 & & & 178522 & & \\
\hline
\end{tabular}

Fonte: própria. 



\section{5}

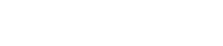

\section{HEURÍSTICA PROPOSTA}

A heurística proposta é derivada do Kernel search, uma heurística baseada em programação matemática que foi inicialmente desenvolvida para resolver um problema de mochila multidimensional (Angelelli, Mansini e Speranza (2010)). Segundo os autores, esta é uma heurística estável e facilmente adaptável para problemas lineares inteiros mistos em que as variáveis inteiras são binárias , o que levou à escolha desta heurística para buscar soluções para o problema.

O método consiste, basicamente, em classificar as variáveis de decisão e identificar um conjunto de variáveis promissoras, chamado de núcleo (kernel). As demais variáveis são divididas em subconjuntos chamados de buckets. A ideia da heurística consiste em resolver subproblemas restritos a conjuntos de variáveis, buscando soluções para estes subproblemas. Desta forma, primeiramente, se resolve o subproblema restrito somente às varáveis do kernel. A partir de sua resolução, são adicionadas variáveis promissoras ao kernel de acordo com a construção dos buckets. Então o subproblema resultante é resolvido. Todos os buckets construídos são avaliados e, por fim, o melhor resultado obtido pelo método é retornado.

A heurística Kernel search foi aplicada com sucesso para resolver diferentes problemas de otimização, tais como o problema de seleção de portfólios (Angelelli, Mansini e Speranza (2010)) e mais recentemente, o de localização de facilidades (Guastaroba e Speranza (2014)).

Frente aos bons resultados obtidos na literatura, neste trabalho propõe-se uma heurística Kernel search para resolução do problema de cross-docking estudado. Na Seção 5.1 descreve-se brevemente a ideia da heurística e, em seguida, o método desenvolvido é detalhado.

\subsection{Kernel search}

O Kernel search é construído, essencialmente, com base na relaxação linear do problema original (Angelelli, Mansini e Speranza (2010)). O método consiste em ordenar as variáveis do problema priorizando as variáveis consideradas promissoras (a partir da solução obtida na 
solução do problema relaxado). São resolvidos subproblemas restritos a conjuntos de variáveis promissoras e, a cada passo, adicionam-se novas variáveis até que todas as variáveis do problema original sejam verificadas.

O Algoritmo 1 apresenta a estrutura básica do método Kernel search, adaptada de Angelelli, Mansini e Speranza (2010). Os Passos 1-6 são chamados de fase de inicialização, pois é nesta fase que o kernel e os buckets são definidos. Basicamente, resolve-se a relaxação linear do problema original (Passo 2) e, a partir de uma solução ótima, as $N$ variáveis binárias do problema são ordenadas de acordo com um critério de ordenação específico (Passo 3). Constrói-se, então, um núcleo inicial $\Lambda$ com as $N K$ primeiras variáveis da ordenação (Passo 4). As demais variáveis são distribuídas em subconjuntos $B_{i}$ (buckets), que podem ou não ter a mesma cardinalidade (Passo 5). Por fim, o subproblema inteiro misto restrito às variáveis pertencentes ao conjunto $\Lambda$ é resolvido e sua solução armazenada (Passo 6).

A próxima fase, representada pelos Passos 7-15, é chamada de fase de extensão. Nesta fase, para cada bucket $B_{i}$ é construído um kernel temporário definido pela união do kernel original com o bucket: $\Lambda_{i}=\Lambda \cup B_{i}$ (Passo 9). Resolve-se, então, o subproblema inteiro restrito às variáveis do kernel temporário adicionando duas restrições: I) o valor da melhor solução encontrada até o momento é um limitante para o subproblema atual, e II) impõe-se que pelo menos uma das variáveis de $B_{i}$ deve ser incluída numa nova solução (Passo 10).

Caso o subproblema encontre uma solução factível, o kernel original $\Lambda$ deve ser atualizado, recebendo todas as variáveis do bucket atual $\left(B_{i}\right)$ que tiveram valor um na solução atual (Passos 11-13). Caso o subproblema não encontre uma solução viável no tempo limite ou seja infactível, o bucket atual é adicionado ao kernel. A etapa de extensão é repetida para todos os subconjuntos $B_{i}$.

\subsection{Kernel search para o problema estudado}

Para o problema de cross-docking estudado, temos 4 conjuntos de variáveis binárias, representadas por:

- $\chi=\left\{x_{i k t}^{e} \mid f \in F, i \in I, k \in K, t \in T\right\}$, em que $x_{i k t}^{e}$ assume o valor 1 se o produto $i$ da entrega $f$ tem descarregamento iniciato no instante $t$ no cross-dock $k$ e, zero caso contrário;

- $=\left\{y_{i k t}^{c} \mid c \in C, i \in I, k \in K, t \in T\right\}$, em que $y_{i k t}^{c}$ assume o valor 1 se o produto $i$ da coleta $c$ tem carregamento iniciado no instante $t$ no cross-dock $k$ e, zero caso contrário;

- $\Delta=\left\{\delta^{c} \mid c \in C\right\}$, em que $\delta^{c}$ assume o valor 1 se a janela de tempo desejável da coleta $c$ é atendida e zero, caso contrário;

- $\zeta=\left\{z_{k k^{\prime} t} \mid k \in K, k^{\prime} \neq k \in K, t \in T\right\}$, em que $z_{k k^{\prime} t}$ assume o valor 1 se há transferência de produtos do cross-dock $k$ para $k^{\prime}$ no período $t$ e zero, caso contrário.

Para adaptar a heurística Kernel search a outros problemas é necessário definir dois 


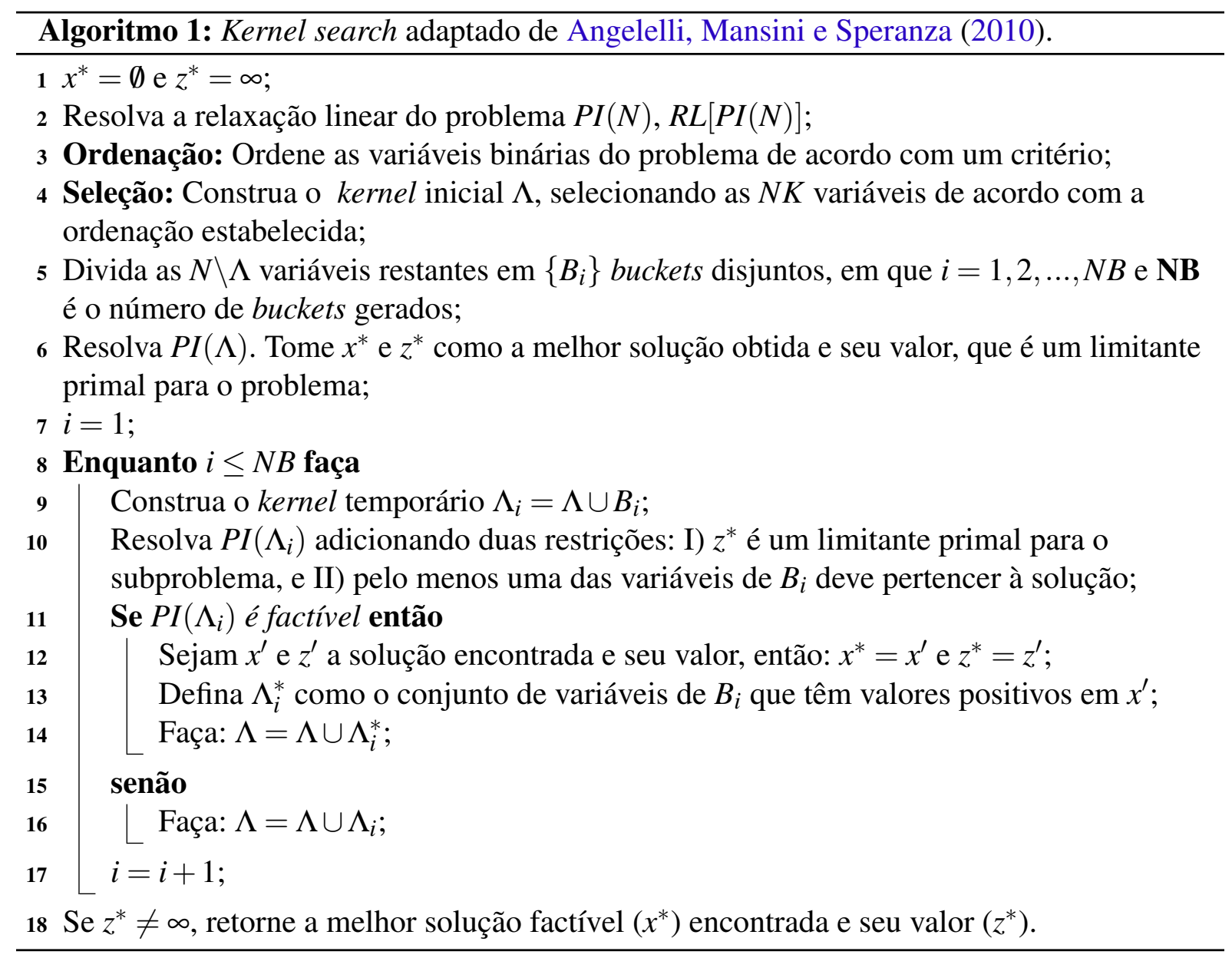

aspectos: I) o critério de ordenação das variáveis; e II) como construir o kernel inicial e os buckets, ou seja, definir a quantidade de variáveis a constituí-los e o número de subconjuntos.

As variáveis ordenadas são apenas as variáveis dos conjuntos $\chi$ e $\Upsilon$, uma vez que as variáveis de transferência (conjunto $\zeta$ ) são fortemente dependentes das entregas e das coletas realizadas nos cross-docks, ou seja, das variáveis $x_{i k t}^{e}$ e $y_{i k t}^{c}$. Desta forma, no critério de ordenação utilizado, as variáveis $x_{i k t}^{e}$ e $y_{i k t}^{c}$ têm prioridade na construção do kernel. As variáveis de transferência são, então, selecionadas para compor o kernel e os buckets a partir das variáveis previamente selecionadas de $\chi$ e $\Upsilon$. Como a quantidade de variáveis $\delta^{c}$ é razoavelmente pequena (cardinalidade igual à quantidade de coletas $C$ ) todas são adicionadas ao kernel.

\subsubsection{Critério de ordenação das variáveis}

Quanto ao critério de ordenação das variáveis e tendo em mãos o resultado obtido na relaxação linear do problema, foram analisadas duas opções:

Estratégia de ordenação $1\left(O_{c r}\right)$ : as variáveis $x_{i k t}^{e}$ e $y_{i k t}^{c}$ são ordenadas, primeiramente, de acordo com seus valores na solução do problema relaxado, em ordem não-crescente. No caso em que as variáveis sejam iguais a um, elas são ordenadas de acordo com o valor de seu custo relativo na solução atual, dando preferência às variáveis com menor custo relativo. Caso existam 
duas ou mais variáveis com custo relativo igual, utiliza-se como critério de desempate seu custo na função objetivo, pois o objetivo é minimizar os custos da solução, logo variáveis com custo mais baixo têm preferência. Em seguida, ordenam-se as variáveis básicas (com valor menor que um e maior que zero) de acordo com o valor de seu custo na função objetivo. Por fim, são ordenadas as variáveis com valor nulo e, neste caso, o critério de ordenação utilizado é o mesmo das variáveis com valor um.

A Figura 10 ilustra um conjunto de variáveis para as quais são reportados os custos na função objetivo, o valor e o custo relativo na solução ótima do problema relaxado. Na Figura 11 são apresentados os passos (E1 e E2) para a ordenação $O_{c r}$. Como descrito, primeiramente se ordena pelos valores na solução (E1). Desta forma, em amarelo ficaram as variáveis com valor 1 ( $q 7$ e $q 9$ ), em rosa as variáveis com valores entre 0 e 1 ( $q 1, q 2$ e $q 8)$, e em azul as variáveis com valor $0(q 3, q 4, q 5, q 6, q 10$ e $q 11)$. As variáveis destacadas em negrito possuem mesmo valor na solução, o que leva a próxima etapa de ordenação (E2), em que as variáveis com valores iguais a 1 e 0 são ordenadas de acordo com seu custo relativo e as variáveis com valores entre 1 e 0 são ordenadas de acordo com seu custo na função objetivo. As variáveis em negrito são as que empatam quanto ao valor do custo relativo, sendo necessário ordená-las pelo terceiro critério, que é o custo na função objetivo. Assim, o resultado da ordenação é representado pelo vetor $O_{c r}=\{q 9, q 7, q 1, q 2, q 8, q 5, q 6, q 11, q 10, q 3, q 4\}$.

Figura 10 - Dados do exemplo para a ordenação .

\begin{tabular}{|c|c|c|c|c|c|c|c|c|c|c|c|}
\hline $\begin{array}{c}\text { Nome da } \\
\text { variável }\end{array}$ & $\mathbf{q 1}$ & $\mathbf{q} 2$ & $\mathbf{q} 3$ & $\mathbf{q 4}$ & $\mathbf{q} 5$ & $\mathbf{q 6}$ & $\mathbf{q 7}$ & $\mathbf{q} 8$ & $\mathbf{q 9}$ & $\mathbf{q 1 0}$ & $\mathbf{q 1 1}$ \\
\hline $\begin{array}{c}\text { Custo na f.o. } \\
5320,00\end{array}$ & 5320,00 & 19110,20 & 19110,20 & 1064,00 & 1064,00 & 3420,00 & 1915,20 & 1064,00 & 10358,80 & 1900,00 \\
\hline $\begin{array}{c}\text { Valor na } \\
\text { soluçäo }\end{array}$ & 0,40 & 0,40 & 0,00 & 0,00 & 0,00 & 0,00 & 1,00 & 0,29 & 1,00 & 0,00 & 0,00 \\
\hline $\begin{array}{c}\text { Custo } \\
\text { relativo }\end{array}$ & 0,00 & 0,00 & 13752,20 & 13752,20 & 0,00 & 0,00 & 0,00 & 0,00 & 0,00 & 5042,17 & 844,80 \\
\hline
\end{tabular}

Fonte: própria.

Figura 11 - Exemplo para a ordenação $O_{c r}$.

\begin{tabular}{|c|c|c|c|c|c|c|c|c|c|c|}
\hline q7 & q9 & $q 1$ & q2 & q8 & q3 & $q 4$ & $q 5$ & $q 6$ & $q 10$ & q11 \\
\hline q7 & q9 & $q 1$ & q2 & q8 & $q 5$ & $q 6$ & $q 11$ & $q 10$ & q3 & q4 \\
\hline q9 & q7 & $q 1$ & $\mathrm{q} 2$ & q8 & q5 & $\overline{q 6}$ & $\overline{q 11}$ & $q 10$ & $\overline{q 3}$ & q4 \\
\hline
\end{tabular}

Fonte: própria.

Estratégia de ordenação $2\left(O_{f o}\right)$ : as variáveis $x_{i k t}^{e}$ e $y_{i k t}^{c}$ são ordenadas, primeiramente, de acordo com seus valores na solução do problema relaxado, em ordem não-crescente. Caso existam duas ou mais variáveis com valor igual, elas são ordenadas de acordo com o valor de seu custo na função objetivo da solução atual, de forma que variáveis com custo mais baixo têm 
preferência. Utilizamos como critério de desempate o valor do custo relativo na solução atual, dando preferência às variáveis com menor custo relativo.

A Figura 12 ilustra os passos da estratégia de ordenação $O_{f o}$ para o exemplo da Figura 10. Como descrito, primeiramente se ordena pelos valores na solução (E1). As variáveis que possuem mesmo valor na solução são destacadas em negrito o que leva a próxima etapa (E2), em que as variáveis são ordenadas de acordo com seu custo na fução objetivo. As variáveis em negrito são as que empatam quanto ao valor do custo na função objetivo, sendo necessário ordená-las pelo terceiro critério, que é o custo relativo. Assim, o resultado da ordenação é representado pelo vetor $O_{f o}=\{q 9, q 7, q 1, q 2, q 8, q 5, q 6, q 11, q 10, q 3, q 4\}$.

Figura 12 - Exemplo para a ordenação $O_{f_{o}}$.

\begin{tabular}{|c|c|c|c|c|c|c|c|c|c|c|}
\hline q7 & q9 & q1 & q2 & q8 & q3 & q4 & q5 & $q 6$ & $q 10$ & q11 \\
\hline q9 & $\mathrm{q} 7$ & q1 & q2 & q8 & q5 & q6 & q11 & $q 10$ & $q^{3}$ & q4 \\
\hline q9 & $q^{7}$ & $q 1$ & q2 & q8 & $q^{5}$ & $q 6$ & $q 11$ & $q 10$ & $q^{3}$ & $\overline{q 4}$ \\
\hline
\end{tabular}

Fonte: própria.

\subsubsection{Seleção de variáveis para a construção do kernel inicial e dos buckets}

O número de variáveis do kernel inicial foi definido com o auxílio de testes computacionais realizados para instâncias de pequena dimensão e considerando que o tempo de execução do método é limitado a 10min. Ele é dado por:

$T K=\min \{40 \%$ das variáveis pertencentes aos conjuntos $\chi$ e/ou $\Upsilon, 1800\}$.

Estes valores foram definidos através da análise das soluções encontradas com o problema restrito ao kernel inicial com tempo máximo de $5 \mathrm{~min}$. Notou-se que subproblemas com até $40 \%$ das variáveis resultavam em soluções ótimas ou com uma diferença média com relação à solução do CPLEX (com 30min de execução) de 0,24\%. Outro fator analisado foi a dimensão dos problemas para a qual o software encontrava a solução ótima para as instâncias pequenas e o tamanho encontrado foi de cerca de 1800 variáveis (considerando-se somente as variáveis dos conjuntos $\chi$ e $\Upsilon$ ).

Para a execução do método foi necessário definir o tempo de execução do primeiro subproblema (somente com o kernel inicial). A Figura 13 apresenta o gráfico com as soluções para as instâncias de pequena dimensão (eixo vertical) encontradas para o subproblema contendo somente o kernel inicial com tempo de execução máximo de 60s, 120s, 180s, 240s, 300s 
e 600s (eixo horizontal). Nota-se que a partir de 180s a qualidade da solução obtida não melhora significativemente. Assim, o tempo máximo de execução estabelecido para o primeiro subproblema foi de 180 s, ou seja, $30 \%$ do tempo total da heurística (10min).

Figura 13 - Gráfico solução x tempo para o kernel inicial de problemas de pequena dimensão.

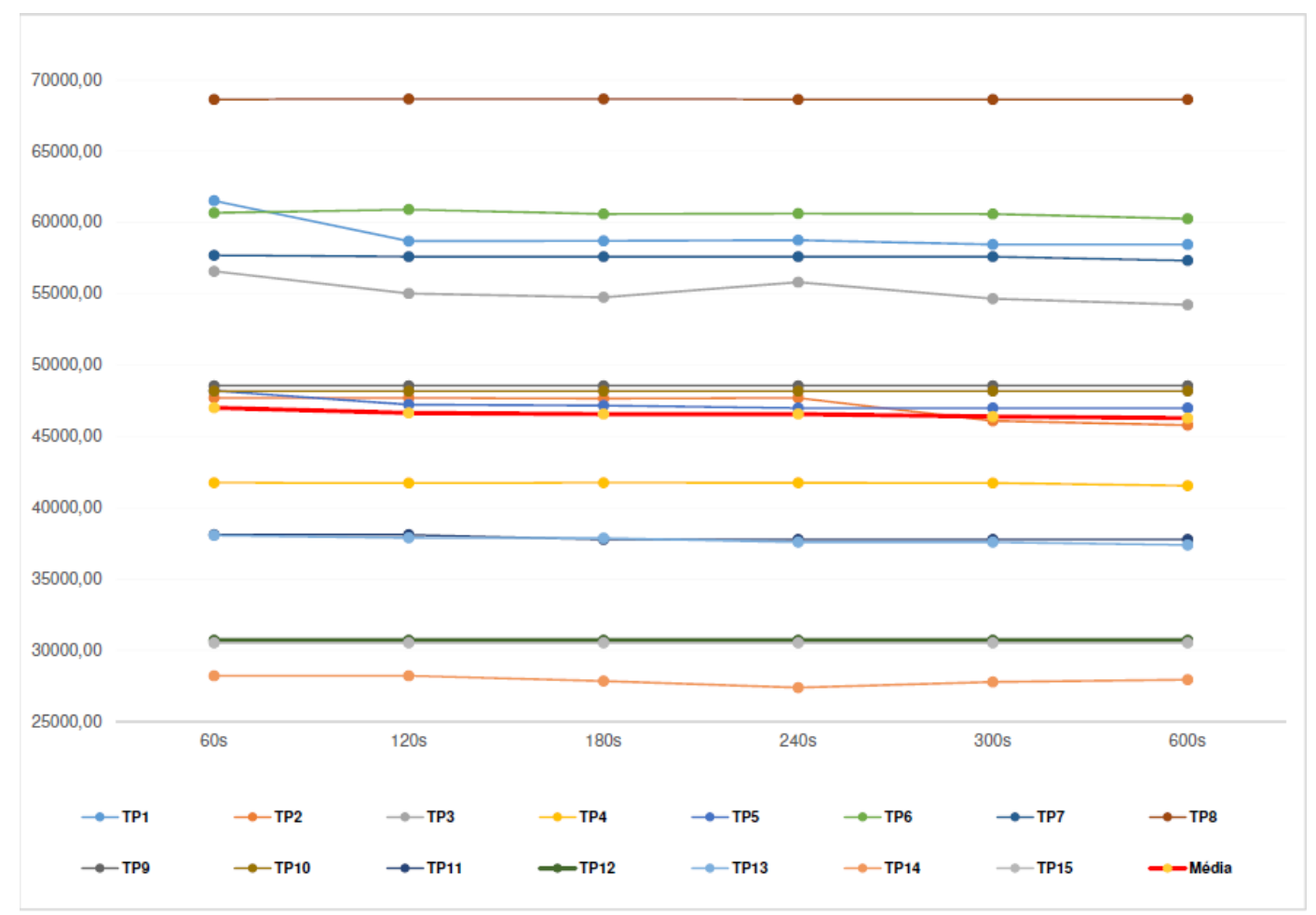

Fonte: própria.

O conjunto $\widehat{\chi}$ representa as variáveis de $\chi$ selecionadas na criação do kernel inicial, enquanto $\widehat{\Upsilon}$ representa as variáveis de $\Upsilon$ que compõem o kernel inicial. A partir dos conjuntos $\widehat{\chi}$ e $\widehat{\Upsilon}$ que compõem o kernel é criado um conjunto $\Phi$ de cross-docks, que corresponde a todos os cross-docks $k$ relacionados às variáveis destes conjuntos. Por exemplo, se uma variável $x_{i 2 t}^{e}$ é adicionada ao kernel inicial, então o cross-dock 2 é incluído no conjunto $\Phi$. Analogamente, se uma variável $y_{i 6 t}^{c}$ é adicionada ao kernel inicial, então o cross-dock 6 é incluído no conjunto $\Phi$.

Para a construção do kernel e seleção de variáveis para construir cada um dos buckets, foram analisadas 3 estratégias de seleção de variáveis:

Seleção $1\left(S_{x y}\right)$ : são selecionadas todas as variáveis $x_{i k t}^{e}$ e $y_{i k t}^{c}$ com valores maiores que zero. Caso o total de variáveis seja inferior a $T K$, complementa-se o conjunto seguindo a ordenação escolhida. A partir do conjunto $\Phi$ de cross-docks, as variáveis $z_{k k^{\prime} t}$ correspondentes a esses cross-docks também são adicionadas ao kernel inicial.

Mais especificamente, a princípio constroem-se dois sub-núcleos, um para as variáveis do conjunto $\chi$ e outro para as variáveis do conjunto $\Upsilon$. O núcleo de $\chi$ é composto por todas as variáveis com valor positivo na relaxação linear e, caso a quantidade de variáveis seja inferior a $T K=\min \{40 \%$ das variáveis pertencentes a $\chi, 1800 *$ porcentagem de variáveis de $\chi\}$ 
são adicionadas as variáveis seguindo a ordenação previamente realizada até que se obtenha tal dimensão. Analogamente, para o núcleo de $\Upsilon$ entrarão todas as variáveis com solução da relaxação linear estritamente positiva e, caso a quantidade de variáveis seja inferior a $T K=$ $\min \{40 \%$ das variáveis pertencentes ao conjunto $\Upsilon, 1800 *$ porcentagem de variáveis de $\Upsilon\}$ são adicionadas as variáveis seguindo a ordenação até que se obtenha tal dimensão. Desta forma, unindo os dois sub-núcleos, obtém-se um núcleo com variáveis de $\chi$ e de $\Upsilon$.

Seleção $2\left(S_{x}\right)$ : são selecionadas todas as variáveis $x_{i k t}^{e}$ com valores maiores que zero. Deseja-se que o kernel tenha pelo menos $T K$ variáveis, então caso esta quantidade de variáveis não seja atingida, complementa-se o kernel seguindo a ordenação escolhida. A partir do conjunto de variáveis $\widehat{\chi}$, as variáveis do conjunto $\Upsilon$ correspondentes a essas variáveis também passam a compor o kernel. Além disso, as variáveis $z_{k k^{\prime} t}$ correspondentes aos cross-docks pertencentes ao conjunto $\Phi$ de cross-docks selecionados através das variáveis selecionadas $x_{i k t}^{e}$ também são selecionadas para compor o kernel inicial.

Nesta estratégia $S_{x}$ são adicionadas ao kernel todas as variáveis de $\chi$ com solução da relaxação linear maior que zero. Em seguida, as variáveis de $\Upsilon$ correspondentes às variáveis pertencentes ao kernel são adicionadas, ou seja, caso uma variável de $\chi \operatorname{com} i=\widehat{i}, k=\widehat{k} \mathrm{e} t=\widehat{t}$ esteja no kernel, todas as variáveis de $\Upsilon \operatorname{com} i=\widehat{i}, k=\widehat{k}$ e $t \geq \widehat{t}$ também estarão no kernel. Caso a dimensão do núcleo até então criado seja inferior a $T K$, adicionam-se uma a uma as variáveis $x_{i k t}^{e}$ de acordo com a ordenação e suas respectivas variáveis do conjunto $\Upsilon$ até que tal dimensão seja atingida.

Seleção $3\left(S_{y}\right)$ : análoga à seleção $S_{x}$, porém a prioridade de seleção deixa de ser das variáveis do conjunto $\chi$ e passa a ser das variáveis do conjunto $\Upsilon$, ou seja, são adicionadas ao kernel todas as variáveis de $\Upsilon$ com solução da relaxação linear maior que zero. Adicionam-se as variáveis de $\Upsilon$ correspondentes às variáveis pertencentes ao conjunto $\widehat{\Upsilon}$. Desta forma, se uma variável $y_{\widehat{i} k \hat{t}}^{c}$ estiver no kernel, as variáveis $\left\{x_{\widehat{i} k t}^{e} \mid t \leq \widehat{t}, e \in E\right\}$ também estarão no kernel. Caso a dimensão do núcleo até então criado seja inferior a $T K$, adicionam-se uma a uma as variáveis $y_{i k t}^{c}$ da ordenação e todas as suas respectivas variáveis do conjunto $\chi$ até que tal dimensão seja atingida.

Para a construção dos buckets, as variáveis restantes são divididas em subconjuntos de tamanho fixo, totalizando $N B$ buckets. O número de buckets foi definido a partir de testes preliminares e é dado por $\frac{\left(N_{x}-N_{k x}\right)+\left(N_{y}-N_{k y}\right)}{T B}$. Desta forma, o tamanho dos buckets é dado por:

$T B=\max \left\{10 \%\right.$ das variáveis pertencentes aos conjuntos $\chi$ e/ou $\left.\Upsilon ; 180 ; \frac{\left(N_{x}-N_{k x}\right)+\left(N_{y}-N_{k y}\right)}{\frac{\text { tempo restante }}{30}}\right\}$,

em que $N_{x}$ é a cardinalidade do conjunto de variáveis $\chi$ e $N_{y}$ é a cardinalidade do conjunto $\Upsilon$. $N_{k x}$ e $N_{k y}$ representam a quantidade de variáveis do cojunto $\widehat{\chi}$ e do conjunto $\widehat{\Upsilon}$, respectivamente, selecionadas para compor o kernel inicial. Para definir a fórmula acima foram realizados testes computacionais com as instâncias utilizadas para definir a cardinalidade do kernel inicial. Para 
que os subproblemas não crescessem de forma repentina, utilizou-se um percentual de variáveis, assim como na construção do núcleo. Assim, estabeleceram-se os valores de $10 \%$ e 180 variáveis (uma vez que 180 representa $10 \%$ das 1800 variáveis que podem pertencer ao kernel). O outro fator da fórmula determina uma quantidade de variáveis para cada bucket de forma que ao adicionar cada um dos buckets haja, pelo menos, 30s para buscar soluções para o subproblema criado $\left(\frac{\left(N_{x}-N_{k x}\right)+\left(N_{y}-N_{k y}\right)}{\frac{\text { tempo restante }}{30}}\right)$.

Para a seleção das variáveis dos buckets, seguiu-se a ordenação utilizada após se extrair as variáveis do kernel inicial, selecionando $T B$ variáveis para cada buckets a menos do último, que pode ter menos variáveis.

\subsubsection{Melhorias propostas}

Com o objetivo de buscar soluções de melhor qualidade, buscou-se analisar estratégias de adaptação para o kernel search. Foram exploradas duas estratégias:

Adaptação $1\left(A_{k}\right)$ : consiste em tentar garantir que o núcleo não tenha uma dimensão muito grande com o desenvolvimento do método (que não fique com a cardinalidade muito próxima da cardinalidade do problema original). Desta forma, quando o subproblema utilizando o bucket atual possui solução infactível ou não encontra solução no tempo limite estabelecido para o subproblema, este subconjunto se une ao próximo, ou seja, o novo subproblema tem um bucket maior, porém o bucket que não retornou um resultado significativo não é adicionado ao kernel, é apenas unido ao próximo bucket.

Assim, estratégia $A_{k}$ consiste em: se a união do bucket 3 ao kernel não retorna uma solução factível, então na próxima etapa serão adicionados os buckets 3 e 4 ao kernel como se a etapa anterior não tivesse ocorrido, ou seja, o bucket atual será composto por dois buckets e terá o dobro da dimensão original.

Adaptação $2\left(A_{b}\right)$ : consiste em tornar menos restritivo um problema ao inserir cada novo bucket, buscando encontrar soluções factíveis para mais subproblemas. Para muitos subproblemas não se encontram soluções factíveis no tempo limite estabelecido ou o subproblema é infactível devido à imposição da restrição (II) adicionada no Passo 10 do Algoritmo 1. Então, o que se faz nesta nova estratégia é não inserir tal restrição no próximo subproblema sempre que a solução atual for infactível ou que não se encontre solução.

Assim, estratégia $A_{b}$ consiste em: se a união do bucket $B_{i}$ ao kernel não retorna uma solução factível, na próxima etapa ao unir o bucket $B_{i+1}$ ao kernel, o novo subproblema não terá a imposição de que pelo menos uma das variáveis do novo bucket adicionado deve estar na nova solução.

No Capítulo 6 são apresentados testes computacionais realizados para avaliar a heurística desenvolvida. 


\section{ANÁLISE DA HEURÍSTICA}

Como destacado anteriormente, uma heurística Kernel search está baseada na escolha das variáveis que compõem o kernel e os buckets. No Capítulo 5 foram propostas duas estratégias de ordenação das variáveis dos conjuntos $\chi$ e $\Upsilon$, três estratégias de seleção de variáveis para a construção do kernel e dos buckets, e duas estratégias de adaptação do Kernel search, com o objetivo de buscar soluções de melhor qualidade. Logo, na primeira etapa dos testes computacionais descrita na Seção 6.1, foram avaliadas as combinações destas estratégias. Uma vez apontada a melhor configuração, na Seção 6.2, foram realizados testes para todas as instâncias geradas na Seção 4.1.

As estratégias descritas na Seção 5.2 foram combinadas em busca da melhor configuração para a heurística Kernel search proposta. Como as estratégias de adaptação surgiram como tentativas de melhoria para as estratégias até então desenvolvidas, as combinações foram divididas em 3 fases:

Fase 1: consiste em combinar as estratégias de seleção $S_{x y}, S_{x}$ e $S_{y}$ às duas estratégias de ordenação apresentadas $\left(O_{c r}\right.$ e $\left.O_{f o}\right)$;

Fase 2: agrega às combinações da Fase 1 a estratégia de adaptação $A_{k}$; e

Fase 3: agrega às combinações da Fase 1 a estratégia de adaptação $A_{b}$.

Assim, a heurística Kernel search desenvolvida é chamada $K S_{S, O, A}$, por exemplo, $K S_{x y, c r}$ é a heurística Kernel search considerando a estratégia de seleção $S_{x y}$ e a de ordenação $O_{c r}$. Outro exemplo seria $K S_{x, f o, k}$, que representa a heurística Kernel search considerando a estratégia de seleção $S_{x}$, a estratégia de ordenação $O_{f o}$ e a estratégia de adaptação $A_{k}$. 


\subsection{Parametrização}

Utilizando-se as definições da Seção 5.2 para ordenação e construção do kernel e dos buckets foram testadas as combinações de estratégias das 3 fases apresentadas.

A análise de cada fase foi realizada a partir da estratégia de seleção utilizada. O desempenho destas variações da heurística foi avaliado utilizando as mesmas 10 instâncias de calibração do Capítulo 4, ou seja, as 10 com maiores GAPs das 15 instâncias (5 de cada um dos 3 cenários existentes) inicialmente selecionadas, como descrito na Seção 4.3.

As Tabelas 24-36 resumem os resultados obtidos pela heurística kernel search durante sua parametrização tendo como tempo de execução máximo $10 \mathrm{~min}$. Sol representa a melhor solução encontrada no tempo $T i$ (dado em segundos) e o fator $D \_30$, dado por $D \_30=100 \frac{\text { Sol.KS-Sol.MPJT }}{\text { Sol.MPJT }}$, que representa a diferença percentual entre a solução encontrada pelo CPLEX no tempo limite de 30min (Tabela 6) e a solução encontrada pela heurística no tempo limite de $10 \mathrm{~min}$ e é dado em porcentagem. As melhores diferenças percentuais para cada variação são destacadas em negrito, assim como a melhor média para cada variação de construção do kernel inicial.

Nas Tabelas 24-26 são exibidos os resultados das seis combinações da Fase 1. A Tabela 24 resume os resultados obtidos para estratégia de seleção de variáveis $S_{x y}$ combinada às duas estratégias de ordenação propostas. Para 7 das 10 instâncias a combinação $K S_{x y, c r}$ apresentou soluções de melhor qualidade com diferença percentual média com relação à solução encontrada pelo CPLEX em 30 min de $10,94 \%$, ou seja, 4,51\% melhor que $K S_{x y, f o}$.

Tabela 24 - Resultados dos testes da combinação da estratégia $S_{x y}$ com as estratégias $O_{c r}$ e $O_{f o}$ para o kernel search com até $10 \mathrm{~min}$ de execução.

\begin{tabular}{|c|c|c|c|c|c|c|c|c|}
\hline & \multicolumn{2}{|c|}{ CPLEX } & \multicolumn{3}{|c|}{$K S_{x y, c r}$} & \multicolumn{3}{|c|}{$K S_{x y, f_{o}}$} \\
\hline & Sol & $\mathbf{T i}$ & Sol & $\mathbf{T i}$ & D_30 & Sol & $\mathbf{T i}$ & D_30 \\
\hline$(24,3,5,10,10) \_1$ & 74630 & 1804 & 77287 & 607 & 3,56 & 101301 & 609 & 35,74 \\
\hline$(24,3,5,10,10) \_2$ & 48361 & 1808 & 48733 & 608 & 0,77 & 57029 & 611 & 17,92 \\
\hline$(24,3,5,10,10) \_3$ & 58138 & 1806 & 60632 & 610 & 4,29 & 63651 & 606 & 9,48 \\
\hline$(24,3,5,10,10) \_4$ & 46981 & 1806 & 48489 & 610 & 3,21 & 51932 & 608 & 10,54 \\
\hline$(24,3,5,10,10) \_5$ & 51170 & 1809 & 51928 & 608 & 1,48 & 54613 & 610 & 6,73 \\
\hline$(24,3,5,5,20) \_1$ & 77368 & 1808 & 81107 & 613 & 4,83 & 93839 & 602 & 21,29 \\
\hline$(24,3,5,20,5) \_1$ & 41239 & 1804 & 44188 & 603 & 7,15 & 49250 & 612 & 19,43 \\
\hline$(24,3,5,20,5) \_3$ & 49700 & 1808 & 60953 & 607 & 22,64 & 55398 & 604 & 11,46 \\
\hline$(24,3,5,20,5) \_4$ & 29613 & 1809 & 37121 & 609 & 25,35 & 34777 & 605 & 17,44 \\
\hline$(24,3,5,20,5) \_5$ & 34299 & 1805 & 46701 & 603 & 36,16 & 35818 & 604 & 4,43 \\
\hline Média & & & & & 10,94 & & & 15,45 \\
\hline
\end{tabular}

Fonte: própria.

Na Tabela 25 os resultados apresentados mostram que para 7 instâncias a combinação $K S_{x, f o}$ apresentou as melhores soluções e a diferença percentual média com relação ao CPLEX 
é de $14,32 \%$.

Tabela 25 - Resultados dos testes da combinação da estratégia $S_{x}$ com as estratégias $O_{c r}$ e $O_{f o}$ para o kernel search com até 10min de execução.

\begin{tabular}{|c|c|c|c|c|c|c|}
\hline & \multicolumn{3}{|c|}{$K S_{x, c r}$} & \multicolumn{3}{|c|}{$K S_{x, f o}$} \\
\hline & Sol & $\mathbf{T i}$ & D_30 & Sol & $\mathbf{T i}$ & D_30 \\
\hline$(24,3,5,10,10) \_1$ & 89482 & 604 & 19,90 & 88957 & 603 & 19,20 \\
\hline$(24,3,5,10,10) \_2$ & 54405 & 605 & 12,50 & 49632 & 603 & 2,63 \\
\hline$(24,3,5,10,10) \_3$ & 87199 & 604 & 49,99 & 68864 & 604 & 18,45 \\
\hline$(24,3,5,10,10) \_4$ & 53292 & 612 & 13,43 & 53145 & 605 & 13,12 \\
\hline$(24,3,5,10,10) \_5$ & 57323 & 611 & 12,02 & 58848 & 608 & 15,00 \\
\hline$(24,3,5,5,20) \_1$ & 80093 & 604 & 3,52 & 81757 & 605 & 5,67 \\
\hline$(24,3,5,20,5) \_1$ & 46008 & 605 & 11,56 & 44189 & 611 & 7,15 \\
\hline$(24,3,5,20,5) \_3$ & 60505 & 606 & 21,74 & 53529 & 605 & $\mathbf{7 , 7 0}$ \\
\hline$(24,3,5,20,5) \_4$ & 37741 & 612 & 27,45 & 34362 & 606 & 16,04 \\
\hline$(24,3,5,20,5) \_5$ & 46521 & 604 & 35,63 & 47426 & 605 & 38,27 \\
\hline Média & & & 20,78 & & & 14,32 \\
\hline
\end{tabular}

Fonte: própria.

Os resultados da Tabela 26 mostram que para 9 das 10 instâncias $K S_{y, c r}$ apresentou melhores resultados que $K S_{y, f_{o}}$ e a diferença percentual média é de $12,87 \%$. Vale destacar que para uma das instâncias a solução média encontrada pelo Kernel search em 10min é melhor que a encontrada pelo CPLEX em 30min $(-0,43 \%)$.

Tabela 26 - Resultados dos testes da combinação da estratégia $S_{y}$ com as estratégias $O_{c r}$ e $O_{f o}$ para o kernel search com até 10min de execução.

\begin{tabular}{|c|c|c|c|c|c|c|}
\hline & \multicolumn{3}{|c|}{$K S_{y, c r}$} & \multicolumn{3}{|c|}{$K S_{y, f o}$} \\
\hline & Sol & $\mathbf{T i}$ & D_30 & Sol & $\mathbf{T i}$ & D_30 \\
\hline$(24,3,5,10,10) \_1$ & 107522 & 605 & 44,07 & 107522 & 604 & 44,07 \\
\hline$(24,3,5,10,10) \_2$ & 50740 & 417 & 4,92 & 56014 & 610 & 15,82 \\
\hline$(24,3,5,10,10) \_3$ & 71569 & 370 & 23,10 & 68294 & 604 & 17,47 \\
\hline$(24,3,5,10,10) \_4$ & 53847 & 501 & 14,61 & 53847 & 605 & 14,61 \\
\hline$(24,3,5,10,10) \_5$ & 56529 & 417 & 10,47 & 60261 & 604 & 17,77 \\
\hline$(24,3,5,5,20) \_1$ & 80928 & 613 & 4,60 & 95251 & 605 & 23,11 \\
\hline$(24,3,5,20,5) \_1$ & 43360 & 512 & 5,14 & 48462 & 605 & 17,51 \\
\hline$(24,3,5,20,5) \_3$ & 49487 & 459 & $-0,43$ & 62966 & 606 & 26,69 \\
\hline$(24,3,5,20,5) \_4$ & 35424 & 409 & 19,62 & 43132 & 605 & 45,65 \\
\hline$(24,3,5,20,5) \_5$ & 35195 & 473 & 2,61 & 42027 & 605 & 22,53 \\
\hline Média & & & 12,8 & & & 24,53 \\
\hline
\end{tabular}

Fonte: própria.

As diferenças percentuais médias encontradas foram de, no mínimo, 10,94\%, o que motivou a busca por estratégias de adaptação para o kernel search. Os resultados mostraram que para duas das 3 estratégias de seleção a melhor combinação é com a ordenação $O_{c r}$, ou seja, quando há prioridade em se ordenar pelo custo reduzido. 
As Tabelas 27-29 exibem resultados obtidos pelo método com tempo máximo de 10min para as seis variações iniciais (da Fase 1) aliadas à estratégia de adaptação $A_{k}$, já descrita (Fase 2).

Na Tabela 27 os resultados mostram que a configuração $K S_{x y, c r, k}$ é a melhor, com 10 soluções melhores que $K S_{x y, f o, k}$ e encontrando soluções melhores que o CPLEX em 30min para 2 instâncias. A redução da diferença percentual quando comparada à melhor combinação encontrada para esta estratégia de seleção de variáveis sem o uso da estratégia de adaptação $\left(K S_{x y, c r}\right)$ é de $7,37 \%$.

Tabela 27 - Resultados obtidos pelo kernel search para a combinação das estratégias $K S_{x y, c r}$ e $K S_{x y, f o}$ à estratégia de adaptação $A_{k}$ com tempo máximo de execução do método de $10 \mathrm{~min}$.

\begin{tabular}{|c|c|c|c|c|c|c|}
\hline & \multicolumn{3}{|c|}{$K S_{x y, c r, k}$} & \multicolumn{3}{|c|}{$K S_{x y, f o, k}$} \\
\hline & Sol & $\mathbf{T i}$ & D_30 & Sol & $\mathbf{T i}$ & D_30 \\
\hline$(24,3,5,10,10) \_1$ & 77287 & 607 & 3,56 & 101301 & 608 & 35,74 \\
\hline$(24,3,5,10,10) \_2$ & 48326 & 578 & $-0,07$ & 54982 & 609 & 13,69 \\
\hline$(24,3,5,10,10) \_3$ & 60632 & 602 & 4,29 & 72437 & 610 & 24,59 \\
\hline$(24,3,5,10,10) \_4$ & 49120 & 607 & 4,55 & 52152 & 605 & 11,01 \\
\hline$(24,3,5,10,10) \_5$ & 51266 & 528 & $\mathbf{0 , 1 9}$ & 58842 & 605 & 14,99 \\
\hline$(24,3,5,5,20) \_1$ & 81600 & 605 & 5,47 & 83327 & 590 & 7,70 \\
\hline$(24,3,5,20,5) \_1$ & 41089 & 603 & $-0,36$ & 46966 & 603 & 13,89 \\
\hline$(24,3,5,20,5) \_3$ & 53245 & 449 & 7,13 & 63747 & 604 & 28,26 \\
\hline$(24,3,5,20,5) \_4$ & 31376 & 256 & 5,95 & 36928 & 604 & 24,70 \\
\hline$(24,3,5,20,5) \_5$ & 36001 & 421 & 4,96 & 36218 & 604 & 5,59 \\
\hline Média & & & 3,57 & & & 18,02 \\
\hline
\end{tabular}

Fonte: própria.

A Tabela 28 mostra que a combinação $K S_{x, f o, k}$ apresenta melhores soluções para 7 instâncias e a diferença percentual média encontrada também é inferior à encontrada pela melhor combinação definida sem a estratégia de adaptação $\left(K S_{x, f o}\right)$ com uma redução de $2,34 \%$.

Os resultados exibidos na Tabela 29 mostram que para 9 instâncias a combinação $K S_{y, c r, k}$ obtém melhores resultados, porém a combinação sem a estratégia de adaptação $\left(K S_{y, c r}\right)$ apresenta um ganho médio melhor, com uma diferença de $4,97 \%$ no valor da diferença percentual média com relação ao CPLEX.

A menor diferença percentual média passa a ser, então, de 3,57\%, o que representa uma redução média de $7,37 \%$. Estes testes reforçam que para duas das estratégias de seleção analisadas devem ser combinadas com a ordenação $O_{c r}$.

Outra estratégia de adaptação explorada é a $A_{b}$, descrita na Subseção 5.2.3. As Tabelas 30-32 exibem resultados da execução do kernel search com tempo até 10min das seis estratégias iniciais (Fase 1) aliadas a essa estratégia de adaptação (Fase 2).

A Tabela 30 mostra que, apesar de $K S_{x y, c r, b}$ apresentar melhores soluções para 6 instâncias 
Tabela 28 - Resultados obtidos pelo kernel search para a combinação das estratégias $K S_{x, c r}$ e $K S_{x, f o}$ à estratégia de adaptação $A_{k}$ com tempo máximo de execução do método de $10 \mathrm{~min}$.

\begin{tabular}{|c|c|c|c|c|c|c|}
\hline & \multicolumn{3}{|c|}{$K S_{x, c r, k}$} & \multicolumn{3}{|c|}{$K S_{x, f o, k}$} \\
\hline & Sol & $\mathbf{T i}$ & D_30 & Sol & $\mathbf{T i}$ & D_30 \\
\hline$(24,3,5,10,10) \_1$ & 89482 & 604 & 19,90 & 91495 & 603 & 22,60 \\
\hline$(24,3,5,10,10) \_2$ & 53570 & 604 & 10,77 & 49014 & 605 & 1,35 \\
\hline$(24,3,5,10,10) \_3$ & 87385 & 605 & 50,31 & 66377 & 602 & 14,17 \\
\hline$(24,3,5,10,10) \_4$ & 53346 & 604 & 13,55 & 49010 & 606 & 4,32 \\
\hline$(24,3,5,10,10) \_5$ & 57488 & 611 & 12,35 & 58782 & 605 & 14,88 \\
\hline$(24,3,5,5,20) \_1$ & 80093 & 604 & 3,52 & 79877 & 604 & 3,24 \\
\hline$(24,3,5,20,5) \_1$ & 46575 & 606 & 12,94 & 44066 & 603 & 6,86 \\
\hline$(24,3,5,20,5) \_3$ & 59915 & 612 & 20,55 & 53751 & 607 & 8,15 \\
\hline$(24,3,5,20,5) \_4$ & 37741 & 606 & 27,45 & 34569 & 604 & 16,74 \\
\hline$(24,3,5,20,5) \_5$ & 46521 & 605 & 35,63 & 43736 & 603 & 27,51 \\
\hline Média & & & 20,70 & & & 11,98 \\
\hline
\end{tabular}

Fonte: própria.

Tabela 29 - Resultados obtidos pelo kernel search para a combinação das estratégias $K S_{y, c r}$ e $K S_{y, f o}$ à estratégia de adaptação $A_{k}$ com tempo máximo de execução do método de 10 min.

\begin{tabular}{|c|c|c|c|c|c|c|}
\hline & \multicolumn{3}{|c|}{$K S_{y, c r, k}$} & \multicolumn{3}{|c|}{$K S_{y, f o, k}$} \\
\hline & Sol & $\mathbf{T i}$ & D_30 & Sol & Ti & D_30 \\
\hline$(24,3,5,10,10) \_1$ & 107522 & 604 & 44,07 & 107522 & 605 & 44,07 \\
\hline$(24,3,5,10,10) \_2$ & 50898 & 421 & 5,25 & 56014 & 611 & 15,82 \\
\hline$(24,3,5,10,10) \_3$ & 99225 & 370 & 70,67 & 69089 & 605 & 18,84 \\
\hline$(24,3,5,10,10) \_4$ & 53847 & 499 & 14,61 & 53847 & 606 & 14,61 \\
\hline$(24,3,5,10,10) \_5$ & 56400 & 417 & 10,22 & 59954 & 604 & 17,17 \\
\hline$(24,3,5,5,20) \_1$ & 81210 & 611 & 4,97 & 94999 & 605 & 22,79 \\
\hline$(24,3,5,20,5) \_1$ & 43749 & 512 & 6,09 & 48462 & 605 & 17,51 \\
\hline$(24,3,5,20,5) \_3$ & 49878 & 459 & 0,36 & 63220 & 605 & 27,20 \\
\hline$(24,3,5,20,5) \_4$ & 35424 & 409 & 19,62 & 42102 & 605 & 42,17 \\
\hline$(24,3,5,20,5) \_5$ & 35179 & 475 & 2,57 & 42027 & 605 & 22,53 \\
\hline ivicusa & & & 17,04 & & & 4,27 \\
\hline
\end{tabular}

Fonte: própria. 
testadas com relação a $K S_{x y, f o, b}$, a melhor combinação quando é realizada a seleção $S_{x y}$ é $K S_{x y, c r, k}$.

Tabela 30 - Resultados obtidos pelo kernel search para as configurações da Fase 1 para a seleção $S_{x y}$ combinadas à estratégia de adaptação $A_{b}$.

\begin{tabular}{|c|c|c|c|c|c|c|}
\hline & \multicolumn{3}{|c|}{$K S_{x y, c r, b}$} & \multicolumn{3}{|c|}{$K S_{x y, f o, b}$} \\
\hline & Sol & $\mathbf{T i}$ & D_30 & Sol & Ti & D_30 \\
\hline$(24,3,5,10,10) \_1$ & 77287 & 607 & 3,56 & 101307 & 611 & 35,75 \\
\hline$(24,3,5,10,10) \_2$ & 48700 & 608 & $\mathbf{0 , 7 0}$ & 57029 & 607 & 17,92 \\
\hline$(24,3,5,10,10) \_3$ & 60253 & 609 & 3,64 & 63527 & 609 & 9,27 \\
\hline$(24,3,5,10,10) \_4$ & 48489 & 612 & 3,21 & 51932 & 607 & 10,54 \\
\hline$(24,3,5,10,10) \_5$ & 51848 & 607 & 1,32 & 67452 & 610 & 31,82 \\
\hline$(24,3,5,5,20) \_1$ & 80969 & 605 & 4,65 & 80598 & 602 & 4,17 \\
\hline$(24,3,5,20,5) \_1$ & 44904 & 609 & 8,89 & 49250 & 613 & 19,43 \\
\hline$(24,3,5,20,5) \_3$ & 60039 & 607 & 20,80 & 55398 & 605 & 11,46 \\
\hline$(24,3,5,20,5) \_4$ & 38289 & 604 & 29,30 & 34705 & 603 & 17,20 \\
\hline$(24,3,5,20,5) \_5$ & 46530 & 604 & 35,66 & 35015 & 603 & 2,09 \\
\hline Média & & & 11,17 & & & 15,96 \\
\hline
\end{tabular}

Fonte: própria.

Nota-se, pelos resultados apresentados na Tabela 31, que $K S_{x, f o, k}$ ainda se mantém melhor para a estratégia de seleção $S_{x}$. Neste caso, $K S_{x, c r, b}$ é melhor que $K S_{x, f o, b}$ para 6 das 10 instâncias, porém a diferença percentual com relação ao CPLEX é $4,70 \%$ pior que quando se utiliza a estratégia de adaptação $A_{k}$.

Tabela 31 - Resultados obtidos pelo kernel search para as configurações da Fase 1 para a seleção $S_{x}$ combinadas à estratégia de adaptação $A_{b}$.

\begin{tabular}{|c|c|c|c|c|c|c|}
\hline & \multicolumn{3}{|c|}{$K S_{x, c r, b}$} & \multicolumn{3}{|c|}{$K S_{x, f o, b}$} \\
\hline & Sol & $\mathbf{T i}$ & D_30 & Sol & $\mathbf{T i}$ & D_30 \\
\hline$(24,3,5,10,10) \_1$ & 89482 & 604 & 19,90 & 89696 & 603 & 20,19 \\
\hline$(24,3,5,10,10) \_2$ & 52131 & 609 & 7,80 & 50482 & 603 & 4,39 \\
\hline$(24,3,5,10,10) \_3$ & 67962 & 605 & 16,90 & 68993 & 605 & 18,67 \\
\hline$(24,3,5,10,10) \_4$ & 53292 & 604 & 13,43 & 49777 & 610 & 5,95 \\
\hline$(24,3,5,10,10) \_5$ & 57488 & 605 & 12,35 & 59046 & 604 & 15,39 \\
\hline$(24,3,5,5,20) \_1$ & 80072 & 604 & 3,49 & 80724 & 604 & 4,34 \\
\hline$(24,3,5,20,5) \_1$ & 46330 & 604 & 12,35 & 57981 & 606 & 40,60 \\
\hline$(24,3,5,20,5) \_3$ & 61185 & 604 & 23,11 & 53987 & 604 & 8,63 \\
\hline$(24,3,5,20,5) \_4$ & 36095 & 605 & 21,89 & 34276 & 614 & 15,75 \\
\hline$(24,3,5,20,5) \_5$ & 46521 & 603 & 35,63 & 52045 & 609 & 51,74 \\
\hline Méd & & & 16,68 & & & 18,56 \\
\hline
\end{tabular}

Fonte: própria.

Na Tabela 32 os resultados mostram que $K S_{y, c r, b}$ encontrou 9 melhores soluções que $K S_{y, f o, b}$ e que foi a única combinação dos testes realizados na Fase 3 que resultou em melhoria com relação à melhor configuração encontrada até então quando se trata da seleção pela estratégia $S_{y}\left(K S_{y, c r}\right)$. 
Tabela 32 - Resultados obtidos pelo kernel search para as configurações da Fase 1 para a seleção $S_{y}$ combinadas à estratégia de adaptação $A_{b}$.

\begin{tabular}{|c|c|c|c|c|c|c|}
\hline & \multicolumn{3}{|c|}{$K S_{y, c r, b}$} & \multicolumn{3}{|c|}{$K S_{y, f o, b}$} \\
\hline & Sol & $\mathbf{T i}$ & D_30 & Sol & $\mathbf{T i}$ & D_30 \\
\hline$(24,3,5,10,10) \_1$ & 107522 & 604 & 44,07 & 107510 & 603 & 44,06 \\
\hline$(24,3,5,10,10) \_2$ & 54746 & 605 & 13,20 & 68694 & 611 & 42,04 \\
\hline$(24,3,5,10,10) \_3$ & 66956 & 604 & 15,17 & 68782 & 603 & 18,31 \\
\hline$(24,3,5,10,10) \_4$ & 53847 & 612 & 14,61 & 53847 & 612 & 14,61 \\
\hline$(24,3,5,10,10) \_5$ & 56288 & 604 & 10,00 & 59856 & 604 & 16,97 \\
\hline$(24,3,5,5,20) \_1$ & 81314 & 604 & 5,10 & 94999 & 605 & 22,79 \\
\hline$(24,3,5,20,5) \_1$ & 41933 & 605 & 1,68 & 47369 & 605 & 14,86 \\
\hline$(24,3,5,20,5) \_3$ & 49635 & 604 & $-0,13$ & 62709 & 605 & 26,18 \\
\hline$(24,3,5,20,5) \_4$ & 31943 & 604 & 7,87 & 42440 & 611 & 43,32 \\
\hline$(24,3,5,20,5) \_5$ & 37304 & 605 & 8,76 & 42027 & 607 & 22,53 \\
\hline Média & & & 12,03 & & & 26,57 \\
\hline
\end{tabular}

Fonte: própria.

Neste caso, a menor diferença percentual média encontrada continuou a ser a mesma $(3,57 \%)$, porém houve redução das diferenças encontradas para a combinação das estratégias de ordenação e adaptação à estratégia de seleção $S_{y}$.

Após tais testes, assim como para a utilização do software CPLEX, aplicou-se a modificação dos parâmetros, ou seja, utilizou-se a calibração manual definida na Seção 4.3 para as três melhores combinações obtidas, que são $K S_{x y, c r, k}, K S_{x, f o, k}$ e $K S_{y, c r, b}$. Os resultados são exibidos nas Tabelas 33-35 e mostram que, em geral, a utilização da modificação dos parâmetros reduz os custos.

Tabela 33 - Resultados obtidos pela combinação $K S_{x y, c r, k}$ sem e com a calibração manual definida na Seção 4.3.

\begin{tabular}{|c|c|c|c|c|c|c|}
\hline & \multicolumn{3}{|c|}{$K S_{x y, c r, k}$} & \multicolumn{3}{|c|}{$K S_{x y, c r, k}^{*}$} \\
\hline & Sol & $\mathbf{T i}$ & D_30 & Sol & $\mathbf{T i}$ & D_30 \\
\hline$(24,3,5,10,10) \_1$ & 77287 & 607 & 3,56 & 75702 & 602 & 1,44 \\
\hline$(24,3,5,10,10) \_2$ & 48326 & 578 & $-0,07$ & 49388 & 172 & 2,12 \\
\hline$(24,3,5,10,10) \_3$ & 60632 & 602 & 4,29 & 59509 & 203 & 2,36 \\
\hline$(24,3,5,10,10) \_4$ & 49120 & 607 & 4,55 & 45921 & 608 & $-2,26$ \\
\hline$(24,3,5,10,10) \_5$ & 51266 & 528 & 0,19 & 51447 & 308 & 0,54 \\
\hline$(24,3,5,5,20) \_1$ & 81600 & 605 & 5,47 & 78618 & 239 & 1,62 \\
\hline$(24,3,5,20,5) \_1$ & 41089 & 603 & $-0,36$ & 44188 & 605 & 7,15 \\
\hline$(24,3,5,20,5) \_3$ & 53245 & 449 & 7,13 & 50100 & 227 & $\mathbf{0 , 8 0}$ \\
\hline$(24,3,5,20,5) \_4$ & 31376 & 256 & 5,95 & 30883 & 242 & 4,29 \\
\hline$(24,3,5,20,5) \_5$ & 36001 & 421 & 4,96 & 37446 & 264 & 9,18 \\
\hline 19теста & & & ונד, & & & 2,72 \\
\hline
\end{tabular}

Fonte: própria.

As três melhores combinações para a heurística foram avaliadas para mais 5 instâncias. 
Tabela 34 - Resultados obtidos pela combinação $K S_{x, f o, k}$ sem e com a calibração manual definida na Seção 4.3.

\begin{tabular}{|c|c|c|c|c|c|c|}
\hline & \multicolumn{3}{|c|}{$K S_{x, f o, k}$} & \multicolumn{3}{|c|}{$K S_{x, f o k}^{*}$} \\
\hline & Sol & $\mathbf{T i}$ & D_30 & Sol & $\mathbf{T i}$ & D_30 \\
\hline$(24,3,5,10,10) \_1$ & 91495 & 603 & 22,60 & 80830 & 604 & 8,31 \\
\hline$(24,3,5,10,10) \_2$ & 49014 & 605 & 1,35 & 50680 & 604 & 4,80 \\
\hline$(24,3,5,10,10) \_3$ & 66377 & 602 & 14,17 & 67892 & 604 & 16,78 \\
\hline$(24,3,5,10,10) \_4$ & 49010 & 606 & 4,32 & 54273 & 605 & 15,52 \\
\hline$(24,3,5,10,10) \_5$ & 58782 & 605 & 14,88 & 57684 & 601 & 12,73 \\
\hline$(24,3,5,5,20) \_1$ & 79877 & 604 & 3,24 & 81808 & 604 & 5,74 \\
\hline$(24,3,5,20,5) \_1$ & 44066 & 603 & 6,86 & 45691 & 605 & 10,80 \\
\hline$(24,3,5,20,5) \_3$ & 53751 & 607 & 8,15 & 53406 & 603 & $\mathbf{7 , 4 6}$ \\
\hline$(24,3,5,20,5) \_4$ & 34569 & 604 & 16,74 & 33952 & 605 & 14,65 \\
\hline$(24,3,5,20,5) \_5$ & 43736 & 603 & 27,51 & 35206 & 605 & 2,64 \\
\hline Média & & & 11,98 & & & 9,94 \\
\hline
\end{tabular}

Fonte: própria.

Tabela 35 - Resultados obtidos pela combinação $K S_{y, c r, b}$ sem e com a calibração manual definida na Seção 4.3.

\begin{tabular}{|c|c|c|c|c|c|c|}
\hline & \multicolumn{3}{|c|}{$K S_{y, c r, b}$} & \multicolumn{3}{|c|}{$K S_{y, c r, b}^{*}$} \\
\hline & Sol & $\mathbf{T i}$ & D_30 & Sol & $\mathbf{T i}$ & D_30 \\
\hline$(24,3,5,10,10) \_1$ & 107522 & 604 & 44,07 & 107510 & 604 & 44,06 \\
\hline$(24,3,5,10,10) \_2$ & 54746 & 605 & 13,20 & 49646 & 604 & 2,66 \\
\hline$(24,3,5,10,10) \_3$ & 66956 & 604 & 15,17 & 62678 & 605 & $\mathbf{7 , 8 1}$ \\
\hline$(24,3,5,10,10) \_4$ & 53847 & 612 & 14,61 & 53847 & 604 & 14,61 \\
\hline$(24,3,5,10,10) \_5$ & 56288 & 604 & 10,00 & 65910 & 602 & 28,81 \\
\hline$(24,3,5,5,20) \_1$ & 81314 & 604 & 5,10 & 81426 & 601 & 5,25 \\
\hline$(24,3,5,20,5) \_1$ & 41933 & 605 & 1,68 & 43206 & 605 & 4,77 \\
\hline$(24,3,5,20,5) \_3$ & 49635 & 604 & $-0,13$ & 50694 & 604 & 2,00 \\
\hline$(24,3,5,20,5) \_4$ & 31943 & 604 & 7,87 & 31030 & 605 & 4,79 \\
\hline$(24,3,5,20,5) \_5$ & 37304 & 605 & 8,76 & 37531 & 605 & 9,42 \\
\hline Média & & & 12,03 & & & 12,42 \\
\hline
\end{tabular}

Fonte: própria. 
Os resultados são exibidos na Tabela 36 (executando o kernel search por $10 \mathrm{~min}$ ). Os resultados obtidos corroboram que a melhor configuração é a $K S_{x y, c r, k}^{*}$, que apresenta uma diferença percentual com relação ao CPLEX de apenas $2,09 \%$ e melhores soluções que $K S_{x, f o, b}^{*}$ e que $K S_{y, c r, b}$ para 11 das 15 instâncias testadas.

Tabela 36 - Resultados obtidos para 15 instâncias de calibração utilizando as 3 melhores estratégias para o kernel search com no máximo 10min de execução.

\begin{tabular}{|c|c|c|c|c|c|c|c|c|c|}
\hline & \multicolumn{3}{|c|}{$K S_{x y, c r, k}^{*}$} & \multicolumn{3}{|c|}{$K S_{x, f o, b}^{*}$} & \multicolumn{3}{|c|}{$K S_{y, c r, b}$} \\
\hline & Sol & $\mathbf{T i}$ & D_30 & Sol & Ti & D_30 & Sol & $\mathbf{T i}$ & D_30 \\
\hline$(24,3,5,10,10) \_1$ & 75702 & 602 & 1,44 & 80830 & 604 & 8,31 & 107522 & 604 & 44,07 \\
\hline$(24,3,5,10,10) \_2$ & 49388 & 172 & 2,12 & 50680 & 604 & 4,80 & 54746 & 605 & 13,20 \\
\hline$(24,3,5,10,10) \_3$ & 59509 & 203 & 2,36 & 67892 & 604 & 16,78 & 66956 & 604 & 15,17 \\
\hline$(24,3,5,10,10) \_4$ & 45921 & 608 & $-2,26$ & 54273 & 605 & 15,52 & 53847 & 612 & 14,61 \\
\hline$(24,3,5,10,10) \_5$ & 51447 & 308 & 0,54 & 57684 & 601 & 12,73 & 56288 & 604 & 10,00 \\
\hline$(24,3,5,5,20) \_1$ & 78618 & 239 & 1,62 & 81808 & 604 & 5,74 & 81314 & 604 & 5,10 \\
\hline$(24,3,5,5,20) \_2$ & 81862 & 174 & $-0,41$ & 82715 & 604 & 0,63 & 82536 & 603 & 0,41 \\
\hline$(24,3,5,5,20) \_3$ & 90691 & 166 & 2,83 & 91158 & 603 & 3,36 & 88630 & 605 & 0,49 \\
\hline$(24,3,5,5,20) \_4$ & 54415 & 274 & 0,09 & 59754 & 605 & 9,91 & 55017 & 606 & 1,20 \\
\hline$(24,3,5,5,20) \_5$ & 52118 & 291 & 0,59 & 61320 & 604 & 18,35 & 52358 & 605 & 1,05 \\
\hline$(24,3,5,20,5) \_1$ & 44188 & 605 & 7,15 & 45691 & 605 & 10,80 & 41933 & 605 & 1,68 \\
\hline$(24,3,5,20,5) \_2$ & 31994 & 252 & 0,98 & 35046 & 604 & 10,62 & 32851 & 604 & 3,69 \\
\hline$(24,3,5,20,5) \_3$ & 50100 & 227 & 0,80 & 53406 & 603 & 7,46 & 49635 & 604 & $-0,13$ \\
\hline$(24,3,5,20,5) \_4$ & 30883 & 242 & 4,29 & 33952 & 605 & 14,65 & 31943 & 604 & 7,87 \\
\hline$(24,3,5,20,5) \_5$ & 37446 & 264 & 9,18 & 35206 & 605 & 2,64 & 37304 & 605 & 8,76 \\
\hline Média & & & 2,09 & & & 9,49 & & & 8,48 \\
\hline
\end{tabular}

\subsection{Análise dos cenários}

Como visto na Seção 6.1, a melhor configuração é a $K S_{x y, c r, k}^{*}$, ou seja, com a ordenação das variáveis primeiramente pelo custo relativo e pelo custo na função objetivo, em caso de empate $\left(O_{c r}\right)$; com a construção do kernel inicial selecionando variáveis dos conjuntos $\chi$ e $\Upsilon$ estritamente positivas na solução da relaxação linear $\left(S_{x y}\right)$; não inserindo a restrição II do Passo 10 do algoritmo (que afirma que pelo menos uma das variáveis do bucket analisado deve ser positiva na solução buscada) caso a solução do subproblema atual não seja encontrada ou seja infactível; e utilizando a mudança de parâmetros segundo a calibração manual da Seção 4.3.

As Tabelas 37 - 39 apresentam os resultados obtidos considerando um tempo máximo de execução de 10 min e de 30 min para os 3 cenários definidos na Seção 4.1. Nas tabelas, D_30* representa a diferença percentual entre a solução obtida e o resultado obtido pelo CPLEX com a calibração manual apresentada na Seção 4.3. Vale ressaltar que apenas para a instância $(24,3,5,5,10) \_2$ o resultado do CPLEX em 30min de execução com a parametrização foi ótimo. 
A Tabela 37 apresenta os resultados obtidos para o cenário com mesma proporção de entregas e de coletas. Quando o tempo máximo foi de $10 \mathrm{~min}$ a diferença percentual média com relação à solução do CPLEX com a configuração padrão é de 33,19\% enquanto que com relação à encontrada quando há calibração é de 37,52\%. Apesar das médias altas, foram encontradas 2 soluções de qualidade melhor que o CPLEX sem calibrar e 1 solução de qualidade melhor que o CPLEX calibrado, porém para 15 das 40 instâncias as diferenças $D \_30$ e para 18 casos as $D \_30 *$ estão acima de $50 \%$.

Ainda na Tabela 37, quando o tempo limite da heurística foi de 30min as diferenças percentuais médias passaram a ser de 20,22\% e 24,34\% (ou seja, reduções de 22,97\% e 23, 18\%, respectivamente). Existem 13 e 6 soluções de qualidade melhor que as soluções do CPLEX sem e com a calibração manual, respectivamente. Quanto às diferenças percentuais de pior qualidade (maiores que 50\%), são 9 quando não há mudança dos parâmetros e 10 quando há.

A Tabela 38 apresenta os resultados obtidos para o cenário que contém mais entregas do que coletas. Quando o tempo máximo foi de $10 \mathrm{~min}$ a diferença percentual média com relação à solução do CPLEX com a configuração padrão é de $8,99 \%$ enquanto que com relação à encontrada quando há calibração é de 12,76\%, uma melhoria significativa quando comparado aos valores obtidos no Cenário 1 . Foram encontradas 7 soluções de qualidade melhor ou igual ao CPLEX com a configuração padrão e 3 soluções de qualidade melhor que o CPLEX calibrado. Além disso, apenas para 2 das 40 instâncias as diferenças $D \_30$ e $D \_30 *$ estão acima de 50\%.

Quando o tempo limite foi de 30min as diferenças percentuais médias passaram a ser de $2,78 \%$ e 6,17\% (ou seja, reduções de 6,21\% e 6,59\%, respectivamente). Existem 13 e 6 soluções de qualidade melhor que o CPLEX sem e com a calibração manual. Quanto às diferenças percentuais, os piores valores encontrados foram de 29,77\% para $D \_30$ e de $45,11 \%$ para $D \_30 *$.

A Tabela 39 resume os resultados obtidos para o cenário que contém poucas entregas e muitas coletas. Quando o tempo máximo foi de $10 \mathrm{~min}$ a diferença percentual média com relação à solução do CPLEX sem calibrar é de 5,89\% enquanto que com relação à encontrada quando há calibração é de $6,58 \%$, os melhores valores quando comparados os 3 cenários. O método encontrou 4 soluções de qualidade melhor ou igual a do CPLEX sem calibrar e 1 solução de qualidade igual a do CPLEX calibrado. Todas as instâncias possuem $D \_30$ e $D \_30 *$ abaixo de $35 \%$.

Quando o tempo limite foi de 30min as diferenças percentuais médias passaram a ser de $1,87 \%$ e $2,52 \%$ (ou seja, reduções de $4,02 \%$ e $4,08 \%$, respectivamente). Existem 10 e 3 soluções de qualidade melhor ou igual à encontrada pelo CPLEX sem e com a calibração manual. Quanto às diferenças percentuais, existem apenas 3 valores de $D \_30$ e 5 de $D \_30 *$ acima de 5\%.

Nota-se, pelos resultados obtidos, que o Cenário 1 representa os problemas de solução mais difícil para a heurística kernel search, havendo casos em que a solução chega a estar a 
Tabela 37 - Resultados do kernel search com tempo limite de 10min e de 30min para o Cenário 1 (mesma proporção de entregas e coletas).

\begin{tabular}{|c|c|c|c|c|c|c|c|c|}
\hline & \multicolumn{4}{|c|}{$K S_{x y, c r, k}^{*}-10 \mathrm{~min}$} & \multicolumn{4}{|c|}{$K S_{x y, c r, k}^{*}-30 \mathrm{~min}$} \\
\hline & Sol_10 & $\mathbf{T}$ & D_30 & D_30* & Sol_30 & $\mathbf{T}$ & D_30 & D_30* \\
\hline$(24,3,5,10,10) \_1$ & 75702 & 602 & 1,44 & 5,82 & 74282 & 1460 & $-0,47$ & 3,83 \\
\hline$(24,3,5,10,10) \_2$ & 49388 & 172 & 2,12 & 2,95 & 48914 & 499 & 1,14 & 1,97 \\
\hline$(24,3,5,10,10) \_3$ & 59509 & 203 & 2,36 & 2,39 & 59349 & 507 & 2,08 & 2,11 \\
\hline$(24,3,5,10,10) \_4$ & 45921 & 608 & $-2,26$ & 1,73 & 45035 & 508 & $-4,14$ & $-0,23$ \\
\hline$(24,3,5,10,10) \_5$ & 51447 & 304 & 0,54 & 3,78 & 51397 & 956 & 0,44 & 3,68 \\
\hline$(24,3,5,20,20) \_1$ & 180061 & 609 & 56,59 & 57,50 & 120704 & 1314 & 4,97 & 5,58 \\
\hline$(24,3,5,20,20) \_2$ & 115348 & 602 & 18,21 & 20,14 & 98173 & 1810 & 0,61 & 2,25 \\
\hline$(24,3,5,20,20) \_3$ & 94435 & 610 & 8,07 & 10,80 & 85157 & 1811 & $-2,55$ & $-0,09$ \\
\hline$(24,3,5,20,20) \_4$ & 101969 & 603 & 14,57 & 13,68 & 89641 & 1809 & 0,72 & $-0,06$ \\
\hline$(24,3,5,20,20) \_5$ & 85465 & 608 & 3,48 & 5,13 & 81556 & 1808 & $-1,25$ & 0,32 \\
\hline$(24,4,5,10,10) \_1$ & 36934 & 603 & 4,47 & 4,30 & 34816 & 1802 & $-1,52$ & $-1,69$ \\
\hline$(24,4,5,10,10) \_2$ & 57165 & 210 & 5,28 & 10,58 & 56129 & 532 & 3,37 & 8,58 \\
\hline$(24,4,5,10,10) \_3$ & 52860 & 603 & 1,53 & 6,44 & 49186 & 1802 & $-5,53$ & $-0,96$ \\
\hline$(24,4,5,10,10) \_4$ & 65242 & 238 & $-1,79$ & 1,57 & 64898 & 565 & $-2,31$ & 1,04 \\
\hline$(24,4,5,10,10) \_5$ & 47810 & 603 & 1,30 & $-0,78$ & 47127 & 1807 & $-0,15$ & $-2,20$ \\
\hline$(24,4,5,20,20) \_1$ & 83546 & 601 & 11,13 & 14,38 & 77934 & 1809 & 3,66 & 6,70 \\
\hline$(24,4,5,20,20) \_2$ & 132333 & 602 & 57,29 & 57,92 & 99802 & 1808 & 18,63 & 19,10 \\
\hline$(24,4,5,20,20) \_3$ & 105994 & 602 & 17,41 & 18,85 & 100903 & 1808 & 11,78 & 13,14 \\
\hline$(24,4,5,20,20) \_4$ & 176728 & 609 & 70,77 & 72,96 & 123259 & 1808 & 19,10 & 20,63 \\
\hline$(24,4,5,20,20) \_5$ & 155059 & 602 & 50,27 & 57,32 & 155059 & 1809 & 50,27 & 57,32 \\
\hline$(24,3,10,10,10) \_1$ & 102625 & 602 & 2,87 & 9,21 & 95491 & 1803 & $-4,28$ & 1,62 \\
\hline$(24,3,10,10,10) \_2$ & 137087 & 296 & 13,43 & 18,74 & 127217 & 717 & 5,26 & 10,19 \\
\hline$(24,3,10,10,10) \_3$ & 107311 & 263 & 8,22 & 7,49 & 100541 & 541 & 1,39 & 0,71 \\
\hline$(24,3,10,10,10) \_4$ & 198954 & 601 & 77,66 & 78,59 & 114637 & 545 & 2,37 & 2,90 \\
\hline$(24,3,10,10,10) \_5$ & 155616 & 602 & 60,83 & 62,41 & 96178 & 513 & $-0,60$ & 0,38 \\
\hline$(24,3,10,20,20) \_1$ & 299764 & 601 & 66,16 & 70,87 & 299764 & 1816 & 66,16 & 70,87 \\
\hline$(24,3,10,20,20) \_2$ & 268208 & 602 & 61,45 & 64,20 & 268208 & 1810 & 61,45 & 64,20 \\
\hline$(24,3,10,20,20) \_3$ & 372054 & 602 & 113,89 & 116,10 & 222429 & 1809 & 27,87 & 29,19 \\
\hline$(24,3,10,20,20) \_4$ & 354371 & 601 & 95,53 & 99,75 & 354371 & 1814 & 95,53 & 99,75 \\
\hline$(24,3,10,20,20) \_5$ & 262998 & 602 & 64,92 & 59,75 & 262998 & 1810 & 64,92 & 59,75 \\
\hline$(24,4,10,10,10) \_1$ & 188873 & 602 & 48,32 & 58,47 & 151332 & 1802 & 18,84 & 26,97 \\
\hline$(24,4,10,10,10) \_2$ & 114623 & 601 & 7,83 & 16,74 & 103451 & 1812 & $-2,68$ & 5,36 \\
\hline$(24,4,10,10,10) \_3$ & 117230 & 496 & 1,83 & 10,44 & 109644 & 1492 & $-4,76$ & 3,29 \\
\hline$(24,4,10,10,10) \_4$ & 92651 & 519 & 0,36 & 6,57 & 89854 & 712 & $-2,67$ & 3,35 \\
\hline$(24,4,10,10,10) \_5$ & 181986 & 573 & 33,14 & 39,34 & 181986 & 1196 & 33,14 & 39,34 \\
\hline$(24,4,10,20,20) \_1$ & 278672 & 603 & 44,33 & 68,71 & 278672 & 1812 & 44,33 & 68,71 \\
\hline$(24,4,10,20,20) \_2$ & 247058 & 603 & 70,80 & 68,68 & 247058 & 1802 & 70,80 & 68,68 \\
\hline$(24,4,10,20,20) \_3$ & 325152 & 602 & 89,80 & 126,47 & 325152 & 1801 & 89,80 & 126,47 \\
\hline$(24,4,10,20,20) \_4$ & 279771 & 602 & 76,55 & 78,71 & 279771 & 1809 & 76,55 & 78,71 \\
\hline$(24,4,10,20,20) \_5$ & 286339 & 603 & 66,72 & 72,23 & 286339 & 1802 & 66,72 & 72,23 \\
\hline Média & & & 33,19 & 37,52 & & & 20,22 & 24,34 \\
\hline Mínimo & & & $-2,26$ & $-0,78$ & & & $-5,53$ & $-2,20$ \\
\hline Máximo & & & 113,89 & 126,47 & & & 95,53 & 126,47 \\
\hline
\end{tabular}


Tabela 38 - Resultados do kernel search com tempo limite de 10min e de 30min para o Cenário 2 (muitas entregas e poucas coletas).

\begin{tabular}{|c|c|c|c|c|c|c|c|c|}
\hline & \multicolumn{4}{|c|}{$K S_{x y, c r, k}^{*}-10 \min$} & \multicolumn{4}{|c|}{$K S_{x y, c r, k}^{*}-30 \mathrm{~min}$} \\
\hline & Sol_10 & $\mathbf{T}$ & D_30 & D_30* & Sol_30 & $\mathbf{T}$ & D_30 & D_30* \\
\hline$(24,3,5,10,5) \_1$ & 627 & 611 & 1,14 & 1, & & $1 \angle \angle 2$ & 0,0 & $0,($ \\
\hline$(24,3,5,10,5) \_2$ & 3410 & 609 & 10,05 & 10,60 & 40948 & 646 & 3,81 & 4,33 \\
\hline$(24,3,5,10,5) \_3$ & 47056 & 239 & 6,91 & 6,91 & 47056 & 638 & 6,91 & 6,91 \\
\hline$(24,3,5,10,5) \_4$ & 34196 & 607 & $-0,63$ & $-0,40$ & 34196 & 1803 & $-0,63$ & $-0,40$ \\
\hline$(24,3,5,10,5) \_5$ & 32354 & 151 & 2,37 & 3,18 & 32354 & 352 & 2,37 & 3,18 \\
\hline$(24,3,5,20,5) \_1$ & 44188 & 605 & 7,15 & 10,16 & 44188 & 1812 & 7,15 & 10,16 \\
\hline$(24,3,5,20,5) \_2$ & 31994 & 267 & 0,98 & 3,19 & 31824 & 1442 & 0,45 & 2,64 \\
\hline 20,5$) \_3$ & 50100 & 228 & 0,80 & & 50226 & 530 & 1,06 & 7,01 \\
\hline$(24,3$ & 30883 & 217 & 4,29 & & & 578 & 3,55 & 3,55 \\
\hline 20,5$) \_5$ & 37446 & 262 & 9,18 & 7,85 & 36168 & 731 & 5,45 & 4,17 \\
\hline$(24,4,5,10,5) \_1$ & 34431 & 481 & $\mathbf{0 , 0 0}$ & & & 705 & $\mathbf{0 , 0 0}$ & 0,09 \\
\hline$(24,4,5,10,5) \_2$ & 34019 & 257 & 7,26 & 8,01 & 31297 & 540 & $-1,32$ & $-0,63$ \\
\hline$(24,4,5,10,5) \_3$ & & 275 & $-1,46$ & $-\mathbf{- 0}$, & 53547 & 474 & $-1,46$ & $-0,75$ \\
\hline$(24,4$ & 82 & 215 & $\mathbf{0 , 0 0}$ & 1, & & 419 & $\mathbf{0 , 0 0}$ & 1,08 \\
\hline$(24,4$ & 50687 & 541 & 8,83 & 9, & 50214 & 684 & 7,82 & 8,16 \\
\hline$(24$, & 24992 & 309 & $-5,41$ & -2 , & & 630 & 0,11 & 3,36 \\
\hline$(24,4,5,20,5) \_2$ & 39308 & 601 & 8,95 & 8, & 38175 & 999 & 5,81 & 5,85 \\
\hline$(24,4$ & 35562 & 344 & 8,85 & & & 486 & 3,64 & 3,20 \\
\hline$(24$, & 37297 & 604 & 16,75 & 20 , & 35 & 1813 & 3,41 & 7,04 \\
\hline$(24$, & 21099 & 218 & $-14,40$ & & 90 & 733 & $-15,24$ & 0,24 \\
\hline -1 1 & 59790 & 325 & 0,81 & 0 & & 400 & $-0,04$ & 0,08 \\
\hline$(24,3$ & 89543 & 603 & 1,01 & 1, & & 1809 & 0,13 & 0,89 \\
\hline$, 10,5) \_3$ & 114583 & 269 & 2,48 & 2,61 & 74 & 670 & 0,59 & 0,72 \\
\hline 10,5)_4 & 86118 & 603 & 7,38 & 11,37 & 55 & 1186 & 0,95 & 4,70 \\
\hline$(24,3,10,10,5) \_5$ & 66243 & 269 & -( & 1,44 & 43 & 95 & 0,96 & 2,66 \\
\hline 20,5$) \_1$ & 791 & 272 & 3,97 & 7, & & 418 & 2,54 & 5,60 \\
\hline$(24,3,10,20,5) \_2$ & 70243 & 603 & 1,91 & 4 & 22 & 720 & 1,30 & 3,72 \\
\hline 3 & 93228 & 603 & 15,73 & 21 & 78340 & 849 & $-2,75$ & 2,04 \\
\hline$, 20,5) \_4$ & 93557 & 604 & 0,44 & 1 & 87912 & 1814 & $-5,62$ & 6,82 \\
\hline$(24,3,10,20,5) \_5$ & 107979 & 603 & 29,82 & 40,76 & 83939 & 874 & 0,91 & 9,42 \\
\hline $0,10,5) \_1$ & 62453 & 603 & 6,06 & & 58552 & 1803 & $-0,56$ & 1,63 \\
\hline$, 10,5) \_2$ & & 352 & & & & 739 & 37 & 64 \\
\hline$(24,4,10,10,5) \_3$ & 74323 & 355 & 5,36 & 9,10 & 72884 & 750 & 3,32 & 6,99 \\
\hline$(24,4,10,10,5) \_4$ & 86764 & 476 & 17,27 & & 82780 & 992 & 11,88 & 13,49 \\
\hline$(24,4,10,10,5) \_5$ & 96864 & 603 & 53,77 & 61,63 & 70073 & 811 & 11,24 & 16,93 \\
\hline$(24,4,10,20,5) \_1$ & 88711 & 601 & 27,86 & 42,97 & 90037 & 1801 & 29,77 & 45,11 \\
\hline$(24,4,10,20,5) \_2$ & 93968 & 604 & 50,79 & 60,82 & 71216 & 1804 & 14,28 & 21,88 \\
\hline$(24,4,10,20,5) \_3$ & 108325 & 604 & 28,63 & 47,59 & 81193 & 1804 & $-3,59$ & 10,62 \\
\hline$(24,4,10,20,5) \_4$ & 72102 & 602 & 15,40 & 21,46 & 66383 & 1803 & 6,25 & 11,83 \\
\hline$(24,4,10,20,5) \_5$ & 67758 & 604 & 14,55 & 21,02 & 61504 & 1804 & 3,97 & 9,85 \\
\hline & & & 8,99 & 12 & & & 2,78 & 6,17 \\
\hline & & & $-14,40$ & $-2,34$ & & & $-15,24$ & $-0,75$ \\
\hline Máximo & & & 53,77 & 61,63 & & & 29,77 & 45,11 \\
\hline
\end{tabular}


Tabela 39 - Resultados do kernel search com tempo limite de 10min e de 30min para o Cenário 3 (poucas entregas e muitas coletas).

\begin{tabular}{|c|c|c|c|c|c|c|c|c|}
\hline & \multicolumn{4}{|c|}{$K S_{x v, c r, k}^{*}-10 \min$} & \multicolumn{4}{|c|}{$K S_{x y, c r, k}^{*}-30 \mathrm{~min}$} \\
\hline & Sol_10 & $\mathbf{T}$ & D_30 & D_30* & Sol_30 & $\mathbf{T}$ & D_30 & D_30* \\
\hline$(24,3,5,5,10) \_1$ & 85091 & 130 & 0,79 & 0,79 & 85091 & 336 & 0,79 & 0,79 \\
\hline$(24,3,5,5,10) \_2$ & 48630 & 102 & $\mathbf{0 , 0 0}$ & $\mathbf{0 , 0 0}$ & 48630 & 166 & $\mathbf{0 , 0 0}$ & $\mathbf{0 , 0 0}$ \\
\hline$(24,3,5,5,10) \_3$ & 53889 & 315 & $-0,21$ & 0,41 & 53889 & 926 & $-0,21$ & 0,41 \\
\hline$(24,3,5,5,10) \_4$ & 79906 & 157 & 0,42 & 0,42 & 79906 & 158 & 0,42 & 0,42 \\
\hline$(24,3,5,5,10) \_5$ & 39191 & 160 & $-1,02$ & 0,07 & 39191 & 370 & $-1,02$ & 0,07 \\
\hline$(24,3,5,5,20) \_1$ & 78747 & 604 & 1,78 & 2,02 & 78320 & 1810 & 1,23 & 1,46 \\
\hline$(24,3,5,5,20) \_2$ & 81862 & 176 & $-0,41$ & 0,29 & 81862 & 332 & $-0,41$ & 0,29 \\
\hline$(24,3,5,5,20) \_3$ & 90691 & 167 & 2,83 & 2,94 & 90691 & 315 & 2,83 & 2,94 \\
\hline$(24,3,5,5,20) \_4$ & 54667 & 276 & 0,56 & 1,22 & 54079 & 747 & $-0,52$ & 0,13 \\
\hline$(24,3,5,5,20) \_5$ & 52118 & 287 & 0,59 & 0,59 & 52118 & 442 & 0,59 & 0,59 \\
\hline$(24,4,5,5,10) \_1$ & 64495 & 602 & 6,16 & 6,25 & 64282 & 1812 & 5,81 & 5,90 \\
\hline$(24,4,5,5,10) \_2$ & 49382 & 603 & 2,53 & 2,50 & 49382 & 1808 & 2,53 & 2,50 \\
\hline$(24,4,5,5,10) \_3$ & 57850 & 215 & 0,65 & 1,17 & 56939 & 458 & $-0,93$ & $-0,42$ \\
\hline$(24,4,5,5,10) \_4$ & 57391 & 256 & 3,48 & 4,19 & 56522 & 665 & 1,92 & 2,61 \\
\hline$(24,4,5,5,10) \_5$ & 55877 & 219 & 0,18 & 0,18 & 55777 & 399 & 0,00 & 0,00 \\
\hline$(24,4,5,5,20) \_1$ & 50616 & 353 & 3,13 & 2,07 & 49727 & 682 & 1,31 & 0,28 \\
\hline$(24,4,5,5,20) \_2$ & 71561 & 603 & 15,78 & 15,98 & 71143 & 1810 & 15,11 & 15,30 \\
\hline$(24,4,5,5,20) \_3$ & 65348 & 382 & 12,11 & 12,79 & 57870 & 798 & $-0,72$ & $-0,12$ \\
\hline$(24,4,5,5,20) \_4$ & 51267 & 240 & 3,63 & 4,49 & 50346 & 780 & 1,77 & 2,61 \\
\hline$(24,4,5,5,20) \_5$ & 58610 & 603 & 4,25 & 4,06 & 57129 & 1615 & 1,62 & 1,43 \\
\hline$(24,3,10,5,10) \_1$ & 107232 & 268 & 23,07 & 24,58 & 87729 & 443 & 0,68 & 1,92 \\
\hline$(24,3,10,5,10) \_2$ & 181027 & 205 & 1,43 & 1,40 & 178715 & 468 & 0,13 & 0,11 \\
\hline$(24,3,10,5,10) \_3$ & 80678 & 190 & 0,19 & 1,42 & 80353 & 354 & $-0,21$ & 1,01 \\
\hline$(24,3,10,5,10) \_4$ & 147282 & 288 & 0,49 & 0,49 & 146566 & 474 & 0,00 & 0,00 \\
\hline$(24,3,10,5,10) \_5$ & 158133 & 224 & 1,47 & 1,56 & 156638 & 734 & 0,51 & 0,60 \\
\hline$(24,3,10,5,20) \_1$ & 91320 & 554 & 3,54 & 4,90 & 88752 & 1811 & 0,63 & 1,95 \\
\hline$(24,3,10,5,20) \_2$ & 104997 & 277 & 3,02 & 5,92 & 100270 & 381 & $-1,62$ & 1,16 \\
\hline$(24,3,10,5,20) \_3$ & 141585 & 604 & 5,25 & 5,85 & 135245 & 1360 & 0,54 & 1,11 \\
\hline$(24,3,10,5,20) \_4$ & 116165 & 571 & 6,01 & 5,77 & 113760 & 588 & 3,81 & 3,58 \\
\hline$(24,3,10,5,20) \_5$ & 166862 & 292 & 3,54 & 3,58 & 166465 & 400 & 3,30 & 3,33 \\
\hline$(24,4,10,5,10) \_1$ & 95199 & 602 & 7,36 & 8,29 & 91815 & 1803 & 3,54 & 4,44 \\
\hline$(24,4,10,5,10) \_2$ & 132819 & 536 & 9,43 & 12,19 & 122964 & 1802 & 1,32 & 3,87 \\
\hline$(24,4,10,5,10) \_3$ & 88173 & 387 & 32,24 & 34,72 & 71980 & 599 & 7,95 & 9,98 \\
\hline$(24,4,10,5,10) \_4$ & 87814 & 428 & 16,66 & 16,75 & 76545 & 616 & 1,69 & 1,76 \\
\hline$(24,4,10,5,10) \_5$ & 73642 & 287 & 3,44 & 3,68 & 71848 & 448 & 0,92 & 1,16 \\
\hline$(24,4,10,5,20) \_1$ & 83310 & 603 & 16,52 & 20,36 & 74919 & 1388 & 4,78 & 8,24 \\
\hline$(24,4,10,5,20) \_2$ & 83394 & 605 & 7,13 & 7,38 & 80981 & 846 & 4,03 & 4,27 \\
\hline$(24,4,10,5,20) \_3$ & 122833 & 603 & 24,77 & 21,75 & 110053 & 1534 & 11,79 & 9,08 \\
\hline$(24,4,10,5,20) \_4$ & 64751 & 493 & 3,83 & 5,06 & 62994 & 710 & 1,01 & 2,21 \\
\hline$(24,4,10,5,20) \_5$ & 101424 & 591 & 8,78 & 15,08 & 91347 & 1809 & $-2,02$ & 3,65 \\
\hline Média & & & 5,89 & 6,58 & & & 1,87 & 2,52 \\
\hline Mínimo & & & $-1,02$ & 0,00 & & & $-2,02$ & $-0,42$ \\
\hline Máximo & & & 32,24 & 34,72 & & & 15,11 & 15,30 \\
\hline
\end{tabular}


mais de $100 \%$ da solução encontrada pelo software. Já os Cenários 2 e 3 tiveram resultados com diferenças percentuais de melhor qualidade indicando que o método é competitivo com o software CPLEX, em especial para as instâncias do Cenário 3. 


\section{CONCLUSÕES E PESQUISAS FUTURAS}

O problema de cross-docking é de grande relevância econômica, uma vez que tem sido utilizado na área de logística e transportes visando a redução dos custos operacionais que, em geral, tendem a ser muito altos. Essa dissertação apresenta uma abordagem do problema considerando várias características em conjunto que, em geral, são tratadas separadamente na literatura; foi gerado um conjunto de instâncias benchmark; e foi proposto um método heurístico para a resolução do problema proposto.

A primeira etapa desse trabalho contou com a revisão da literatura na qual o objeto de estudo se encaixava (o problema de integração do planejamento e da programação de uma rede de distribuição) foi descrito e evidenciou-se a falta de um modelo na literatura que reunisse todas as características avaliadas individualmente nos modelos já existentes. Desta forma, foi desenvolvdo um modelo para cobrir esta lacuna de pesquisa. O modelo busca se aproximar do problema real, unindo a ideia da existência de múltiplos cross-docks, possibilidade de transferência de produtos entre eles e janelas de tempo desejáveis e obrigatórias para as coletas. Desta primeira etapa foi redigido o artigo publicado no "XLVII Simpósio Brasileiro de Pesquisa Operacional", em 2015.

Para os testes computacionais, uma vez que não se conseguiu acesso aos dados da literatura, optou-se por gerar instâncias que resultaram num benchmark, que também está disponível para a comunidade científica.

$\mathrm{Na}$ análise computacional do modelo, o modelo proposto foi comparado com um modelo da literatura (Javanmard, Vahdani e Tavakkoli-Moghaddam (2014)). A partir dos resultados obtidos, nota-se que a transferência de produtos entre cross-docks pode reduzir custos, uma vez que facilita a composição de cargas para coleta. Quanto às janelas de tempo flexíveis para coletas, além delas serem importantes do ponto de vista prático, a penalidade associada à sua violação reduz o número de soluções alternativas, facilitando a obtenção de soluções de melhor qualidade.

Após verificar que a nova proposta de modelo pode resultar em redução de custos operacionais, foi estudada a possibilidade de calibração do software utilizado, o ILOG CPLEX, 
com o intuito de buscar soluções de melhor qualidade. Esta ideia tem sido utilizada com grande frequência para buscar a melhor configuração do software na resolução de cada tipo de problema, uma vez que pode ocorrer que a configuração padrão do CPLEX pode não ser a mais indicada para a resolução do problema estudado. Nesta etapa, notou-se que a calibração manual, uma vez que conta com um conhecimento prévio de algumas características do problema pode retornar soluções de melhor qualidade que ao utilizar a calibração automática do software.

Propôs-se, então, para a resolução do problema, um método heurístico Kernel search. O método teve de ser adaptado ao problema de cross-docking e seus parâmetros calibrados como apresentado no Capítulo 5. Os resultados computacionais apresentados no Capítulo 6 mostram que para os cenários em que entregas e coletas ocorrem em proporções diferentes o método é competitivo com o software CPLEX calibrado para o problema de cross-docking, havendo casos em que a heurística em 10min encontra soluções melhores que o CPLEX em 30min de execução.

De forma geral, foi proposto um modelo matemático; foram criadas instâncias benchmark para posterior uso da comunidade; foi realizado o estudo de calibração do software buscando por soluções de melhor qualidade; e, por fim, foi proposta uma heurística para a resolução do problema de cross-docking através do modelo proposto.

Como perspectiva para trabalhos futuros, sugere-se adaptar o modelo para aproximá-lo ainda mais da realidade, uma vez que cada vez mais as empresas estão utilizando essa estratégia de distribuição. Outra sugestão é que instâncias baseadas em dados reais sejam avaliadas, para posterior comparação às estratégias utilizadas na prática. Por fim, os resultados indicam que a heurística Kernel search ainda poderia ser avaliada com outras estratégias em busca de resultados melhores, em especial para situações em que o número de coletas e entregas sejam muito próximos. 


\section{REFERÊNCIAS}

ANGELELLI, E.; MANSINI, R.; SPERANZA, M. G. Kernel search: A general heuristic for the multi-dimensional knapsack problem. Computers and Operational Research, v. 37, p. 2017-2026, 2010. Citado 4 vezes nas páginas 17, 69, 70 e 71.

BELLE, J. V.; VALCKENAERS, P.; CATTRYSSE, D. Cross-docking: State of the art. Omega, v. 40, n. 6, p. $827-846,2012$. Citado 4 vezes nas páginas 26, 29, 30 e 32.

BOYSEN, N.; FLIEDNER, M. Cross dock scheduling: Classification, literature review and research agenda. Omega, v. 38, n. 6, p. 413-422, 2010. Citado na página 32.

BUIJS, P.; VIS, I. F.; CARLO, H. J. Synchronization in cross-docking networks: A research classification and framework. European Journal of Operational Research, v. 239, n. 3, p. 593-608, 2014. Citado 5 vezes nas páginas 25, 26, 31, 32 e 39.

CARGOBR. Cross-Docking - Inovação na logística. 2013. Disponível em: < http://cargobr. com/blog/cross-docking-inovacao-na-logistica-cargobr/>. Acesso em: 10/02/2016. Citado na página 39.

CARRARO, L. e. T. Cross-Docking. 2008. Disponível em: <http://carrarologistica.com.br/serv_ cross.html>. Acesso em: 10/02/2016. Citado 2 vezes nas páginas 30 e 39.

CHEN, P.; GUO, Y.; LIM, A.; RODRIGUES, B. Multiple crossdocks with inventory and time windows. Computers \& operations research, v. 33, n. 1, p. 43-63, 2006. Citado 6 vezes nas páginas 27, 32, 33, 34, 47 e 48.

COVISI, T. Conceitos e principais objetivos do Cross Docking. 2016. Disponível em: <http: $/ /$ covisi.com.br/site/index.php?option=com_content\&view=article\&id=54\&Itemid=63>. Acesso em: 10/02/2016. Citado 2 vezes nas páginas 30 e 39.

GHIANI, G.; LAPORTE, G.; MUSMANNO, R. Introduction to logistics systems planning and control. [S.1.]: John Wiley \& Sons, 2004. Citado na página 26.

GUASTAROBA, G.; SPERANZA, M. G. A heuristic for blip problems: The single source capacitates facility location problem. European Journal of Operational Research, v. 238, p. 438 - 450, 2014. Citado na página 69.

JAVANMARD, S.; VAHDANI, B.; TAVAKKOLI-MOGHADDAM, R. Solving a multi-product distribution planning problem in cross docking networks: An imperialist competitive algorithm. The International Journal of Advanced Manufacturing Technology, v. 70, n. 9-12, p. 17091720, 2014. Citado 10 vezes nas páginas 15, 27, 34, 39, 40, 45, 48, 53, 54 e 91.

LADIER, A.-L.; ALPAN, G. Cross-docking operations: Current research versus industry practice. Omega, Elsevier, 2015. Disponível em: <http://dx.doi.org/10.1016/j.omega.2015.09.006>. Citado 2 vezes nas páginas 30 e 32. 
LIM, A.; MIAO, Z.; RODRIGUES, B.; XU, Z. Transshipment through crossdocks with inventory and time windows. Naval Research Logistics (NRL), v. 52, n. 8, p. 724-733, 2005. Citado 3 vezes nas páginas 27,32 e 33 .

MA, H.; MIAO, Z.; LIM, A.; RODRIGUES, B. Crossdocking distribution networks with setup cost and time window constraint. Omega, v. 39, n. 1, p. 64-72, 2011. Citado 3 vezes nas páginas 27,33 e 34 .

MARJANI, M. R.; HUSSEINI, S. M. M.; KARIMI, B. Bi-objective heuristics for multi-item freights distribution planning problem in crossdocking networks. The International Journal of Advanced Manufacturing Technology, v. 58, n. 9-12, p. 1201-1216, 2012. Citado 2 vezes nas páginas 34 e 44 .

MARONI, G. Armazenagem e Cross docking. 2013. Disponível em: <http://transmaroni.com. br/armazenagem-e-cross-docking/>. Acesso em: 10/02/2016. Citado 2 vezes nas páginas 30 e 39.

MIAO, Z.; YANG, F.; FU, K.; XU, D. Transshipment service through crossdocks with both soft and hard time windows. Annals of Operations Research, v. 192, n. 1, p. 21-47, 2012. Citado 6 vezes nas páginas 27, 33, 42, 43, 45 e 48 .

MIRANDA, S. Cross Docking and Supply Chain Success. 2015. Disponível em: <http: //usacrossdocking.com/cross-docking-and-supply-chain-success/>. Acesso em: 10/02/2016. Citado na página 39.

MIYAZAKI-TENÓRIO, P. a. S.; TOLEDO, F. M.; ARMENTANO, V. A. Um modelo para o problema de programação de múltiplos cross-docks. XLVII SBPO, 2015. Citado na página 27.

MIYAZAKI-TENÓRIO, P. S.; TOLEDO, F. M. Benchmark. 2016. Disponível em: <https: //www.dropbox.com/sh/8ot2agt5i3rn175/AAAiiw0G4TPs_nrj9YzYoMPKa?dl=0>. Acesso em: 15/02/2016. Citado 2 vezes nas páginas 27 e 47.

SIMCHI-LEVI, D.; KAMINSKY, P.; SIMCHI-LEVI, E. Designing and managing the supply chain: concepts, strategies, and case studies. 2. ed. ed. Boston, Mass. [u.a.]: McGraw-Hill/Irwin, 2003. (The McGraw-Hill/Irwin series in operations and decision sciences). Citado na página 39.

YU, W.; EGBELU, P. J. Scheduling of inbound and outbound trucks in cross docking systems with temporary storage. European Journal of Operational Research, v. 184, n. 1, p. 377-396, 2008. Citado na página 29. 